Cochrane Database of Systematic Reviews

\title{
Single versus multiple visits for endodontic treatment of permanent teeth (Review)
}

Manfredi M, Figini L, Gagliani M, Lodi G

Manfredi M, Figini L, Gagliani M, Lodi G.

Single versus multiple visits for endodontic treatment of permanent teeth.

Cochrane Database of Systematic Reviews 2016, Issue 12. Art. No.: CD005296.

DOI: 10.1002/14651858.CD005296.pub3.

www.cochranelibrary.com 
TABLE OF CONTENTS

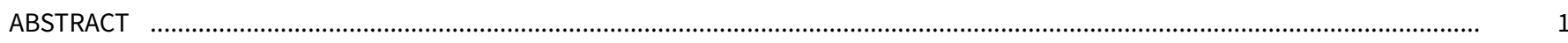

PLAIN LANGUAGE SUMMARY

SUMMARY OF FINDINGS

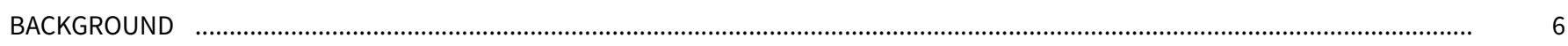

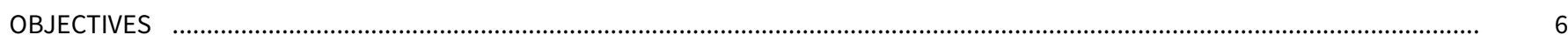

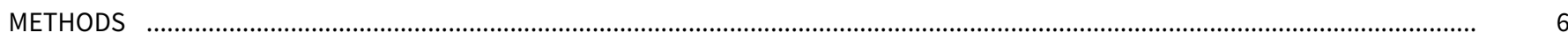

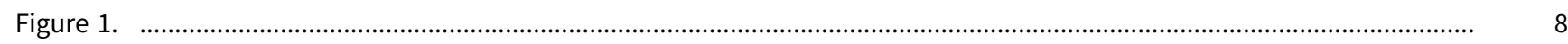

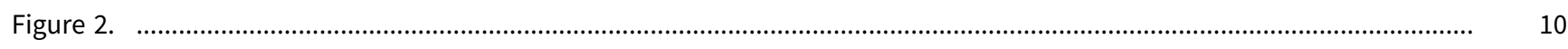

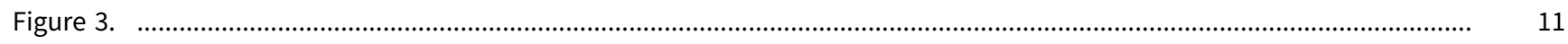

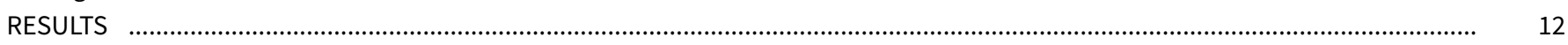

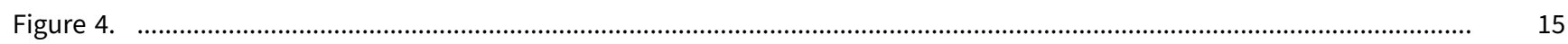

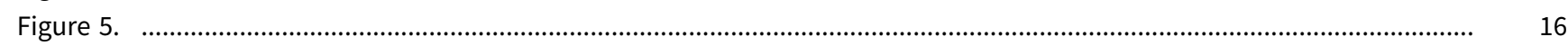

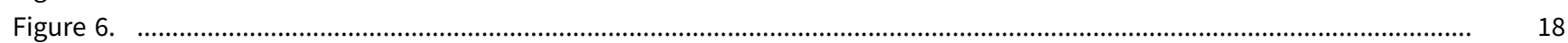

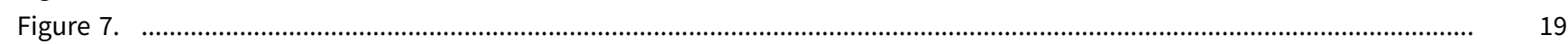

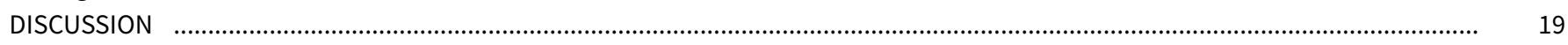

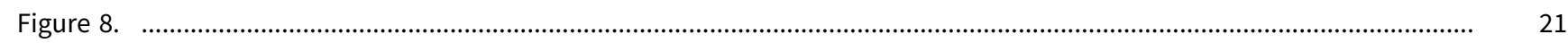

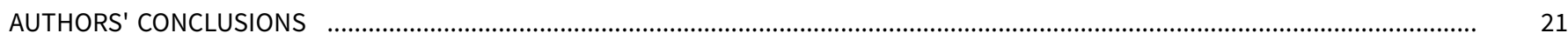

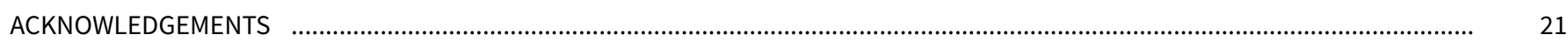

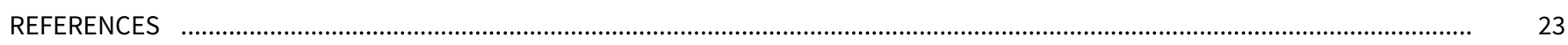

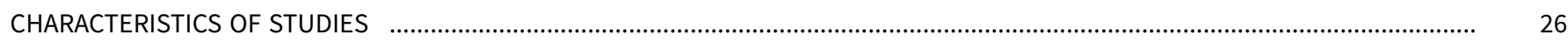

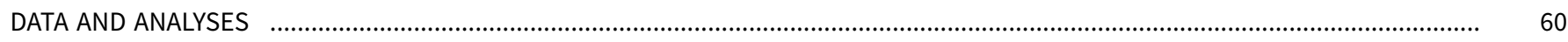

Analysis 1.1. Comparison 1 Single versus multiple visits for endodontic treatment of permanent teeth - primary outcomes, 60

Outcome 1 Extraction due to endodontic problems.

Analysis 1.2. Comparison 1 Single versus multiple visits for endodontic treatment of permanent teeth - primary outcomes, Outcome 2 Radiological failure.

Analysis 2.1. Comparison 2 Single versus multiple visits for endodontic treatment of permanent teeth - secondary outcomes, Outcome 1 Pain (dichotomous).

Analysis 2.2. Comparison 2 Single versus multiple visits for endodontic treatment of permanent teeth - secondary outcomes, Outcome 2 Pain (continuous).

Analysis 2.3. Comparison 2 Single versus multiple visits for endodontic treatment of permanent teeth - secondary outcomes, Outcome 3 Swelling or flare-up.

Analysis 2.4. Comparison 2 Single versus multiple visits for endodontic treatment of permanent teeth - secondary outcomes, Outcome 4 Painkiller use.

Analysis 2.5. Comparison 2 Single versus multiple visits for endodontic treatment of permanent teeth - secondary outcomes, Outcome 5 Persistent sinus track or fistula.

Analysis 2.6. Comparison 2 Single versus multiple visits for endodontic treatment of permanent teeth - secondary outcomes,

Outcome 6 Any complication.

ADDITIONAL TABLES

APPENDICES

WHAT'S NEW

HISTORY

CONTRIBUTIONS OF AUTHORS

DECLARATIONS OF INTEREST

SOURCES OF SUPPORT

DIFFERENCES BETWEEN PROTOCOL AND REVIEW

INDEX TERMS 
[Intervention Review]

\title{
Single versus multiple visits for endodontic treatment of permanent teeth
}

\author{
Maddalena Manfredi ${ }^{1}$, Lara Figini², Massimo Gagliani³ ${ }^{3}$ Giovanni Lodi ${ }^{4}$
}

1Polo Clinico di Odontostomatologia, SBiBiT Department, University of Parma, Parma, Italy. 2 Milan, Italy. ${ }^{3}$ Clinica Odontoiatrica, DMCO San Paolo, Milan, Italy. ${ }^{4}$ Dipartimento di Scienze Biomediche, Chirurgiche e Odontoiatriche, Università degli Studi di Milano, Milan, Italy

Contact: Maddalena Manfredi, Polo Clinico di Odontostomatologia, SBiBiT Department, University of Parma, Via Gramsci, 14, Parma, 43100, Italy. maddalena.manfredi@unipr.it.

Editorial group: Cochrane Oral Health Group.

Publication status and date: New search for studies and content updated (no change to conclusions), published in Issue 12, 2016.

Citation: Manfredi M, Figini L, Gagliani M, Lodi G. Single versus multiple visits for endodontic treatment of permanent teeth. Cochrane Database of Systematic Reviews 2016, Issue 12. Art. No.: CD005296. DOI: 10.1002/14651858.CD005296.pub3.

Copyright @ 2016 The Cochrane Collaboration. Published by John Wiley \& Sons, Ltd.

\section{A B S T R A C T}

\section{Background}

Root canal treatment (RoCT), or endodontic treatment, is a common procedure in dentistry. The main indications for RoCT are irreversible pulpitis and necrosis of the dental pulp caused by carious processes, tooth cracks or chips, or dental trauma. Successful RoCT is characterised by an absence of symptoms (i.e. pain) and clinical signs (i.e. swelling and sinus tract) in teeth without radiographic evidence of periodontal involvement (i.e. normal periodontal ligament). The success of RoCT depends on a number of variables related to the preoperative condition of the tooth, as well as the endodontic procedures. This review updates the previous version published in 2007.

\section{Objectives}

To determine whether completion of root canal treatment (RoCT) in a single visit or over two or more visits, with or without medication, makes any difference in term of effectiveness or complications.

\section{Search methods}

We searched the following electronic databases: Cochrane Oral Health's Trials Register (to 14 June 2016), Cochrane Central Register of Controlled Trials (CENTRAL) (the Cochrane Library, 2016, Issue 5), MEDLINE Ovid (1946 to 14 June 2016), and Embase Ovid (1980 to 14 June 2016). We searched ClinicalTrials.gov and the World Health Organization International Clinical Trials Registry Platform for ongoing trials to 14 June 2016. We did not place any restrictions on the language or date of publication when searching the electronic databases.

\section{Selection criteria}

We included randomised controlled trials (RCTs) and quasi-RCTs of people needing RoCT. We excluded surgical endodontic treatment. The outcomes of interest were tooth extraction for endodontic problems; radiological failure after at least one year, i.e. periapical radiolucency; postoperative pain; swelling or flare-up; painkiller use; sinus track or fistula formation; and complications (composite outcome including any adverse event).

\section{Data collection and analysis}

We collected data using a specially designed extraction form. We contacted trial authors for further details where these were unclear. We assessed the risk of bias in the studies using the Cochrane tool and we assessed the quality of the body of evidence using GRADE criteria. When valid and relevant data were collected, we undertook a meta-analysis of the data using the random-effects model. For dichotomous outcomes, we calculated risk ratios (RRs) and 95\% confidence intervals (Cls). For continuous data, we calculated mean differences (MDs) and $95 \% \mathrm{Cls}$. We examined potential sources of heterogeneity. We conducted subgroup analyses for necrotic and vital teeth. 


\section{Main results}

We included 25 RCTs in the review, with a total of 3780 participants, of whom we analysed 3751 . We judged three studies to be at low risk of bias, 14 at high risk, and eight as unclear.

Only one study reported data on tooth extraction due to endodontic problems. This study found no difference between treatment in one visit or treatment over multiple visits (1/117 single-visit participants lost a tooth versus $2 / 103$ multiple-visit participants; odds ratio (OR) $0.44,95 \%$ confidence interval $(\mathrm{Cl}) 0.04$ to 4.78 ; very low-quality evidence).

We found no evidence of a difference between single-visit and multiple-visit treatment in terms of radiological failure (risk ratio (RR) 0.91 , $95 \% \mathrm{Cl} 0.68$ to 1.21 ; 1493 participants, 11 studies, I2 = 18\%; low-quality evidence); immediate postoperative pain (dichotomous outcome) (RR $0.99,95 \% \mathrm{Cl} 0.84$ to $1.17 ; 1560$ participants, 9 studies, $\mathrm{I}^{2}=33 \%$; moderate-quality evidence); swelling or flare-up incidence (RR 1.36, $95 \% \mathrm{Cl} 0.66$ to $2.81 ; 281$ participants, 4 studies, $\left.\right|^{2}=0 \%$; low-quality evidence); sinus tract or fistula formation (RR $0.98,95 \% \mathrm{Cl} 0.15$ to 6.48 ; 345 participants, 2 studies, $\mathrm{I}^{2}=0 \%$; low-quality evidence); or complications (RR $0.92,95 \% \mathrm{Cl} 0.77$ to 1.11 ; 1686 participants, 10 studies, $\mathrm{I}^{2}$ $=18 \%$; moderate-quality evidence).

The studies suggested people undergoing RoCT in a single visit may be more likely to experience pain in the first week than those whose RoCT was over multiple visits (RR $1.50,95 \% \mathrm{Cl} 0.99$ to $2.28 ; 1383$ participants, 8 studies, $12=54 \%$ ), though the quality of the evidence for this finding is low.

Moderate-quality evidence showed people undergoing RoCT in a single visit were more likely to use painkillers than those receiving treatment over multiple visits ( $\mathrm{RR} 2.35,95 \% \mathrm{Cl} 1.60$ to $3.45 ; 648$ participants, 4 studies, $\mathrm{I} 2=0 \%$ ).

\section{Authors' conclusions}

There is no evidence to suggest that one treatment regimen (single-visit or multiple-visit root canal treatment) is better than the other. Neither can prevent all short- and long-term complications. On the basis of the available evidence, it seems likely that the benefit of a singlevisit treatment, in terms of time and convenience, for both patient and dentist, has the cost of a higher frequency of late postoperative pain (and as a consequence, painkiller use).

\section{PLAIN LANGUAGE SUMMARY}

\section{Should root canal treatment be performed in one dental visit or over several visits?}

\section{Review question}

Is there any difference in effectiveness when undertaking root canal treatment in one visit compared to over several visits, and what are the effects on pain and complications, regardless of whether medication is used?

\section{Background}

This is an update of a review first published in 2007.

Root canal treatment, or endodontic treatment, is a common procedure in dentistry. The main reasons that root canal treatment are needed are persistent inflammation of the dental pulp (pulpitis) and death of the dental pulp (dead or non-vital tooth) caused by tooth decay, cracks or chips, or other accidental damage to teeth.

Root canal treatment is considered successful when there are no symptoms, for example pain, and when $\mathrm{x}$-rays show no signs of damage to bone and other supporting tissues of the tooth. The success of root canal treatment depends on the preoperative condition of the tooth, as well as the endodontic procedures used.

\section{Study characteristics}

We searched the literature up to 14 June 2016. We found 25 relevant studies with a total of 3780 participants. The studies compared root canal treatment performed at a single appointment with root canal treatment performed over two or more appointments on vital permanent teeth, non-vital permanent teeth, or both.

\section{Key results}

No apparent difference exists between single- and multiple-visit root canal treatment on x-ray examination, an indicator which does not affect the patient directly, but is known to be important as a measure of effective treatment. Only one study measured the likelihood of tooth extraction due to endodontic problems and did not find evidence of a difference between single- and multiple-visit treatment. Most short- and long-term complications (pain, swelling, fistula, and tooth extraction) were similar in terms of frequency, although people undergoing a single visit were more likely to experience pain in the first week and to take painkillers.

\section{Quality of the evidence}


We assessed the available evidence as moderate to low quality because a number of the studies were at high risk of bias, there was inconsistency between study results, and results were imprecise. 


\section{SUMMARY OF FINDINGS}

\section{Summary of findings for the main comparison. Single visit versus multiple visit treatment for endodontic treatment of permanent teeth}

Single-visit compared to multiple-visit treatment for endodontic treatment of permanent teeth

Patient or population: people receiving endodontic treatment of permanent teeth

Setting: university dental clinics, dental hospitals, and private dental practices

Intervention: single-visit treatment

Comparison: multiple-visit treatment

\begin{tabular}{|c|c|c|c|c|c|c|}
\hline \multirow[t]{2}{*}{ Outcomes } & \multicolumn{2}{|c|}{ Anticipated absolute effects* $(95 \% \mathrm{Cl})$} & \multirow{2}{*}{$\begin{array}{l}\text { Relative effect } \\
(95 \% \mathrm{Cl})\end{array}$} & \multirow{2}{*}{$\begin{array}{l}\text { Number of par- } \\
\text { ticipants } \\
\text { (studies) }\end{array}$} & \multirow{2}{*}{$\begin{array}{l}\text { Quality of the } \\
\text { evidence } \\
\text { (GRADE) }\end{array}$} & \multirow[t]{2}{*}{ Comments } \\
\hline & $\begin{array}{l}\text { Risk with mul- } \\
\text { tiple-visit } \\
\text { treatment }\end{array}$ & $\begin{array}{l}\text { Risk with single-visit } \\
\text { treatment }\end{array}$ & & & & \\
\hline $\begin{array}{l}\text { Tooth extraction due to endodon- } \\
\text { tic problems }\end{array}$ & 19 per 1000 & $\begin{array}{l}9 \text { per } 1000 \\
(1 \text { to } 88)\end{array}$ & $\begin{array}{l}\text { RR } 0.44 \\
\text { (0.04 to } 4.78)\end{array}$ & $\begin{array}{l}220 \\
(1 \mathrm{RCT})\end{array}$ & $\begin{array}{l}\oplus \ominus \ominus \ominus \\
\text { VERY LOW 1, 2, } 3\end{array}$ & \\
\hline $\begin{array}{l}\text { Pain (dichotomous) - pain in the } \\
\text { immediate postoperative period } \\
\text { (until } 72 \text { hours postobturation) }\end{array}$ & 379 per 1000 & $\begin{array}{l}375 \text { per } 1000 \\
\text { (318 to } 443)\end{array}$ & $\begin{array}{l}\text { RR } 0.99 \\
\text { (0.84 to } 1.17)\end{array}$ & $\begin{array}{l}1560 \\
\text { (9 RCTs) }\end{array}$ & $\begin{array}{l}\oplus \oplus \oplus \ominus \\
\text { MODERATE } 4\end{array}$ & \\
\hline $\begin{array}{l}\text { Pain (dichotomous) - pain at } 1 \\
\text { week }\end{array}$ & 109 per 1000 & $\begin{array}{l}164 \text { per } 1000 \\
(108 \text { to } 249)\end{array}$ & $\begin{array}{l}\text { RR } 1.50 \\
\text { (0.99 to } 2.28)\end{array}$ & $\begin{array}{l}1383 \\
\text { (8 RCTs) }\end{array}$ & $\begin{array}{l}\oplus \oplus \ominus \ominus \\
\text { LOW } 4,6\end{array}$ & \\
\hline Painkiller use & 97 per 1000 & $\begin{array}{l}228 \text { per } 1000 \\
\text { (155 to } 335)\end{array}$ & $\begin{array}{l}\text { RR } 2.35 \\
\text { (1.60 to } 3.45)\end{array}$ & $\begin{array}{l}648 \\
(4 \mathrm{RCTs})\end{array}$ & $\begin{array}{l}\oplus \oplus \oplus \ominus \\
\text { MODERATE } 4\end{array}$ & \\
\hline Sinus track or fistula formation & 12 per 1000 & $\begin{array}{l}12 \text { per } 1000 \\
(2 \text { to } 78)\end{array}$ & $\begin{array}{l}\text { RR } 0.98 \\
\text { (0.15 to } 6.48)\end{array}$ & $\begin{array}{l}345 \\
(2 \mathrm{RCTs})\end{array}$ & $\begin{array}{l}\oplus \oplus \ominus \ominus \\
\text { LOW } 4,7\end{array}$ & \\
\hline Any complication & 286 per 1000 & $\begin{array}{l}263 \text { per } 1000 \\
\text { (220 to } 317)\end{array}$ & $\begin{array}{l}\text { RR } 0.92 \\
\text { (0.77 to } 1.11)\end{array}$ & $\begin{array}{l}1686 \\
\text { (10 RCTs) }\end{array}$ & $\begin{array}{l}\oplus \oplus \oplus \ominus \\
\text { MODERATE } 4\end{array}$ & \\
\hline
\end{tabular}


${ }^{\star}$ The risk in the intervention group (and its 95\% confidence interval) is based on the assumed risk in the comparison group and the relative effect of the intervention (and its $95 \% \mathrm{Cl})$.

Cl: confidence interval; $\mathbf{R C T}$ : randomised controlled trial; RR: risk ratio.

\section{GRADE Working Group grades of evidence}

High quality: we are very confident that the true effect lies close to that of the estimate of the effect.

Moderate quality: we are moderately confident in the effect estimate: The true effect is likely to be close to the estimate of the effect, but there is a possibility that it is substantially different.

Low quality: our confidence in the effect estimate is limited: The true effect may be substantially different from the estimate of the effect.

Very low quality: we have very little confidence in the effect estimate: The true effect is likely to be substantially different from the estimate of effect.

1 The study was judged at high risk of bias.

2 The results are based on a single study performed in a university centre.

3 The results are based on an single study, with relatively few participants and events.

4 The results are based on a number of studies judged at high risk of bias.

5 The results showed significant imprecision.

6 The studies showed significant heterogeneity.

7 The results are based on two studies only, with relatively few participants and events. 


\section{B A C K G R O U N D}

\section{Description of the condition}

Irreversible pulpitis of the dental pulp and its subsequent necrosis (death of dental pulp) are caused by carious processes, tooth cracks or chips, or dental trauma and represent the main indications for root canal treatment (RoCT). The primary symptom of irreversible pulpitis is severe pain, and RoCT is necessary to relieve symptoms and to avoid tooth extraction due to complications following necrosis of the dental pulp.

\section{Description of the intervention}

RoCT is a common procedure in dentistry that is performed to remove organic tissue, infected debris, and pathogenic bacteria from the root canal system by means of mechanical instrumentation associated with copious irrigation with disinfectant agents. Two approaches have been proposed to solve this problem. In the first approach, residual bacteria are eliminated or prevented from repopulating the root canal system by introducing an interappointment dressing into the root canal, generally falling into the following categories: phenolic derivatives (eugenol, camphorated paramonochlorophenol, camphorated phenol, metacresyl acetate, beechwood creosote), aldehydes (formocresol), halides (iodinepotassium iodide), calcium hydroxide, antibiotics, or other combinations. The most popular intracanal medication currently in use is calcium hydroxide. Some studies have shown that calcium hydroxide fails to produce sterile root canals and even allows regrowth in some cases (Kvist 2004; Orstavik 1991; Reit 1988). However, even a negative culture before obturation gives no guarantee of healing in all cases (Trope 1999; Weiger 2000). The second approach aims to eliminate remaining bacteria or render them harmless by entombing them by complete and three-dimensional obturation, finishing the treatment in one visit to deprive the micro-organisms of nutrition and the space required to survive and multiply (Soltanoff 1978; Weiger 2000). The antimicrobial activity of the sealer or the zinc ions of gutta-percha can kill the residual bacteria (Moorer 1982; Siqueira 2000).

Endodontic techniques can claim many improvements through the use of rubber dam, magnifying devices, electronic apex locators, and engine-driven rotary nickel titanium files, which have improved the success rate of endodontic treatment and shortened the time needed for treatment (Bystrom 1981; Orstavik 1998; Reit 1988). The basic biological rationale for achieving final success of RoCT consists primarily of eliminating micro-organisms from the entire root canal system and preventing their re-entry. Different therapeutic procedures can be employed, depending upon the biological condition of the tooth being treated, its pathological state, clinician expertise, instrument availability, and patient preference. Successful RoCT is characterised by the absence of symptoms and clinical signs of infection in a tooth without radiographic evidence of periodontal involvement (Friedman 2002). The success of RoCT depends on variables related to the preoperative condition of the tooth, as well as the endodontic procedures.

\section{How the intervention might work}

RoCT can be followed by numerous short- and long-term complications (Battrum 1996). The former include immediate postoperative inflammation of periradicular tissues associated with pain, either spontaneous or provoked. The correlation of postoperative pain with different variables, including the number of visits needed to complete RoCT, operative procedures, pulp vitality and dental anatomy, has been the objective of numerous studies (Albashaireh 1998; DiRenzo 2002; Gambarini 1991; Soltanoff 1978). The main long-term complications include the persistence of inflammation of fistula or sinus track, pain, or both, and an absence of radiographic healing. Several studies have investigated the frequency of radiographic healing in teeth with preoperative periapical pathology and have compared single- and multiple-visit approaches, employing interappointment medication (Katebzadeh 2000; Peters 2002; Soltanoff 1978; Trope 1999; Weiger 2000). The results of such investigations have led to conflicting conclusions. Some studies have suggested that the use of different medications between visits can contribute to the elimination of all bacteria (Fava 1995). In contrast, others have emphasised the need to seal the endodontic space as quickly as possible, i.e. in a single visit, as temporary cements are unreliable in maintaining a good coronal seal during the time between visits. Postoperative complications have been reported with both methods, varying from $5 \%$ in Abbott 2000 to more than 20\% in Friedman 1995.

\section{Why it is important to do this review}

Cochrane Oral Health undertook an extensive prioritisation exercise in 2014 to identify a core portfolio of titles that were the most clinically important ones to maintain in the Cochrane Library (Worthington 2015). The operative and prosthodontic dentistry expert panel identified this review as a priority title (Cochrane Oral Health priority review portfolio).

RoCT is an extremely common procedure, performed on thousands of people every day. If a single-visit approach is shown to be as effective and safe as multiple-visit treatment, it could result in a significant saving in time and money for patients and dentists.

\section{O B JECT IVES}

To determine whether completion of root canal treatment (RoCT) in a single visit or over two or more visits, with or without medication, makes any difference in term of effectiveness or complications.

\section{METHODS}

\section{Criteria for considering studies for this review}

\section{Types of studies}

We included randomised controlled trials (RCTs) and quasi-RCTs (i.e. those using an alternative assignment based on, for example, birth date). We also considered split-mouth studies. We excluded studies that did not measure at least one of our outcomes.

\section{Types of participants}

Participants aged 10 years or above who required root canal treatment. All participants had teeth with a completely formed apex and without internal resorption.

\section{Types of interventions}

Root canal treatment in a single visit or multiple visits, i.e. two or more appointments.

Any systemic medical treatment (antibiotics, non-steroidal antiinflammatories or analgesics) was to be the same in both groups. 


\section{Types of outcome measures}

\section{Primary outcomes}

- Tooth extraction due to endodontic problems (binary, yes/no).

- Radiological failure after at least one year, i.e. the presence of any periapical radiolucency (binary, yes/no). Additional Table 1 summarises how we adapted the most common scales of radiological healing to a binary outcome.

\section{Secondary outcomes}

- Postoperative pain (binary, yes/no; continuous).

- Swelling or flare-up (binary, yes/no).

- Painkiller use (binary, yes/no).

- Sinus track or fistula formation (binary, yes/no).

- Any complication defined as a composite outcome including any adverse event (pain, painkiller use, swelling or flare-up) occurring within one month from the treatment (binary, yes $/ \mathrm{no}$ ).

\section{Search methods for identification of studies}

To identify studies for this review, we developed detailed search strategies for each database searched. These were based on the search strategy developed for MEDLINE Ovid (Appendix 3), but revised appropriately for each database.

\section{Electronic searches}

We searched the following electronic databases.

- Cochrane Oral Health Group's Trials Register (to 14 June 2016) (see Appendix 1).

- Cochrane Central Register of Controlled Trials (CENTRAL; 2015, Issue 5) in the Cochrane Library (searched 14 June 2016) (see Appendix 2).

- MEDLINE Ovid (1946 to 14 June 2016) (see Appendix 3).
- Embase Ovid (1980 to 14 June 2016) (see Appendix 4).

We did not place any restrictions on the language or date of publication when searching the electronic databases.

\section{Searching other resources}

We searched the following trial registries for ongoing studies (see Appendix 5).

- US National Institutes of Health Ongoing Trials Register ClinicalTrials.gov (clinicaltrials.gov; searched 14 June 2016).

- World Health Organization International Clinical Trials Registry Platform (apps.who.int/trialsearch; searched 14 June 2016).

We did not perform a separate search for adverse effects of interventions; we considered adverse effects as described in included studies only.

We checked all references in the identified papers and we contacted the authors to identify any additional published or unpublished data.

\section{Data collection and analysis}

\section{Selection of studies}

Two review authors (MM and LF) independently examined the title and abstract (when available) of each article identified by the search strategy. Where studies appeared to meet the inclusion criteria for this review or where there were insufficient data in the title and abstract to make a clear decision, we obtained the full report. The full report was then assessed by at least two of the review authors (MM, LF, GL, MG), to determine whether studies met the inclusion criteria. We resolved any disagreements by discussion. We recorded studies rejected at this or subsequent stages in the Characteristics of excluded studies table, with the reason(s) for exclusion. See Figure 1 for a flow chart that summarises the results of the search. 
Figure 1. Study flow diagram: review update

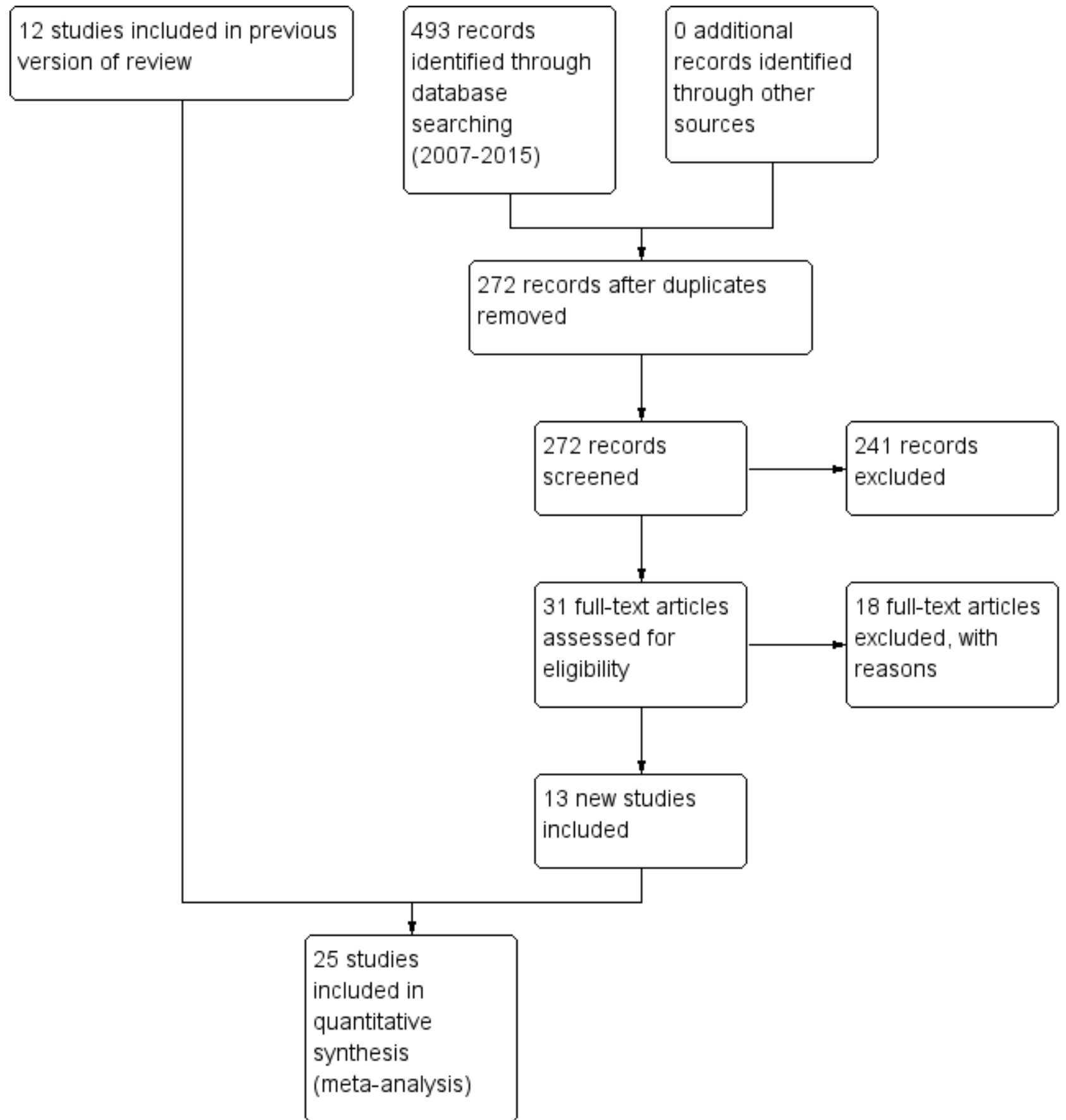

\section{Data extraction and management}

At least two review authors (MM, LF) independently extracted data using a specially designed data extraction form and entered them into a spreadsheet. At least two review authors (GL, MM) authors independently assessed the risk of bias in the included studies. We discussed any discrepancies to reach agreement. When necessary, we contacted study authors for clarification or missing information. For each trial, we recorded the following data.

- Year of publication, country of origin, number of centres, source of study funding, recruitment period.
- Details of the participants including demographic characteristics and criteria for inclusion and exclusion, type of tooth treated (vital or non-vital) and reasons of the treatment, diagnostic criteria for pulpal or periapical disease, numbers randomised to each treatment group.

- Details about the number of visits performed to treat the root canal (single or multiple), number of operators involved in the treatment, use of rubber dam and magnification loupes, type of canal shaping, type of irrigation, method used to establish the working length of the root canal, type of obturation of the 
canal. In the multiple visits approach, we also recorded the type of medication used in the interappointment period.

- Details of pain management.

- Details of the outcomes reported, including method of assessment, and time(s) assessed.

- Description of operators.

\section{Assessment of risk of bias in included studies}

Two review authors (GL, MM) independently assessed the risk of bias of the included trials and any disagreement was resolved through discussion and consensus. We used the recommended approach for assessing risk of bias in studies included in Cochrane Reviews (Higgins 2011). We addressed six domains:

- random sequence generation (selection bias);

- allocation concealment (selection bias);

- blinding of outcome assessment (detection bias);

- incomplete outcome data (attrition bias);

- selective reporting (reporting bias);
- other bias.

Each domain in the tool includes one or more entries in the 'Characteristics of included studies' table. Within each entry, we described what was reported to have happened in the study, in sufficient detail to support a judgement about the risk of bias. We then assigned a judgement relating to the risk of bias for that entry, either 'low', 'high', or 'unclear' risk of bias. After taking into account the additional information provided by the authors of the trials, we summarised the risk of bias in the studies as:

- low risk of bias = low risk of bias for all key domains;

- unclear risk of bias = unclear risk of bias for one or more key domains;

- high risk of bias = high risk of bias for one or more key domains.

We completed a 'Risk of bias' table for each included study (see Characteristics of included studies), and presented results graphically by study and by domain across all studies (Figure 2; Figure 3). 
Figure 2. 'Risk of bias' summary: review authors' judgements about each risk of bias item for each included study

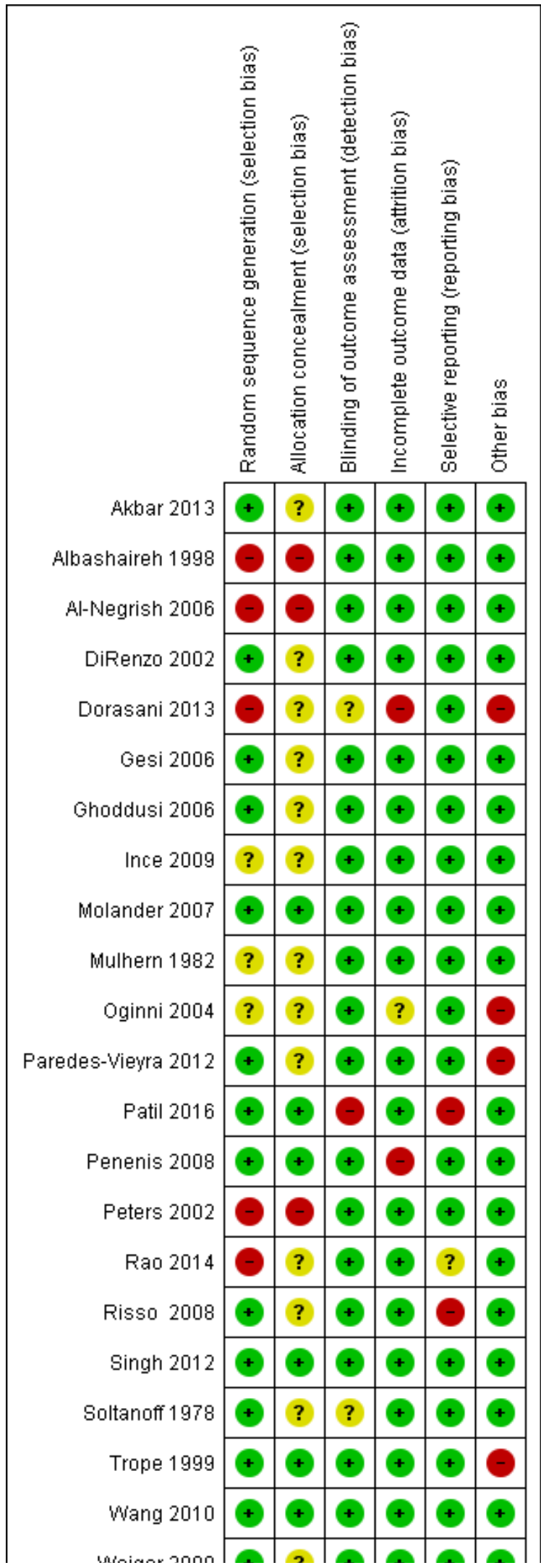


Figure 2. (Continued)

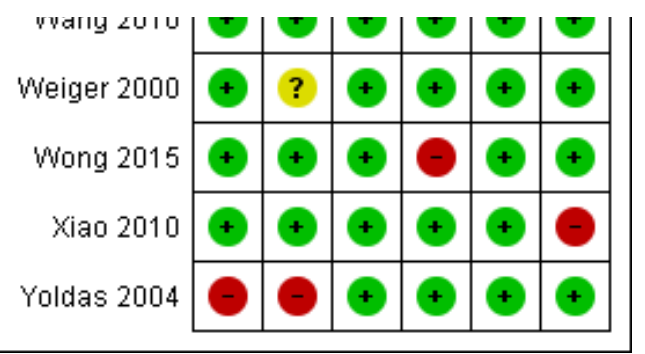

Figure 3. 'Risk of bias' graph: review authors' judgements about each risk of bias item presented as percentages across all included studies

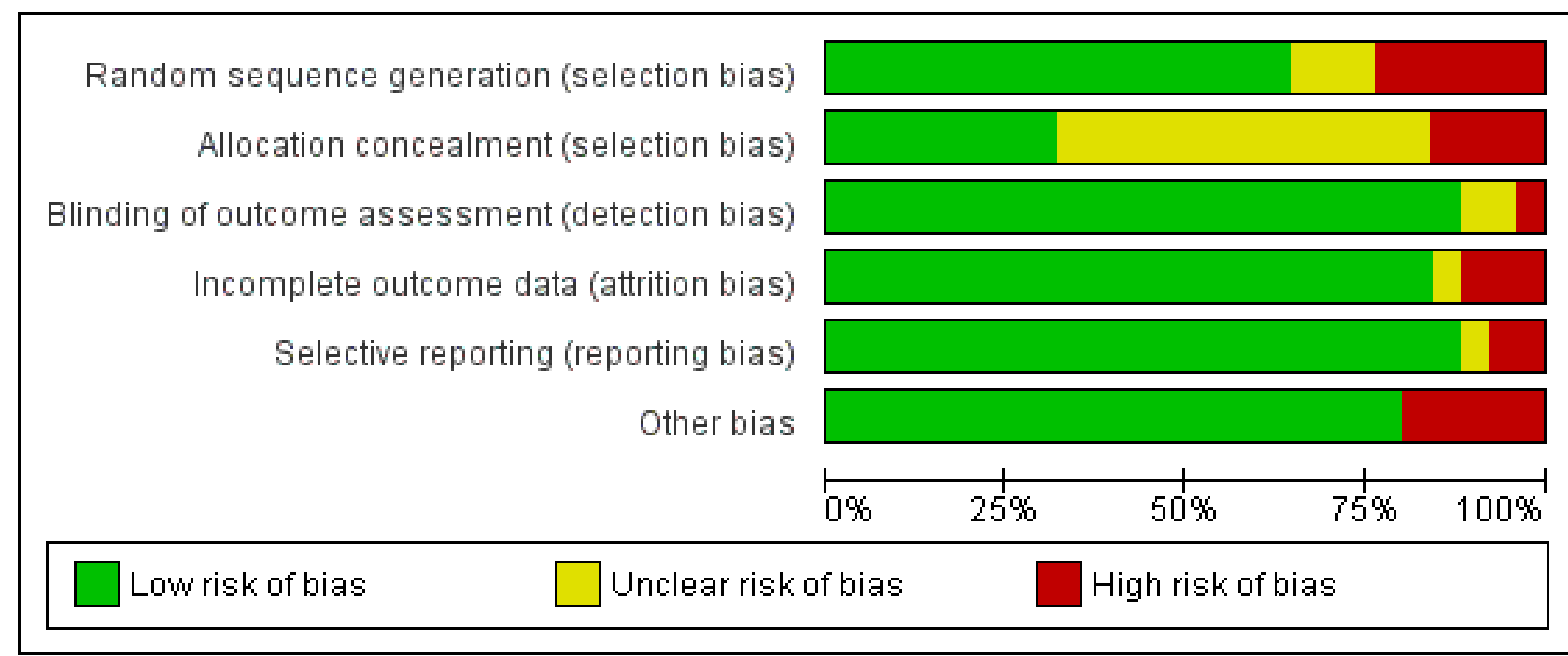

\section{Measures of treatment effect}

Our primary measures of intervention effect were tooth extraction due to endodontic problems and radiological failure after one year. We dichotomised data on radiological healing when this was measured on ordinal scales (see Table 1 for details). Our other outcomes were incidence of postoperative pain, presence of swelling or flare-up, painkiller use, sinus track or fistula formation, and any complication. We analysed dichotomous data by calculating risk ratios (RRs) and 95\% confidence intervals (Cls). When pain was recorded as a continuous outcome, we analysed data by calculating mean differences (MDs) and 95\% Cls.

\section{Unit of analysis issues}

The statistical unit was the individual participant. We considered studies using the tooth as the statistical unit, making the assumption that participants were randomised a number of times equal to the number of teeth. When this was not explicitly stated, we considered the study potentially affected by a bias of allocation.

\section{Dealing with missing data}

When raw data were not available, we obtained them by consulting tables and graphs, or by contacting the trial authors.

\section{Assessment of heterogeneity}

We assessed heterogeneity by inspection of the point estimates and $\mathrm{Cls}$ on the forest plots. We assessed the variation in treatment effects by means of Cochran's test for heterogeneity and quantified by the $1^{2}$ statistic. We considered heterogeneity statistically significant if $P<0.1$. A rough guide to the interpretation of the 12 statistic given in the Cochrane Handbook for Systematic Reviews of Interventions is: $0 \%$ to $40 \%$ might not be important, $30 \%$ to $60 \%$ may represent moderate heterogeneity, $50 \%$ to $90 \%$ may represent substantial heterogeneity, $75 \%$ to $100 \%$ may represent very substantial ('considerable') heterogeneity (Higgins 2011).

\section{Assessment of reporting biases}

Only a proportion of research projects conducted are ultimately published in an indexed journal and become easily identifiable for inclusion in systematic reviews. Reporting biases arise when the reporting of research findings is influenced by the nature and direction of the findings of the research. We attempted to minimise potential reporting biases including publication bias, time lag bias, multiple (duplicate) publication bias, and language bias in this review. If there had been more than 10 studies evaluating one outcome, we planned to construct a funnel plot. If there had been asymmetry in the funnel plot indicating possible publication bias, we planned to undertake statistical analysis using the methods introduced by Egger 1997 (continuous outcome) and 
Rucher 2008 (dichotomous outcome). We attempted to avoid time lag bias, multiple (duplicate) publication bias, and language bias by conducting a detailed sensitive search, including searching for ongoing studies. We did not impose any restrictions on language, and we found translators for potentially relevant trials published in other languages.

\section{Data synthesis}

For each intervention, we sought and summarised data on the number of participants in intervention and control groups who experienced the event (outcome) and the total number of participants. We only conducted a meta-analysis if there were studies of similar comparisons reporting the same outcome measures. We combined RRs for dichotomous data, and MDs for continuous data, using a random-effects model in Review Manager software (RevMan 2014).

\section{Subgroup analysis and investigation of heterogeneity}

We had planned subgroup analyses to investigate the relevance of pretreatment conditions (vital teeth versus necrotic teeth), pretreatment symptoms (symptomatic versus asymptomatic teeth), pretreatment radiographic periapical appearance (apical radiolucency versus no apical radiolucency), endodontic technique, and antimicrobials employed (antimicrobial A versus antimicrobial B). Only data on pretreatment conditions (vital teeth versus necrotic teeth) were available for a subgroup analysis.

\section{Sensitivity analysis}

We performed a sensitivity analysis, excluding studies at high risk of bias.

\section{Presentation of main results}

Using GRADEpro GDT software (GRADEpro GDT 2014), we produced Summary of findings table 1 for all outcomes. We assessed the quality of the evidence as high, moderate, low, or very low, with reference to study limitations, inconsistency, imprecision, indirectness, and risk of publication bias (Atkins 2004). We explained decisions to downgrade the quality of evidence using footnotes in the 'Summary of findings' table.

\section{RES U L T S}

\section{Description of studies}

\section{Results of the search}

We found 25 studies suitable for inclusion in this review (see Figure $1)$.

\section{Included studies}

\section{Characteristics of trial design and settings}

For a summary of the characteristics of each of the included studies, see Characteristics of included studies.

Of the 25 included studies, five were conducted in the USA (DiRenzo 2002; Mulhern 1982; Penenis 2008; Soltanoff 1978; Trope 1999), four in India (Dorasani 2013; Patil 2016; Rao 2014; Singh 2012), two in Jordan (Albashaireh 1998; Al-Negrish 2006), three in China (Wang 2010; Wong 2015; Xiao 2010), two in Turkey (Ince 2009; Yoldas 2004), and single studies were conducted in Italy (Gesi 2006), Iran (Ghoddusi 2006), Sweden (Molander 2007), Nigeria (Oginni 2004),
Mexico (Paredes-Vieyra 2012), the Netherlands (Peters 2002), Brazil (Risso 2008), Germany (Weiger 2000), and Pakistan (Akbar 2013).

Twenty-two of the studies were performed in university clinics or hospitals. Gesi 2006 was undertaken in private practice. Two studies did not provide details about the settings of the study (Mulhern 1982; Rao 2014).

All the studies used parallel group designs and most had two treatment arms. Two studies had three arms, which compared a single visit, multiple visits without intracanal medication, and multiple visits with intracanal medication (calcium hydroxide) (Ghoddusi 2006; Trope 1999). In order to include such data in the meta-analysis, we combined the two multi-visit arms. In the same meta-analysis, we pooled data from studies that used or did not use a dressing.

Four studies reported that they had received research grants for the conduct of the study (Ghoddusi 2006; Mulhern 1982; Penenis 2008; Risso 2008).

\section{Characteristics of participants}

A total of 3780 participants were enrolled in the 25 studies included in this review, and a total of 3571 participants were analysed.

All studies considered one tooth per participant, with the exception of Dorasani 2013, Oginni 2004, Paredes-Vieyra 2012, Trope 1999, Wong 2015, and Xiao 2010. Dorasani 2013 considered 64 teeth in 43 participants ( 5 participants contributed 2 teeth and 1 participant contributed 3 teeth). In Oginni 2004, participants requiring root canal treatment (RoCT) on more than one tooth, underwent consecutive treatment of each tooth with an interval of at least four weeks to allow proper evaluation: 283 teeth were randomised in 255 participants. In Paredes-Vieyra 2012, the study authors reported that 287 participants and 300 teeth were enrolled; they stated that 21 participants contributed more than one tooth, but according to these figures, no more than 13 participants could have contributed more than one tooth. Trope 1999 considered 102 teeth in 81 participants (61 participants had a single tooth, 18 had 2 teeth and 2 participants had 3 teeth). Finally in Xiao 2010, 86 participants were enrolled with a total of 138 teeth. For these five studies, the analysis was conducted at the level of the tooth.

Fourteen studies included participants with necrotic teeth only (Akbar 2013; Al-Negrish 2006; Dorasani 2013; Ghoddusi 2006; Molander 2007; Mulhern 1982; Paredes-Vieyra 2012; Penenis 2008; Peters 2002; Rao 2014; Risso 2008; Trope 1999; Weiger 2000; Xiao 2010). Yoldas 2004 is the only study that included retreatment, while Gesi 2006 and Wang 2010 included only participants with vital teeth. Seven studies included both necrotic teeth and vital teeth (Albashaireh 1998; DiRenzo 2002; Ince 2009; Oginni 2004; Patil 2016; Singh 2012, Wong 2015), but two of them did not provide details on the numbers in the two categories (DiRenzo 2002; Oginni 2004). One study did not provide details on the pretreatment status (Soltanoff 1978). One study included maxillary central incisors only (Patil 2016).

None of the data reported by the included studies allowed us to analyse the effects of the two approaches stratified on the basis of preoperative conditions of patients, specifically presence of symptoms (pain) or signs (infection). 


\section{Characteristics of interventions}

Of the 25 studies included in this review, the majority compared RoCT performed in a single visit with RoCT performed in two visits (Akbar 2013; Al-Negrish 2006; Albashaireh 1998; DiRenzo 2002; Dorasani 2013; Gesi 2006; Ghoddusi 2006; Ince 2009; Molander 2007; Paredes-Vieyra 2012; Patil 2016; Penenis 2008 Peters 2002; Rao 2014; Singh 2012; Trope 1999; Weiger 2000; Wang 2010; Yoldas 2004). In one study, the multiple-visit RoCT lasted three visits (Mulhern 1982). One study (Wong 2015) reported that multiple visit treatment had been performed in two or three appointments depending on the complexity of the RoCT. In two studies, the number of visits was not specified (Oginni 2004; Soltanoff 1978).

In the multiple-visit approach, nine studies did not use any intracanal medications in the interappointment period (Albashaireh 1998; DiRenzo 2002; Ghoddusi 2006; Ince 2009; Mulhern 1982; Patil 2016; Rao 2014; Singh 2012; Trope 1999). In 12 studies, the root canals were medicated with a calcium hydroxide paste (Akbar 2013; Al-Negrish 2006; Dorasani 2013; Gesi 2006; Molander 2007; Paredes-Vieyra 2012; Peters 2002; Risso 2008; Wang 2010; Weiger 2000; Wong 2015; Xiao 2010), while two studies used a medication with calcium hydroxide and chlorhexidine (Penenis 2008; Yoldas 2004). Two studies did not specify the type of interappointment medication (Oginni 2004; Soltanoff 1978).

Eleven studies did not report use of rubber dam to isolate the tooth during RoCT (Albashaireh 1998; Ince 2009; Molander 2007; Oginn 2004; Rao 2014; Risso 2008; Singh 2012; Soltanoff 1978; Wang 2010; Xiao 2010; Yoldas 2004), and use of magnification loupes was reported by three studies only (Penenis 2008; Peters 2002; Wong 2015).

Working length was established using an electronic apex locator and radiographs in seven studies (DiRenzo 2002; Paredes-Vieyra 2012; Patil 2016; Peters 2002; Rao 2014; Risso 2008; Yoldas 2004), by an electronic apex locator only in four studies (Penenis 2008; Singh 2012; Wang 2010; Xiao 2010), and by radiographs only in nine studies (Akbar 2013; Al-Negrish 2006; Dorasani 2013; Gesi 2006; Ghoddusi 2006; Ince 2009; Mulhern 1982; Trope 1999; Weiger 2000). Five studies did not report information about working length evaluation (Albashaireh 1998; Molander 2007; Oginni 2004; Soltanoff 1978; Wong 2015).

Canal shaping was performed using conventional hand instruments in 10 studies (Akbar 2013; Al-Negrish 2006; Dorasani 2013; Gesi 2006; Ghoddusi 2006; Ince 2009; Peters 2002; Risso 2008; Soltanoff 1978; Weiger 2000), a combination of hand files and nickel titanium rotary files in seven studies (DiRenzo 2002; Molander 2007; Paredes-Vieyra 2012; Rao 2014; Singh 2012; Wang 2010; Yoldas 2004), and rotary nickel titanium files only in four studies (Patil 2016; Penenis 2008; Wong 2015; Xiao 2010). Four studies did not report canal shaping instrumentation in a satisfactory way (Albashaireh 1998; Mulhern 1982; Oginni 2004; Trope 1999).

Twenty-four studies reported that canal obturation was performed with gutta-percha using the lateral condensation technique; only one study reported use of the vertical condensation technique (Penenis 2008).

In 21 studies, sodium hypochlorite with a range between $0.5 \%$ to $5.25 \%$ was used as irrigant (Akbar 2013; Al-Negrish 2006; Albashaireh 1998; DiRenzo 2002; Dorasani 2013; Gesi 2006; Ince
2009; Molander 2007; Mulhern 1982; Paredes-Vieyra 2012; Patil 2016; Penenis 2008; Peters 2002; Rao 2014; Singh 2012; Trope 1999; Wang 2010; Weiger 2000; Wong 2015; Xiao 2010; Yoldas 2004), while two studies used saline solution as irrigant (Ghoddusi 2006; Soltanoff 1978). In Risso 2008, a combination of sodium hypochlorite, citric acid, and sodium thiosulfate was used as irrigant. In Oginni 2004, the type of irrigant used was not specified.

Nine studies reported that RoCT was performed by a single operator (Al-Negrish 2006; Albashaireh 1998; Dorasani 2013; Ghoddusi 2006; Paredes-Vieyra 2012; Patil 2016; Peters 2002; Risso 2008; Trope 1999), while 10 studies reported two or more operators were involved in RoCT (DiRenzo 2002; Gesi 2006; Ince 2009; Molander 2007; Mulhern 1982; Penenis 2008; Wang 2010; Weiger 2000; Wong 2015; Yoldas 2004). Six studies specified that treatment was conducted by trained or experienced operators (Ince 2009; Molander 2007; Penenis 2008; Peters 2002; Wang 2010; Weiger 2000), while three studies reported that RoCT was performed by postgraduate students (DiRenzo 2002; Mulhern 1982; Risso 2008). Six studies did not provide details about the operators (Akbar 2013; Oginni 2004; Rao 2014; Singh 2012; Soltanoff 1978; Xiao 2010).

\section{Characteristics of outcomes}

One study only provided information on tooth extraction due to endodontic problems as outcome measure (Wong 2015).

Radiological failure was investigated in 11 studies (Dorasani 2013; Gesi 2006; Molander 2007; Paredes-Vieyra 2012; Penenis 2008; Peters 2002; Soltanoff 1978; Trope 1999; Weiger 2000; Wong 2015; Xiao 2010). Additional Table 1 shows methods adopted to construct scales for radiological healing or failure. Follow-up varied from one year in Trope 1999 to five years in Weiger 2000.

Seventeen studies investigated postoperative pain (Al-Negrish 2006; Albashaireh 1998; DiRenzo 2002; Gesi 2006; Ghoddusi 2006; Ince 2009; Mulhern 1982; Oginni 2004; Patil 2016; Rao 2014; Risso 2008; Singh 2012; Soltanoff 1978; Wang 2010; Wong 2015; Xiao 2010; Yoldas 2004). The methods for evaluating postoperative pain are summarised in the 'Characteristics of included studies' table. Whenever possible, we dichotomised pain data into 'pain' or 'no pain' values. Four studies recorded pain as a continuous variable measured by visual analogue scale (VAS) (DiRenzo 2002; Patil 2016; Singh 2012; Wang 2010). We only considered pain after canal obturation, assessing pain incidence in the immediate postobturation period (until 72 hours), at one week, and at one month. We did not consider pain during the interappointment period in the multiple-visit approach, as we could not compare this with a similar situation in the single-visit approach. Five studies examined the need for participants to take analgesics to relieve pain (Mulhern 1982; Rao 2014; Soltanoff 1978; Wang 2010; Yoldas 2004).

Eight studies investigated the incidence of swelling or flare-up (Akbar 2013; DiRenzo 2002; Ghoddusi 2006; Mulhern 1982; ParedesVieyra 2012; Penenis 2008; Rao 2014; Wang 2010). Definitions of flare-up varied (see Table 2). Only DiRenzo 2002, Mulhern 1982, Ghoddusi 2006, and Akbar 2013 clearly defined flare-up as swelling. Therefore, we considered only studies clearly indicating swelling as a specific outcome, not simply as one of the signs related to the tooth infection. 
Four studies provided information on fistula or sinus track formation as an outcome measure (Penenis 2008; Paredes-Vieyra 2012; Wong 2015; Xiao 2010).

\section{Excluded studies}

Our main reason for excluding each of the 20 studies is recorded in the 'Characteristics of excluded studies' tables.

We excluded 10 studies because they were not RCTs (ElMubarak 2010; Fava 1989; Fava 1994; Friedman 1995; Jabeen 2014; Ng 2004; Prashanth 2011; Roane 1983; Walton 1992; Jabeen 2014). We excluded five studies because they evaluated only the microbiological status of RoCT (Gurgel-Filho 2007; Kvist 2004; Trusewicz 2005; Vera 2012; Xavier 2013), and two because the studies were conducted in animals (Holland 2003; Silveira 2007). We excluded two studies because they included primary teeth (Orhan 2010; Kabaktchieva 2013). We excluded one study because it did not include any of the outcomes considered in this review (Waltimo 2005).

\section{Risk of bias in included studies}

On the basis of criteria used in the critical appraisal of the studies, we assessed three studies as being at overall low risk of bias (Molander 2007; Singh 2012; Wang 2010); eight studies as being at unclear risk of bias (Akbar 2013; DiRenzo 2002; Gesi 2006; Ghoddusi 2006; Ince 2009; Mulhern 1982; Soltanoff 1978; Weiger 2000); and the remaining studies as being at high risk of bias (Albashaireh 1998; Al-Negrish 2006; Dorasani 2013; Oginni 2004; Paredes-Vieyra 2012; Patil 2016; Penenis 2008; Peters 2002; Rao 2014; Risso 2008; Trope 1999; Wong 2015; Xiao 2010; Yoldas 2004). See Figure 2.

\section{Allocation}

We assessed the generation of randomisation sequence as being at low risk of bias in 16 trials (64\%), unclear risk in three trials (12\%), and high risk in six trials (24\%). The concealment of allocation was at low risk of bias in eight trials (32\%), unclear risk in 13 (52\%), and high risk in four (16\%). See Figure 3.

\section{Blinding}

We assessed blinding of outcome assessment as being at low risk of detection bias for 22 trials (88\%), unclear for two trials ( $8 \%$ ), and high risk for one trial (4\%) (Patil 2016).

\section{Incomplete outcome data}

The reported dropout rate ranged from $0 \%$ to $35 \%$ (Penenis 2008). We assessed $21(84 \%)$ trials as being at low risk with regard to attrition bias, either due to no dropouts or dropouts being unlikely to influence findings. For one study (4\%), it was not possible to assess such bias. For three trials, we considered the high dropout rates to put the studies at high risk of attrition bias (12\%).

\section{Selective reporting}

Two trials (8\%) did not report one of the outcomes planned and for this reason we assessed them as being at high risk of reporting bias. For another trial, this bias was impossible to assess (4\%). We assessed the remaining 22 studies ( $88 \%$ ) as being at low risk of bias.

\section{Other potential sources of bias}

We judged flve studies (20\%) as being at high risk of other bias because they did not explicitly state that participants with more that one tooth needing treatment were randomised the same number of times.

\section{Effects of interventions}

See: Summary of findings for the main comparison Single visit versus multiple visit treatment for endodontic treatment of permanent teeth

\section{Single visit versus multiple visit root canal treatment Primary outcomes \\ Tooth extraction due to endodontic problems (binary, yes/no)}

Only one study reported data on tooth extraction due to endodontic problems (Wong 2015); there was no evidence of a difference between single- and multiple-visit treatment (odds ratio (OR) 0.44 , $95 \%$ confidence interval $(\mathrm{Cl}) 0.04$ to $4.78 ; 220$ participants) (Analysis 1.1). The quality of the evidence was very low (Summary of findings for the main comparison).

Radiological failure after at least one year, i.e. the presence of any periapical radiolucency (binary, yes/no)

We combined results from 11 studies (Dorasani 2013; Gesi 2006; Molander 2007; Penenis 2008; Paredes-Vieyra 2012; Peters 2002; Soltanoff 1978; Trope 1999; Weiger 2000; Wong 2015; Xiao 2010), that included 1467 participants with 1493 teeth (Analysis 1.2; Figure 4). The follow-up was one year (Dorasani 2013; Penenis 2008; Trope 1999), 18 months (Wong 2015), two years (Molander 2007; Paredes-Vieyra 2012; Soltanoff 1978; Xiao 2010), or more than three years (Gesi 2006; Peters 2002; Weiger 2000). The radiological failure rate was based on binary data, that is, radiological healing versus lack of such healing; scores including more than two values were dichotomised according to the methods indicated in Table 1. The studies, when pooled together, irrespective of the followup duration, showed no difference in terms of radiological failure between the treatments and were homogeneous (RR 0.91, 95\% Cl 0.68 to $1.21 ; 1493$ participants, 11 studies, $12=18 \%$ ). The quality of the evidence related to this outcome, as assessed using the GRADE method and presented in Summary of findings for the main comparison was low (Atkins 2004). 
Figure 4. Forest plot of comparison: 1 Primary outcomes, outcome: 1.2 Radiological failure

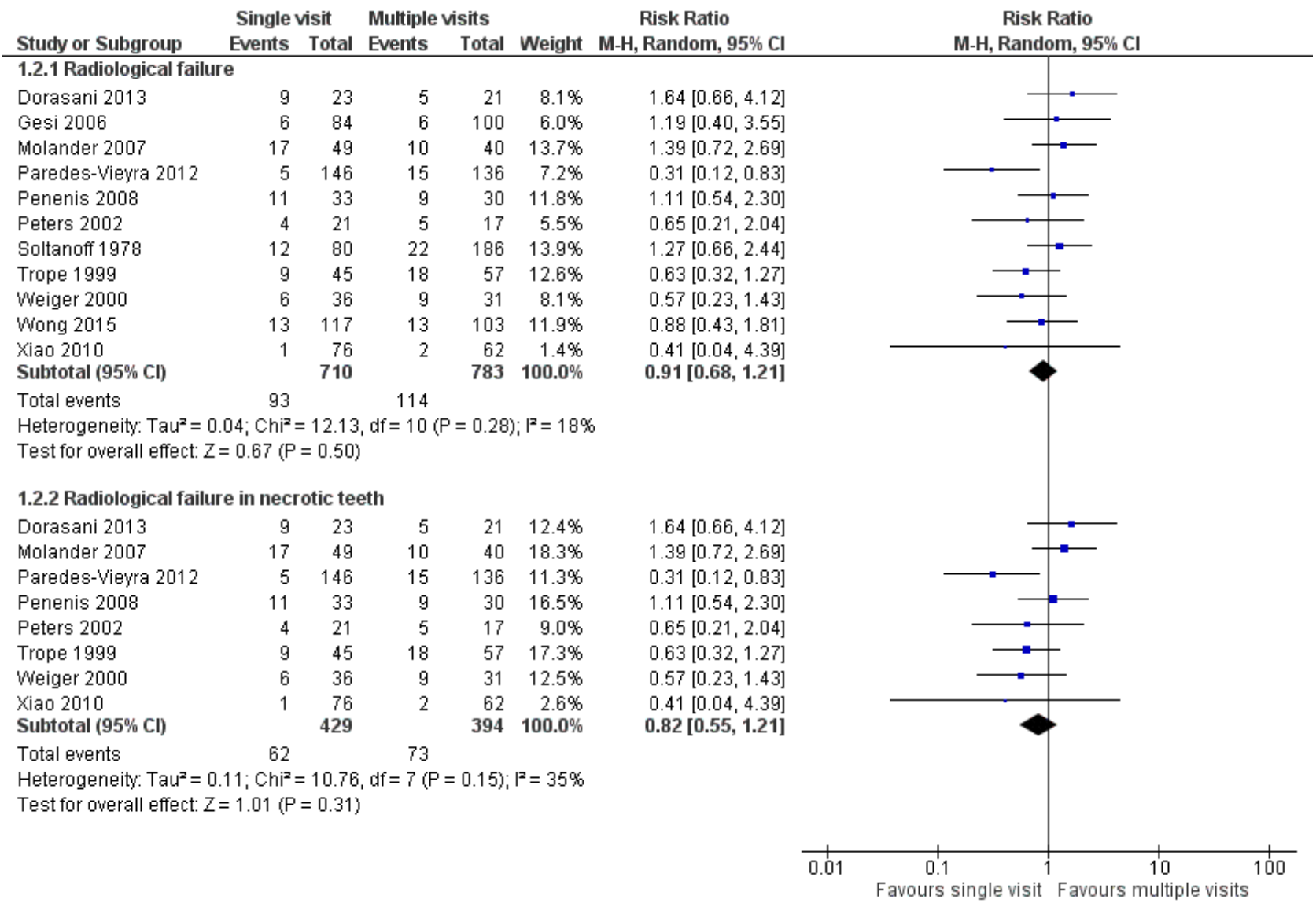

\section{Necrotic teeth}

For eight studies (Dorasani 2013; Molander 2007; Paredes-Vieyra 2012; Penenis 2008; Peters 2002; Trope 1999; Weiger 2000; Xiao 2010), it was possible to analyse radiological failure for necrotic teeth only. Meta-analysis of these studies showed no difference between participants treated in a single visit versus those treated in multiple visits, with low statistical heterogeneity (RR $0.82,95 \% \mathrm{Cl}$ 0.55 to $1.21 ; 823$ participants, 8 studies, $\left.\right|^{2}=35 \%$; Figure 4).

\section{Vital teeth}

There was one study reporting the rate of radiological failure in teeth vital at enrolment (Gesi 2006). This study found no difference between participants treated in single-visit RoCT in comparison to

those treated in multiple visits (RR $0.80,95 \% \mathrm{Cl} 0.59$ to $1.07 ; 184$ participants).

\section{Secondary outcomes}

Pain in the immediate postoperative period (up to 72 hours postobturation)

Nine studies, with a total of 1560 participants, reported pain incidence 72 hours after canal obturation as a dichotomous outcome (Al-Negrish 2006; Albashaireh 1998; Ghoddusi 2006; Ince 2009; Mulhern 1982; Oginni 2004; Risso 2008; Soltanoff 1978; Wang 2010). No difference was found between groups, with low statistical heterogeneity (RR $0.99,95 \% \mathrm{Cl} 0.84$ to $1.17 ; \mathrm{I}^{2}=33 \%$; Figure 5 ; Analysis 2.1). 
Figure 5. Forest plot of comparison: 2 Secondary outcomes, outcome: 2.1 Pain (dichotomous)

\begin{tabular}{|c|c|c|c|c|c|c|c|}
\hline \multirow{2}{*}{ Study or Subgroup } & \multicolumn{2}{|c|}{ Single visit } & \multicolumn{2}{|c|}{ Multiple visits } & \multicolumn{2}{|r|}{ Risk Ratio } & \multirow{2}{*}{$\begin{array}{c}\text { Risk Ratio } \\
\text { M-H, Random, } 95 \% \mathrm{Cl}\end{array}$} \\
\hline & Events & Total & Events & Total & Weight & M-H, Random, 95\% Cl & \\
\hline \multicolumn{7}{|c|}{ 2.1.1 Pain in the immediate postoperative period (until 72 hours postobturation) } & \\
\hline Al-Negrish 2006 & 8 & 54 & 14 & 58 & $4.0 \%$ & $0.61[0.28,1.35]$ & \\
\hline Albashaireh 1998 & 39 & 142 & 56 & 149 & $15.0 \%$ & $0.73[0.52,1.02]$ & \\
\hline Ghoddusi 2006 & 8 & 20 & 10 & 40 & $4.3 \%$ & $1.60[0.75,3.42]$ & \\
\hline Ince 2009 & 107 & 153 & 106 & 153 & $30.2 \%$ & $1.01[0.87,1.17]$ & \\
\hline Mulhern 1982 & 7 & 30 & 6 & 30 & $2.8 \%$ & $1.17[0.44,3.06]$ & \\
\hline Oginni 2004 & 58 & 107 & 61 & 136 & $20.5 \%$ & $1.21[0.94,1.56]$ & \\
\hline Risso 2008 & 6 & 57 & 14 & 61 & $3.2 \%$ & $0.46[0.19,1.11]$ & \\
\hline Soltanoff 1978 & 20 & 88 & 40 & 193 & $9.4 \%$ & $1.10[0.68,1.76]$ & \\
\hline Wang 2010 & 21 & 43 & 21 & 46 & $10.5 \%$ & $1.07[0.69,1.66]$ & \\
\hline Subtotal $(95 \% \mathrm{Cl})$ & & 694 & & 866 & $100.0 \%$ & $0.99[0.84,1.17]$ & \\
\hline Total events & 274 & & 328 & & & & \\
\hline \multirow{2}{*}{\multicolumn{8}{|c|}{$\begin{array}{l}\text { Heterogeneity: } \operatorname{Tau}^{2}=0.02 ; \mathrm{Chi}^{2}=11.94, \mathrm{df}=8(\mathrm{P}=0.15) ; \mathrm{I}^{2}=33 \% \\
\text { Test for overall effect: } Z=0.12(\mathrm{P}=0.90)\end{array}$}} \\
\hline & & & & & & & \\
\hline \multicolumn{8}{|c|}{ 2.1.2 Pain in the immediate postoperative period in necrotic teeth (until 72 hours postobturation) } \\
\hline Al-Negrish 2006 & 8 & 54 & 14 & 58 & $11.3 \%$ & $0.61[0.28,1.35]$ & \\
\hline Albashaireh 1998 & 33 & 102 & 55 & 113 & $26.4 \%$ & $0.66[0.47,0.93]$ & \\
\hline Ghoddusi 2006 & 8 & 20 & 10 & 40 & $11.8 \%$ & $1.60[0.75,3.42]$ & \\
\hline Ince 2009 & 47 & 66 & 62 & 87 & $32.7 \%$ & $1.00[0.82,1.22]$ & \\
\hline Mulhern 1982 & 7 & 30 & 6 & 30 & $8.3 \%$ & $1.17[0.44,3.06]$ & \\
\hline Risso 2008 & 6 & 57 & 14 & 61 & $9.5 \%$ & $0.46[0.19,1.11]$ & \\
\hline Subtotal $(95 \% \mathrm{Cl})$ & & 329 & & 389 & $100.0 \%$ & $0.84[0.62,1.16]$ & \\
\hline Total events & 109 & & 161 & & & & \\
\hline \multirow{2}{*}{\multicolumn{8}{|c|}{$\begin{array}{l}\text { Heterogeneity: } \operatorname{Tau}^{2}=0.07 ; \mathrm{Chi}^{2}=10.56, \mathrm{df}=5(\mathrm{P}=0.06) ; \mathrm{I}^{2}=53 \% \\
\text { Test for overall effect: } Z=1.05(P=0.29)\end{array}$}} \\
\hline & & & & & & & \\
\hline \multicolumn{8}{|c|}{ 2.1.3 Pain in the immediate postoperative period in vital teeth (until 72 hours postobturation) } \\
\hline Albashaireh 1998 & 4 & 40 & 3 & 36 & $1.9 \%$ & $1.20[0.29,5.00]$ & \\
\hline Ince 2009 & 60 & 87 & 44 & 66 & $78.3 \%$ & $1.03[0.83,1.29]$ & \\
\hline Wang 2010 & 21 & 43 & 21 & 46 & $19.9 \%$ & $1.07[0.69,1.66]$ & \\
\hline Subtotal $(95 \% \mathrm{Cl})$ & & 170 & & 148 & $100.0 \%$ & $1.04[0.86,1.27]$ & \\
\hline Total events & 85 & & 68 & & & & \\
\hline \multicolumn{8}{|c|}{ Heterogeneity: $\mathrm{Tau}^{2}=0.00 ; \mathrm{Chi}^{2}=0.06, \mathrm{df}=2(\mathrm{P}=0.97) ; \mathrm{I}^{2}=0 \%$} \\
\hline \multicolumn{8}{|c|}{ Test for overall effect: $Z=0.43(P=0.66)$} \\
\hline 2.1.4 Pain at 1 week & & & & & & & \\
\hline Al-Negrish 2006 & 2 & 54 & 6 & 58 & $5.6 \%$ & $0.36[0.08,1.70]$ & \\
\hline Gesi 2006 & 16 & 130 & 18 & 126 & $16.1 \%$ & $0.86[0.46,1.61]$ & \\
\hline Mulhern 1982 & 3 & 30 & 2 & 30 & $4.8 \%$ & $1.50[0.27,8.34]$ & \\
\hline Oginni 2004 & 17 & 104 & 14 & 123 & $15.6 \%$ & $1.44[0.74,2.77]$ & \\
\hline Soltanoff 1978 & 5 & 88 & 7 & 193 & $9.0 \%$ & $1.57[0.51,4.80]$ & \\
\hline Wang 2010 & 17 & 43 & 13 & 46 & $16.8 \%$ & $1.40[0.78,2.52]$ & \\
\hline Wong 2015 & 25 & 117 & 12 & 103 & $16.0 \%$ & $1.83[0.97,3.46]$ & \\
\hline Xiao 2010 & 43 & 76 & 9 & 62 & $16.0 \%$ & $3.90[2.06,7.36]$ & \\
\hline Subtotal $(95 \% \mathrm{Cl})$ & & 642 & & 741 & $100.0 \%$ & $1.50[0.99,2.28]$ & \\
\hline Total events & 128 & & 81 & & & & \\
\hline Heterogeneity: Tau $^{2}=$ & $0.18 ; \mathrm{Chi}^{-}$ & $=15.33$ & $33, d f=7$ & $=0.03$ & $i^{2}=54 \%$ & & \\
\hline Test for overall effect & $Z=1.89$ & $P=0.06$ & & & & & \\
\hline 2.1.5 Pain at 1 week & n necrotic & cteeth & & & & & \\
\hline Al-Negrish 2006 & 2 & 54 & 6 & 58 & $53.3 \%$ & $0.36[0.08,1.70]$ & \\
\hline Mulhern 1982 & 3 & 30 & 2 & 30 & $46.7 \%$ & $1.50[0.27,8.34]$ & \\
\hline Subtotal $(95 \% \mathrm{Cl})$ & & 84 & & 88 & $100.0 \%$ & $0.70[0.17,2.85]$ & \\
\hline Total events & 5 & & 8 & & & & \\
\hline Heterogeneity: Tau $^{2}=$ & $0.33 \mathrm{Chi}^{-}$ & $=1.48$, & $d f=1(F$ & $=0.22) ;$ & $p^{2}=32 \%$ & & \\
\hline Test for overall effect & $Z=0.50$ & $P=0.62$ & & & & & \\
\hline 2.1.6 Pain at 1 week & n vital tee & & & & & & \\
\hline Wang 2010 & 17 & 43 & 13 & 46 & $100.0 \%$ & $1.40[0.78,2.52]$ & \\
\hline Subtotal $(95 \% \mathrm{Cl})$ & & 43 & & 46 & $100.0 \%$ & $1.40[0.78,2.52]$ & \\
\hline Total events & 17 & & 13 & & & & \\
\hline Heterogeneity: Not a & plicable & & & & & & \\
\hline Test for overall effect & $Z=1.11$ & $P=0.27$ & & & & & \\
\hline 2.1.7 Pain at 1 montl & & & & & & & \\
\hline Albashaireh 1998 & 0 & 142 & 0 & 149 & & Not estimable & \\
\hline Oginni 2004 & 0 & 102 & 0 & 120 & & Not estimable & \\
\hline Subtotal $(95 \% \mathrm{Cl})$ & & 244 & & 269 & & Not estimable & \\
\hline Total events & 0 & & 0 & & & & \\
\hline
\end{tabular}


Figure 5. (Continued)

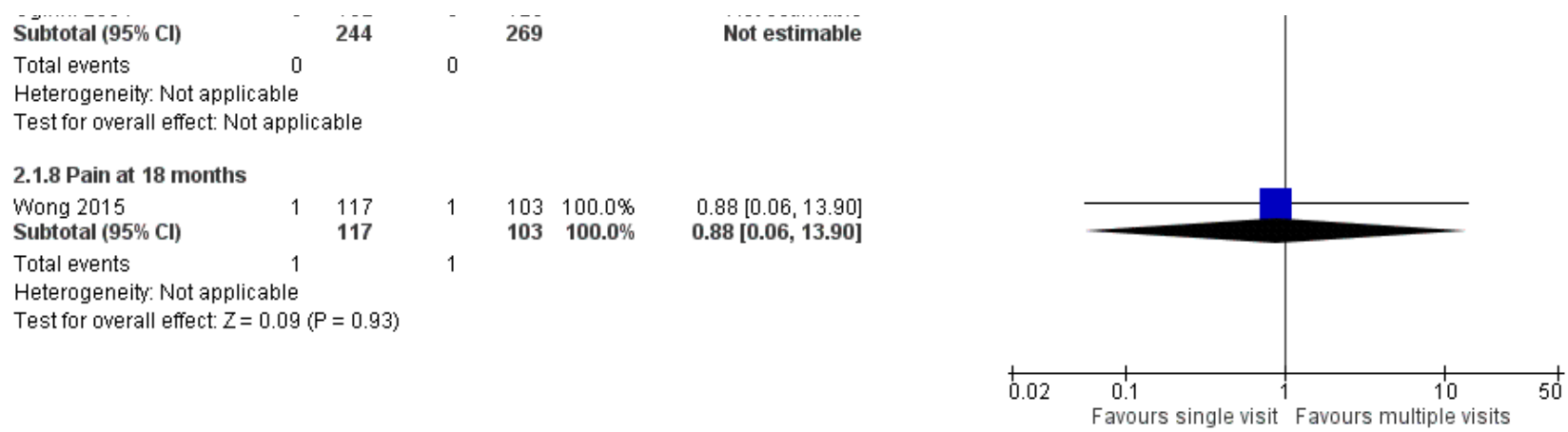

The evidence related to this outcome, as assessed using the GRADE method and presented in 'Summary of findings for the main comparison, is moderate quality.

Gesi 2006, Ghoddusi 2006, Mulhern 1982, and Xiao 2010 reported pain incidence in the interappointment period of the multiple-visit RoCT; such data are not included in the meta-analysis, as they cannot be compared with a similar outcome of the single-visit approach.

Four studies with 414 participants evaluated postoperative pain as a continuous outcome (DiRenzo 2002; Patil 2016; Singh 2012; Wang 2010). In order to perform a meta-analysis, we standardised the results of the VAS in two studies from a $170 \mathrm{~mm}$ scale to a $100 \mathrm{~mm}$ scale (DiRenzo 2002; Patil 2016). No difference was found between the two treatments, with no statistical heterogeneity (mean difference (MD) $0.12,95 \% \mathrm{Cl}-0.59$ to $0.82 ; \mathrm{I}^{2}=0 \%$; Analysis 2.2).

Results from Yoldas 2004 were excluded from meta-analysis of postoperative pain because the data were not stratified according to time of onset. In this study, single- and multiple-visit RoCT showed no significant difference in incidence of pain. The incidence of pain was greatest during the first 48 hours after obturation, and then decreased steadily in the subsequent seven days. Of the 227 participants enrolled in the study, 68 had symptomatic and 159 had asymptomatic teeth. When data were analysed to consider the presence of symptoms before RoCT, postoperative pain was found significantly more often in participants with symptomatic teeth.

\section{Necrotic teeth}

Six studies with 718 participants reported immediate pain as a dichotomous outcome in necrotic teeth (Albashaireh 1998; AlNegrish 2006; Ghoddusi 2006; Ince 2009; Mulhern 1982; Risso 2008). The pooled estimate from the studies showed no differences between treatments in participants with necrotic teeth (RR 0.84, $95 \% \mathrm{Cl} 0.62$ to $1.16 ; 1^{2}=53 \%$; Figure 5).

Three studies (DiRenzo 2002; Patil 2016; Singh 2012), including a total of 158 participants, evaluated pain in the immediate postoperative period in non-vital teeth, as a continuous outcome, and found no difference between the two treatment groups, with no statistical heterogeneity (MD $-0.21,95 \% \mathrm{Cl}-0.44$ to $0.03 ; \mathrm{I}^{2}=0 \%$ ).

\section{Vital teeth}

Three studies analysed immediate postoperative pain as a dichotomous outcome in teeth vital at enrolment, for a total of 318 participants (Albashaireh 1998; Ince 2009; Wang 2010). There was no difference in the pain incidence immediately after RoCT between treatment groups, with no statistical heterogeneity (RR 1.04, 95\% $\mathrm{Cl} 0.86$ to $1.27 ; \mathrm{I}^{2}=0 \%$; Figure 5 ). One study (30 participants) reported no difference between treatments for postoperative pain as a continuous outcome in vital teeth (Patil 2016).

\section{Pain at one week}

Eight studies reported pain at one week as a dichotomous outcome in a total of 1383 participants and suggested that participants treated in a single visit were more likely to experience pain than those treated over multiple visits (Al-Negrish 2006; Gesi 2006; Mulhern 1982; Oginni 2004; Soltanoff 1978; Wang 2010; Wong 2015; Xiao 2010), though the difference is not statistically significant and the meta-analysis showed substantial statistical heterogeneity (RR $1.50,95 \% \mathrm{Cl} 0.99$ to $2.28 ; \mathrm{I}^{2}=54 \%$; Figure 5 ). The evidence related to this outcome, as assessed using the GRADE method and presented in Summary of findings for the main comparison, is low-quality.

\section{Pain at one week in necrotic teeth}

Al-Negrish 2006 and Mulhern 1982 evaluated the incidence of pain one week after the RoCT in non-vital teeth and found no difference between participants treated in a single visit in comparison to those treated in multiple visits, with low statistical heterogeneity (RR 0.70, $95 \% \mathrm{Cl} 0.17$ to $2.85 ; 172$ participants, 2 studies, $\mathrm{I}^{2}=32 \%$; Figure 5).

\section{Pain at one week in vital teeth}

Wang 2010 was the only study reporting the incidence of pain at one week after RoCT in teeth vital at enrolment. This study found no difference in this outcome between participants treated in one single visit in comparison to those treated in multiple visits (RR 1.40, $95 \% \mathrm{Cl} 0.78$ to 2.52 ; Figure 5).

\section{Pain at one month}

Only two studies reported pain at one month after canal obturation as a dichotomous outcome (Albashaireh 1998; Oginni 2004). In both studies, no participant had persistent pain at one month. Thus, a meta-analysis of the studies was not possible.

\section{Pain at 18 months}

Wong 2015 was the only study reporting incidence of pain at 18 months after RoCT. This study found no difference in this outcome between participants treated in one single visit in comparison to those treated in multiple visits (RR 0.88, 95\% Cl 0.06 to 13.90; 220 participants). 


\section{Swelling or flare-up}

We considered all studies reporting flare-up as swelling and those where flare-up was defined as swelling (with or without moderate or intense pain). For definitions of flare-up, see Table 2. We included four studies with 281 participants in a meta-analysis (DiRenzo 2002; Ghoddusi 2006; Mulhern 1982; Wang 2010), which did not find a difference between single and multiple visits (RR 1.36, 95\% Cl 0.66 to $2.81 ; \mathrm{I}^{2}=0 \%$ ). The evidence related to this outcome, as assessed using the GRADE method and presented in Summary of findings for the main comparison, is low quality.

\section{Swelling or flare-up in necrotic teeth}

Two studies reported data on this outcome in necrotic teeth for a total of 120 participants (Ghoddusi 2006; Mulhern 1982), showing no difference between participants treated in a single visit versus those treated in multiple visits, with no statistical heterogeneity (RR $1.52,95 \% \mathrm{Cl} 0.70$ to $\left.3.31 ;\left.\right|^{2}=0 \%\right)$.

\section{Swelling or flare-up in vital teeth}

Wang 2010 was the only study reporting the incidence of swelling or flare-up in teeth vital at enrolment. This study found no difference between participants treated in one single visit in comparison to those treated in multiple visits (RR $1.07,95 \% \mathrm{Cl} 0.07$ to $16.57 ; 89$ participants).

\section{Painkiller use}

Use of painkillers was reported by four studies (Mulhern 1982; Soltanoff 1978; Wang 2010; Yoldas 2004), including a total of 648 participants. Pooled estimates from all studies showed that the use of painkillers after RoCT was more common among participants undergoing the single-visit approach (RR $2.35,95 \% \mathrm{Cl} 1.60$ to 3.45 ; Figure 6). The studies were homogeneous $\left(\mathrm{Chi}^{2}=1.81, \mathrm{df}=3(\mathrm{P}=\right.$ $0.61) ; I^{2}=0 \%$ ). The evidence related to this outcome, as assessed using the GRADE method and presented in Summary of findings for the main comparison, is moderate quality.

\section{Figure 6. Forest plot of comparison: 2 Secondary outcomes, outcome: 2.4 Painkiller use}

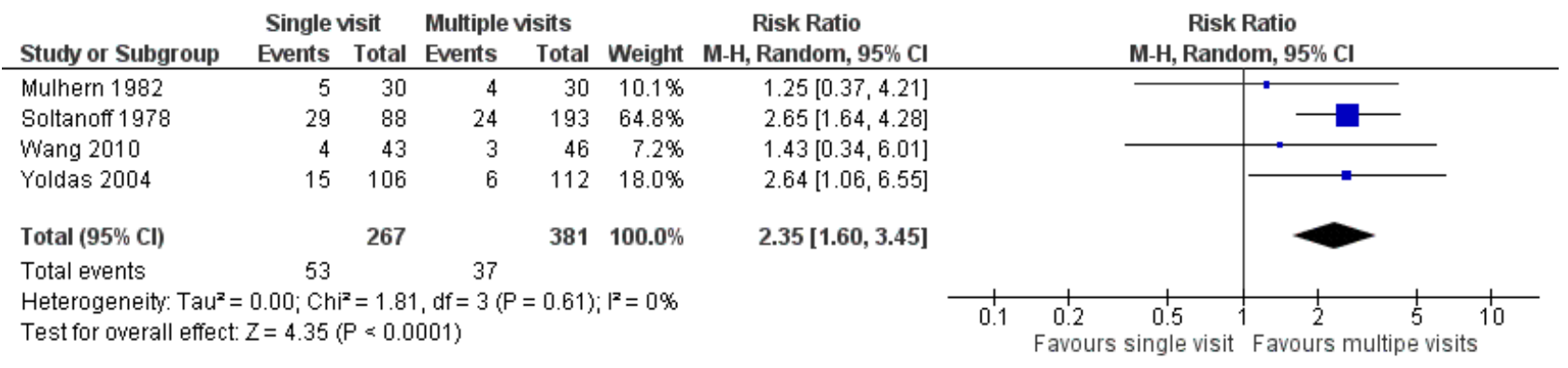

\section{Necrotic teeth}

\section{Sinus track or fistula formation}

Mulhern 1982 reported the use of painkillers in necrotic teeth, showing no difference between participants treated in a single visit versus those treated in multiple visits (RR $1.25,95 \% \mathrm{Cl} 0.37$ to 4.21 ; 60 participants).

Only two studies reported persistent sinus track or fistula, both of which included necrotic teeth only (Paredes-Vieyra 2012; Penenis 2008). The studies were homogeneous and did not find a difference between single and multiple visits (RR $0.98,95 \% \mathrm{Cl} 0.15$ to 6.48 ; 345 participants; $1^{2}=0 \%$, Figure 7 ). The evidence related to this outcome, as assessed using the GRADE method and presented in Summary of findings for the main comparison is low quality. 
Figure 7. Forest plot of comparison: 2 Secondary outcomes, outcome: 2.6 Any complication

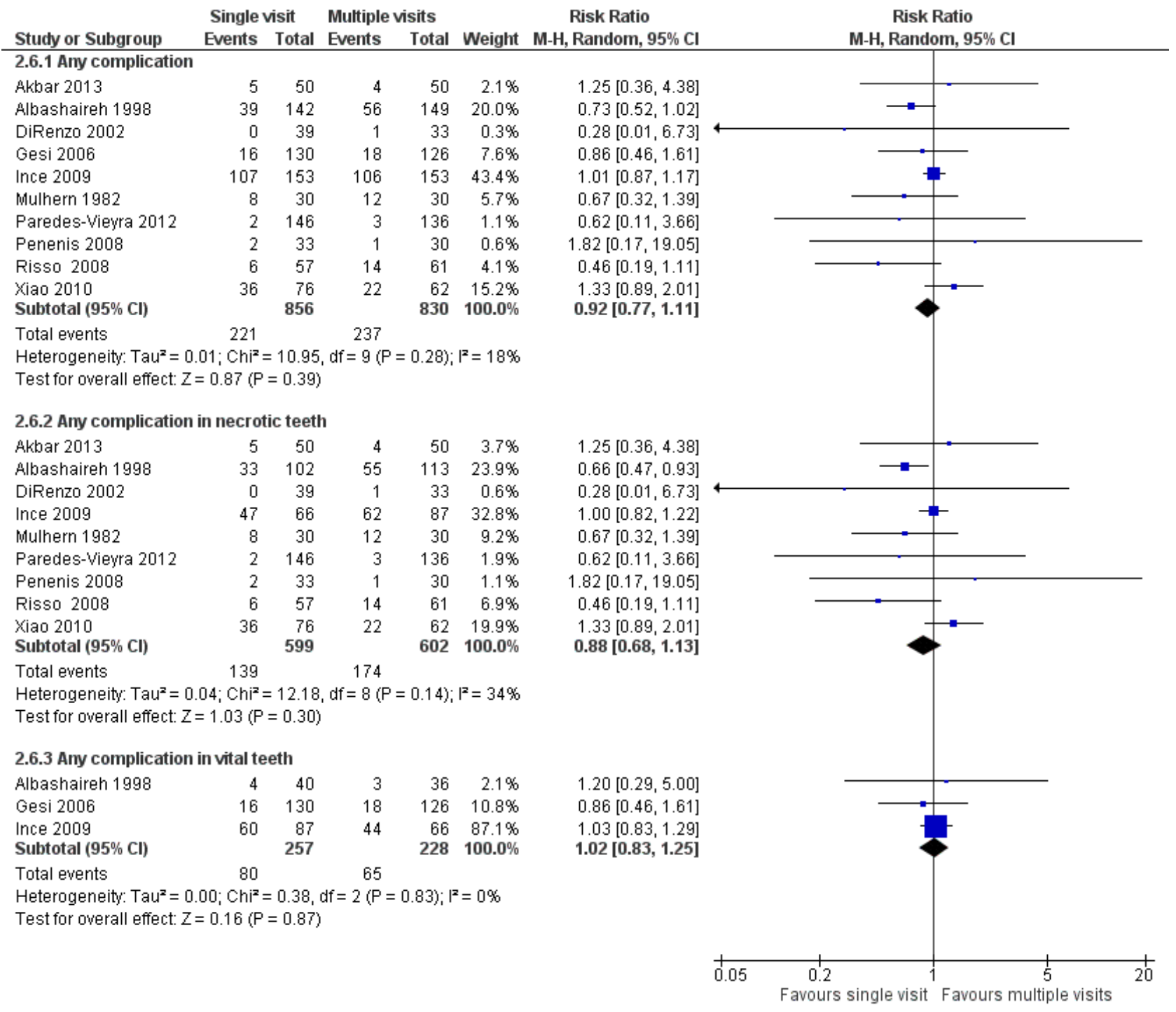

\section{Any complication}

\section{Any complication in vital teeth}

We could extrapolate accurate data for 10 studies: Akbar 2013; Albashaireh 1998; DiRenzo 2002; Gesi 2006; Ince 2009; Mulhern 1982; Paredes-Vieyra 2012; Penenis 2008; Risso 2008; Xiao 2010. A total of 1686 participants were included in this meta-analysis, which did not find a difference between single and multiple visits; the studies were homogeneous (RR $0.92,95 \% \mathrm{Cl} 0.77$ to $1.11 ; \mathrm{I}^{2}=$ $18 \%$; Figure 7). The evidence related to this outcome, as assessed using the GRADE method and presented in Summary of findings for the main comparison is moderate quality.

\section{Any complication in necrotic teeth}

We could extrapolate accurate data on necrotic teeth from nine studies (Akbar 2013; Albashaireh 1998; DiRenzo 2002; Ince 2009; Mulhern 1982; Paredes-Vieyra 2012; Penenis 2008; Risso 2008; Xiao 2010), with a total of 1201 participants. Meta-analysis showed no difference between participants treated in a single visit versus those treated in multiple visits, with low statistical heterogeneity (RR $0.88,95 \% \mathrm{Cl} 0.68$ to 1.13 ; 12 = 34\%; Figure 7 ).

There were three studies (Albashaireh 1998; Gesi 2006; Ince 2009), including 485 participants, available to analyse the frequencies of any complication. No difference in frequency of complications was found between participants treated in a single visit versus those treated in multiple visits, with no statistical heterogeneity (RR 1.02, $95 \% \mathrm{Cl} 0.83$ to $1.25 ; 1^{2}=0 \%$; Figure 7 ).

\section{DISCUSSION}

\section{Summary of main results}

This review included 25 randomised controlled trials (RCTs) with a total of 3780 participants undergoing root canal treatment (RoCT) in a single visit or over multiple visits. Only one study reported data on dental extraction due to endodontic problems (Wong 2015).

The results of this review show that, at present, there is no evidence of a substantial advantage of one of the two approaches of RoCT we compared. 
Endodontic success indicators can be short- or long-term. The short-term indicators concern the absence of any postoperative discomfort, the most important short-term outcome of RoCT. Pain perception is highly subjective and modulated by multiple physical and psychological factors, and the measurement of pain is fraught with hazards and opportunities for errors. The level of discomfort must be rated in categories arranged in advance and exactly described (for example, slight pain: the tooth involved was slightly painful for a time, regardless of duration, but no need existed to take analgesics). From the results obtained in this review, there is evidence that the incidence of postobturation pain (evaluated at different times and using both dichotomous and continuous data) is similar in single- and multiple-visit RoCT, although pain at one week and painkiller use might be less in people undergoing multiple-visit RoCT. It is possible that in the single-visit approach the working time is longer, causing a more severe acute inflammatory response. Another factor could be the beneficial effect of the intracanal medication in the between-visit interval.

There is no evidence of a difference in the incidence of shortterm swelling between people undergoing the single and multiplevisit approach. Among the four studies considering this outcome (DiRenzo 2002; Ghoddusi 2006; Mulhern 1982; Wang 2010), one evaluated teeth with vital pulp only (Wang 2010). Only two participants (one from the single-visit group and one from the multiple-visit group) experienced slight swelling and flare-up that required a visit to the clinic the day after obturation. The Ghoddusi 2006 study is of particular interest. In fact, when no interappointment canal medication was employed, the incidence of swelling was very similar in the two groups, while when calcium hydroxide was left in the canals between visits, the multiple-visit treatment performed much better. Such a difference may have occurred because normal saline solution was used as the sole irrigant during RoCT. Thus, with the single-visit approach, nothing with any antibacterial activity was included in the RoCT. While with the multiple-visit treatment employing interappointment medication, antibacterial activity was provided by calcium hydroxide.

Only two studies reported data on sinus track or fistula formation and from the data available there is no evidence of a difference between RoCT performed in a single visit versus multiple visits (Paredes-Vieyra 2012; Penenis 2008).

Long-term success is based mainly on the healing of periapical lesions, whenever present, and the prevention of new lesions. The healing rate can be established by radiographic interpretation, a method very dependent on human visual perception. There is no evidence of a difference, however, in terms of radiological healing between people treated in a single visit when compared with those undergoing a multiple-visit approach.

We pooled data from 10 studies to assess the incidence of any complication reported by participants in the short-term (Akbar 2013; Albashaireh 1998; DiRenzo 2002; Gesi 2006; Ince 2009; Mulhern 1982; Paredes-Vieyra 2012; Penenis 2008; Risso 2008; Xiao 2010), finding no evidence of a difference between the two groups.
We performed subgroup analysis for vital and necrotic teeth when data were available. In the previous version of this systematic review (Figini 2007), a meta-analysis of a small number of studies suggested a possible difference in radiological healing among necrotic teeth, in favour of single-visit RoCT; this result was not confirmed in this update, where a larger number of studies were included in the meta-analysis.

Thus, the effectiveness of single- and multiple-visit RoCT does not seem to be substantially different. Most short- and long-term complications are similar in terms of frequency, although patients undergoing single-visit RoCT may experience a higher level of pain at one week after RoCT and are more likely to take analgesics.

\section{Overall completeness and applicability of evidence}

The available evidence is from a range of countries and is applicable to healthy patients aged over 10 years. Identified trials did not include patients with depressed immune systems, patients with other illnesses, or elderly patients. The results of this review may or may not be generalisable to these groups, which would be expected to have different rates of short- and long-term endodontic success.

The majority of the trials were conducted in public structures (hospitals or university clinics) and only one trial was performed in a private practice. This may influence the generalisability of our results, with particular regard to the number of operators involved in the RoCT or their clinical skill, as those in the included studies varied from expert endodontists working in referral centres to postgraduate students. Whether results would be similar for general dental practitioners is unclear.

About half of the studies (11/25) did not report the use of rubber dam during the RoCT procedure. Although the use of rubber dam is considered part of the RoCT, and for this reason several authors may have not reported its use during the procedure, this might represent a limit in terms of external validity.

\section{Quality of the evidence}

On the basis of the criteria used in the critical appraisal of the studies, only three of the 25 included studies resulted in a low risk of bias (Molander 2007; Singh 2012; Wang 2010). Less than 25\% of the studies were at low risk of selection bias (i.e. with inadequate random sequence generation and/or allocation concealment). We judged the risk of attrition bias, detection bias, reporting bias, and other bias, as low in more than $75 \%$ of the studies. When assessed using the GRADE method (Atkins 2004), evidence on immediate pain (dichotomous), painkiller use and any complication, resulted in moderate quality; radiological failure, swelling or flare-up, pain at one week and persistent sinus tract or fistula resulted in low quality; extraction due to endodontic problems resulted in very low quality (Summary of findings for the main comparison).

\section{Potential biases in the review process}

We have taken steps to minimise the bias in every step of the review. We searched databases, and trial registries with no language limitations, to identify all the relevant reports. We tried to contact the study authors for missing data through e-mails. We did not detect publication bias on the basis of the funnel plots analysis (Figure 8). 
Figure 8. Funnel plot of comparison: 2 Signs, outcome: 2.3 Radiological failure

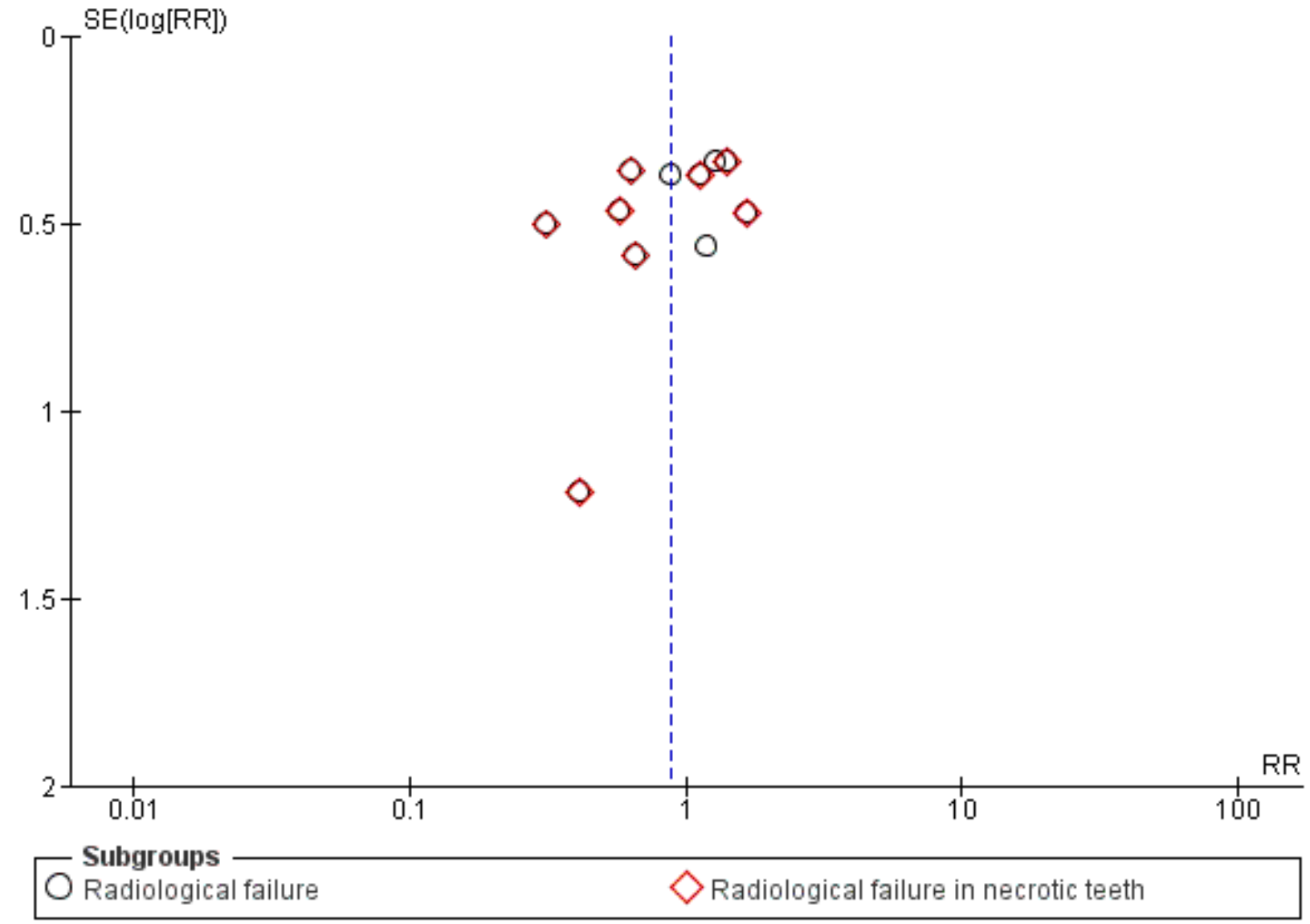

\section{Agreements and disagreements with other studies or reviews}

We found four other systematic reviews that compared pain and long-term radiological healing between single- and multiple-visit RoCT. The Sathorn 2005 review focused on postoperative pain and flare-up, coming to the same conclusions as our present review. Su 2011 and Zhang 2015 analysed the differences between the two approaches, in teeth with infected root canals only. The results of the two reviews did not differ significantly from those of our subgroup analysis in necrotic teeth. In the systematic review by Su 2011, when short-term postobturation pain was analysed, a benefit for patients undergoing single-visit RoCT was evident. This difference from our result reporting no statistical difference can be explained by the difference in inclusion criteria (necrotic teeth only), which led to a different set of studies being combined. The review by Wong 2014 concluded that the studies reported in the literature showed that neither single-visit endodontic treatment nor multiple-visit treatment could guarantee the absence of postoperative pain. It found that neither single-visit endodontic treatment nor multiple-visit treatment had superior results in terms of healing or success rate, which our review also found.

\section{AUTHORS' CONCLUSIONS \\ Implications for practice}

There is no evidence to suggest that one treatment regimen (singlevisit or multiple-visit root canal treatment (RoCT)) is better than the other. Neither can prevent all short- and long-term complications. On the basis of the available moderate-quality evidence, it seems likely that the benefit of a single-visit treatment, in terms of time and convenience, for both patient and dentist, has the cost of a higher frequency of late postoperative pain (and as a consequence, painkiller use).

\section{Implications for research}

As use of rotary nickel titanium instruments is increasing, a well-designed RCT comparing single-visit and multiple-visit RoCT, both performed with such instruments, would be an important contribution. It would be very helpful for clinicians that researchers include tooth loss as a primary outcome in new studies, even reporting if none occurs.

\section{ACK N O WLEDGEMENTS}

The review authors wish to thank Giovanni Mergoni and Stefano Daniele for comments and reviewing, and Cochrane Oral Health for their continuous support (Laura MacDonald, Anne-Marie Glenny, Helen Worthington, Anne Littlewood, Trevor Johnson). All the 
researchers of the cited studies who have provided some of the data useful in the review, and the referees, Paul Dummer and Mikako Hayashi for their useful suggestions. Thank you to Claire Dooley for final copy editing. A special thanks to Silvia Motta for translation from the Russian language and to Hu Luca and Ye Qing Hu for translation from Chinese. 


\section{R E F E R E N C E S}

\section{References to studies included in this review}

Akbar 2013 \{published data only\}

Akbar I, Iqbal A, Al-Omiri MK. Flare-up in molars with periapical radiolucency. Journal of Contemporary Dental Practice 2013;14(3):414-8.

\section{Albashaireh 1998 \{published data only\}}

Albashaireh ZS, Alnegrish AS. Postobturation pain after singleand multiple-visit endodontic therapy. A prospective study. Journal of Dentistry 1998;26(3):227-32.

\section{Al-Negrish 2006 \{published data only\}}

Al-Negrish AR, Habahbeh R. Flare up rate related to root canal treatment of asymptomatic pulpally necrotic central incisor teeth in patients attending a military hospital. Journal of Dentistry 2006;34(9):635-40.

\section{DiRenzo 2002 \{published data only\}}

DiRenzo A, Gresla T, Johnson BR, Rogers M, Tucker D, BeGole EA. Postoperative pain after 1- and 2-visit root canal therapy. Oral Surgery, Oral Medicine, Oral Pathology, Oral Radiology, and Endodontics 2002;93(5):605-10.

\section{Dorasani 2013 \{published data only\}}

Dorasani G, Madhusudhana K, Chinni SK. Clinical and radiographic evaluation of single-visit band multi-visit endodontic treatment of teeth with periapical pathology: an in vivo study. Journal of Conservative Dentistry 2013;16:484-8.

\section{Gesi 2006 \{published data only\}}

Gesi A, Hakeberg M, Warfvinge J, Bergenholtz G. Incidence of periapical lesions and clinical symptoms after pulpectomya clinical and radiographic evaluation of 1-versus 2-session treatment. Oral Surgery, Oral Medicine, Oral Pathology, Oral Radiology, and Endodontics 2006;101(3):379-88.

\section{Ghoddusi 2006 \{published data only\}}

Ghoddusi J, Javidi M, Zarrabi MH, Bagheri H. Flare-ups incidence and severity after using calcium hydroxide as intracanal dressing. The New York State Dental Journal 2006;72(4):24-8.

\section{Ince 2009 \{published data only\}}

Inde B, Ercan E, Dalli M, Dulgergil CT, Zorba YO, Colak H. Incidence of postoperative pain after single- and multi-visit endodontic treatment in teeth with vital and non-vital pulp. European Journal of Dentistry 2009;3:273-9.

\section{Molander 2007 \{published data only\}}

Molander A, Warfvinge J, Reit C, Kvist T. Clinical and radiographic evaluation of one-and two-visit endodontic treatment of asymptomatic necrotic teeth with apical periodontitis: a randomized clinical trial. Journal of Endodontics 2007;33(10):1145-48.

\section{Mulhern 1982 \{published data only\}}

Mulhern JM, Patterson SS, Newton CW, Ringel AM. Incidence of postoperative pain after one-appointment endodontic treatment of asymptomatic pulpal necrosis in single-rooted teeth. Journal of Endodontics 1982;8(8):370-5.

Oginni 2004 \{published data only\}

Oginni AO, Udoye $\mathrm{Cl}$. Endodontic flare-ups: comparison of incidence between single and multiple visit procedures in patients attending a Nigerian teaching hospital. BMC Oral Health 2004;4(1):4.

\section{Paredes-Vieyra 2012 \{published data only\}}

Paredes-Vieyra J, Enriquez FJ. Success rate of single- versus twovisit root canal treatment of teeth with apical periodontitis: a randomized controlled trial. Journal of Endodontics 2012;38(9):1164-9.

Patil 2016 \{published data only\}

Patil AA, Joshi SB, Bhagwat SV, Patil SA. Incidence of postoperative pain after single visit and two visit root canal therapy: a randomized controlled trial. Journal of Clinical and Diagnostic Research 2016;10(5):ZC09-12.

Penenis 2008 \{published data only\}

Penenis VA, Fitzgerald PI, Fayad MI, Wenckus CS, BeGole EA, Johnson BR. Outcome of one-visit and two-visit endodontic treatment of necrotic teeth with apical periodontitis: a randomized controlled trial with one-year evaluation. Journal of Endodontics 2008;34(3):251-7.

Peters 2002 \{published data only\}

Peters LB, Wesselink PR. Periapical healing of endodontically treated teeth in one and two visits obturated in the presence or absence of detectable microorganisms. International Endodontic Journal 2002;35(8):660-7.

Rao 2014 \{published data only\}

Rao NK, Kandaswamy R, Umashetty G, Rathore VP, Hotkar C, Patil BS. Post-obturation pain following one-visit and twovisit root canal treatment in necrotic anterior teeth. Journal of International Oral Health 2014;6(2):28-32.

\section{Risso 2008 \{published data only\}}

Risso PA, Cunha AJLA, Araujo MCP, Luiz RR. Postobturation pain and associated factors in adolescent patients undergoing one- and two-visit root canal treatment. Journal of Dentistry 2008;36:928-34.

Singh 2012 \{published data only\}

Singh S, Garg A. Incidence of post-operative pain after single visit and multiple visit root canal treatment: a randomized controlled trial. Journal of Conservative Dentistry 2012;15(4):323-7.

\section{Soltanoff 1978 \{published data only\}}

Soltanoff W. A comparative study of the single-visit and the multiple-visit endodontic procedure. Journal of Endodontics 1978;4(9):278-81. 
Trope 1999 \{published data only\}

Trope M, Delano EO, Orstavik D. Endodontic treatment of teeth with apical periodontitis: single vs. multivisit treatment. Journal of Endodontics 1999;25(5):345-50.

\section{Wang 2010 \{published data only\}}

Wang C, Xu P, Ren L, Dong G, Ye L. Comparison of postobturation pain experience following one-visit and two visit root-canal treatment on teeth with vital pulps: a randomized controlled trial. International Endodontic Journal 2010;43:692-7.

\section{Weiger 2000 \{published data only\}}

Weiger R, Rosendahl R, Lost C. Influence of calcium hydroxide intracanal dressings on the prognosis of teeth with endodontically induced periapical lesions. International Endodontic Journal 2000;33(3):219-26.

\section{Wong 2015 \{published data only\}}

Wong AW, Tsang CS, Zhang S, Li KY, Zhang C, Chu CH. Treatment outcomes of single-visit versus multiple-visit non-surgical endodontic therapy: a randomised clinical trial. BMC Oral Health 2015;15:62.

\section{Xiao 2010 \{published data only\}}

* Xiao D, Zhang DH. A clinical study of one-visit endodontic treatment for infected root canals. Hua Xi Kou Qiang Yi Xue Za Zhi 2010;28:57-60.

\section{Yoldas 2004 \{published data only\}}

Yoldas O, Topuz A, Isci AS, Oztunc H. Postoperative pain after endodontic retreatment: single - versus two -visit treatment. Oral Surgery, Oral Medicine, Oral Pathology, Oral Radiology, and Endodontics 2004;98(4):483-7.

\section{References to studies excluded from this review}

ElMubarak 2010 \{published data only\}

ElMubarak AHH, Abu-bakr NH, Ibrahim YE. Postoperative pain in multiple-visit and single-visit root canal treatment. Journal of Endodontics 2010;36(1):36-9.

\section{Fava 1989 \{published data only\}}

Fava LR. A comparison of one versus two appointment endodontic therapy in teeth with non-vital pulps. International Endodontic Journal 1989;22(4):179-83.

\section{Fava 1994 \{published data only\}}

Fava LR. A clinical evaluation of one and two-appointment root canal therapy using calcium hydroxide. International Endodontic Journal 1994;27(1):47-51.

\section{Friedman 1995 \{published data only\}}

Friedman S, Löst C, Zarrabian M, Trope M. Evaluation of success and failure after endodontic therapy using a glass ionomer cement sealer. Juornal of Endodontics 1995;21(7):384-90.

\section{Gurgel-Filho 2007 \{published data only\}}

Gurgel-Filho ED, Vivacqua-Gomes N, Gomes BP, Ferraz CC, Zaia AA, Souza-Filho FJ. In vitro evaluation of the effectiveness of the chemomechanical preparation against Enterococcus faecalis after single-or multiple-visit root canal treatment. Brazilian Oral Resarch 2007;21(4):308-13.

Holland 2003 \{published data only\}

Holland R, Otoboni Filho JA, De Souza V, Nery MJ, Bernabè PF, Dezan E Jr. A comparison of one versus two appointment endodontic therapy in dogs' teeth with apical periodontitis. Journal of Endodontics 2003;29(2):121-4.

Jabeen 2014 \{published data only\}

Jabeen S, Khurshiduzzaman M. Incidence of post obturation pain following single and multi visit root canal treatment in a teaching hospital of Bangladesh. Mymensingh Medical Journal 2014;23(2):254-60.

\section{Kabaktchieva 2013 \{published data only\}}

Kabaktchieva R, Gateva N, Nikolova K. Succes rate of one session and two session techniques for treatment of asymptomatic pulpitis of primary teeth with indirect pulp capping. Journal of IMAB 2013;19(2):269-73.

\section{Kvist 2004 \{published data only\}}

Kvist T, Molander A, Dahlen G, Reit C. Microbiological evaluation of one- and two-visit endodontic treatment of teeth with periapical periodontitis: a randomized, clinical trial. Journal of Endodontics 2004;30(8):572-6.

Ng 2004 \{published data only\}

$\mathrm{Ng}$ YL, Glennon JP, Setchell DJ, Gulabivala K. Prevalence of and factors affecting post-obturation pain in patient undergoing root canal treatment. International Journal of Endodontics 2004;37(6):381-91.

\section{Orhan 2010 \{published data only\}}

* Orhan Al, Oz FT, Orhan K. Pulp exposure occurrence and outcomes after 1- or 2-visit indirect pulp therapy vs complete caries removal in primary and permanent molars. Pediatric Dentistry 2010;32(4):347-55

\section{Papworth B 1998 \{published data only\}}

Papworth B. Comparing the outcome of necrotic cases using two different treatment methods. New Mexico Dental Journal 1998;49(3):14-5.

\section{Prashanth 2011 \{published data only\}}

Prashanth MB, Tavane PN, Abraham S, Chacko L. Comparative evaluation of pain, tenderness and swelling followed by radiographic evaluation of periapical changes at various intervals of time following single and multiple visit endodontic therapy: an in vivo study. Journal of Contemporary Dental Practice 2011;12(3):187-91.

\section{Roane 1983 \{published data only\}}

Roane JB, Dryden JA, Grimes EW. Incidence of postoperative pain after single- and multiple-visit endodontic procedures. Oral Surgery, Oral Medicine, and Oral Pathology 1983;55(1):68-72.

\section{Silveira 2007 \{published data only\}}

Silveira AM, Lopes HP, Siqueira JF Jr, Macedo SB, Consolaro A. Periradicular repair after two-visit endodontic treatment 
using two different intracanal medications compared to single-visit endodontic treatment. Brazilian Dental Journal 2007;18(4):299-304.

\section{Trusewicz 2005 \{published data only\}}

Trusewicz M, Buczkowska-Radlinska J, Giedrys-Kalemba S. The effectiveness of some methods in eliminating bacteria from the root canal of a tooth with chronic apical periodontitis. Annales Academiae Medicae Stetinensis 2005;51(2):43-8.

\section{Vera 2012 \{published data only\}}

Vera J, Siqueira JF Jr, Ricucci D, Loghin S, Fernàndez N, Flores B, et al. One- versus two-visit endodontic treatment of teeth with periapical periodontitis: a histobacteriologist study. Journal of Endodontics 2012;38(8):1040-52.

\section{Waltimo 2005 \{published data only\}}

Waltimo T, Trope M, Haapasalo M, Orstavik D. Clinical efficacy of treatment procedures in endodontic infection control and one year follow-up of periapical healing. Journal of Endodontics 2005;331(12):863-6.

\section{Walton 1992 \{published data only\}}

Walton R, Fouad A. Endodontic interappointment flare-ups: a prospective study of incidence and related factors. Journal of Endodontics 1992;18(4):172-7.

\section{Xavier 2013 \{published data only\}}

Xavier AC, Martinho FC, Chung A, Oliveira LD, Jorge Ao, Valera MC, et al. One-visit versus two-visit root canal treatment: effectiveness in the removal of endotoxins and cultivable bacteria. Journal of Endodontics 2013;39(8):359-64.

\section{Additional references}

\section{Abbott 2000}

Abbott PV. Selective and intelligent use of antibiotics in endodontics. Australian Endodontic Journal 2000;26(1):30-9.

\section{Atkins 2004}

Atkins D, Best D, Briss PA, Eccles M, Falck-Ytter Y, Flottorp S, et al. GRADE Working Group. Grading quality of evidence and strength of recommendations. BMJ 2004;328(7454):1490.

\section{Battrum 1996}

Battrum D, Gutmann J. Efficacy of ketorolac in the management of pain associated with root canal treatment. Journal of the Canadian Dental Association 1996;62(1):36-42.

\section{Bystrom 1981}

Bystrom A, Sundqvist G. Bacteriologic evaluation of the efficacy of mechanical root canal instrumentation in endodontic therapy. Scandinavian Journal of Dental Research 1981;89(4):321-8.

\section{Chu 2005}

Chu CH, Lo EC, Cheung GS. Outcome of root canal treatment using Thermafil and cold lateral condensation filling techniques. International Endodontics Journal 2005;38:179-85.

\section{Egger 1997}

Egger M, Davey Smith G, Schneider M, Minder C. Bias in meta-analysis detected by a simple, graphical test. $B M J$ 1997;315(7109):629-34.

\section{Fava 1995}

Fava LR. Single visit root canal treatment: Incidence of postoperative pain using three different instrumentation techniques. International Endodontic Journal 1995;28(2):103-7.

\section{Friedman 2002}

Friedman S. Considerations and concepts of case selection in the management of post-treatment endodontic disease (treatment failure). Endodontic Topics 2002;1:54-78.

\section{Gambarini 1991}

Gambarini G. Incidenza di riacutizzazioni flogistiche dopo il trattamento endodontico di denti necrotici in una seduta o dopo medicazioni con idrossido di calcio. Giornale Italiano di Endodonzia 1991;4:155-8.

\section{GRADEpro GDT 2014 [Computer program]}

GRADE Working Group, McMaster University. GRADEpro GDT. Hamilton (ON): GRADE Working Group, McMaster University, 2014.

\section{Halse 1986}

Halse A, Molven O. A strategy for the diagnosis of periapical pathosis. Journal of Endodontics 1986;12:534-8.

\section{Higgins 2011}

Higgins JP, Green S, editor(s). Cochrane Handbook for Systematic Reviews of Interventions Version 5.1.0 (updated March 2011). The Cochrane Collaboration, 2011. Available from handbook.cochrane.org.

\section{Katebzadeh 2000}

Katebzadeh N, Sigurdsson A, Trope M. Radiographic evaluation of periapical healing after obturation of infected root canals: An in vivo study. International Endodontic Journal 2000;33(1):60-6.

\section{Moorer 1982}

Moorer WR, Genet JM. Evidence for antibacterial activity of endodontic gutta-percha cones. Oral Surgery, Oral Medicine, and Oral Pathology 1982;53(5):503-7.

\section{Orstavik 1991}

Orstavik D, Kerekes K, Molven O. Effects of extensive apical reaming and calcium hydroxide dressing on bacterial infection during treatment of apical periodontitis: a pilot study. International Endodontic Journal 1991;24(1):1-7.

\section{Orstavik 1998}

Ørstavik D, Pitt Ford TR. Apical periodontitis. Microbial infection and host responses. Essential Endodontology: Prevention and treatment of apical periodontitis. Oxford: Blackwell Science, 1998. 


\section{Petersson 1991}

Petersson K, Håkansson R, Håkansson J, Olsson B, Wennberg A. Follow-up study of endodontic status in an adult Swedish population. Endodontic Dental Traumatology 1991;7:221-5.

\section{Reit 1988}

Reit C, Dahlèn G. Decision making analysis of endodontic treatment strategies in teeth with apical periodontitis. International Endodontic Journal 1988;21(5):291-9.

\section{RevMan 2014 [Computer program]}

Review Manager (RevMan). Version 5.3. Copenhagen: The Nordic Cochrane Centre, The Cochrane Collaboration, 2014.

\section{Rucher 2008}

Rucher G, Schwarzer G, Carpenter J. Arcsine test for publication bias in meta-analyses with binary outcomes. Statistical Medicine 2008;27(5):746-63.

\section{Sathorn 2005}

Sathorn C, Parashos P, Messer HH. Effectiveness of singleversus multiple-visit endodontic treatment of teeth with apical periodontitis: a systematic review and meta-analysis. International Endodontic Journal 2005;38(6):347-55.

\section{Siqueira 2000}

Siqueira JF, Favieri A, Gahyva SM, Moraes SR, Lima KC, Lopes HP. Antimicrobial activity and flow rate of newer and established root canal sealers. Journal of Endodontics 2000;26(5):274-7.

\section{Strinberg 1956}

Strindberg LZ. The dependence of the results of pulp therapy on certain factors. Acta Odontologica Scandinavica 1956;14(Suppl):21.

\section{Su 2011}

Su Y, Wang C, Ye L. Healing rate and post-obturation pain of single- versus multiple-visit endodontic treatment for infected root canals: a systematic review. Journal of Endodontics 2011:37:125-32.

\section{Wong 2014}

Wong AWY, Zhang C, Chu C. A systematic review of nonsurgical single-visit versus multiple-visit endodontic treatment. Clinical, Cosmetic and Investigational Dentistry 2014;6:45-56.

\section{Worthington 2015}

Worthington $\mathrm{H}$, Clarkson J, Weldon J. Priority oral health research identification for clinical decision-making. Evidencebased Dentistry 2015;16(3):69-71.

\section{Zhang 2015}

Zhang YY, Liang XP, Zhao J. Healing rate of single- versus multiple-visit root canal treatment for teeth with infected root canals: a meta-analysis. Chinese Journal of Evidence-Based Medicine 2015;15:1202-6.

\section{References to other published versions of this review Figini 2007}

Figini L, Lodi G, Gorni F, Gagliani M. Single versus multiple visits for endodontic treatment of permanent teeth. Cochrane Database of Systematic Reviews 2007, Issue 4. [DOI: 10.1002/14651858.CD005296.pub2]

\section{Gagliani 2005}

Gagliani M, Colombo M, Maddalone M, Figini L, Gorni F, Lodi G. Single versus multiple visits for endodontic treatment of permanent teeth. Cochrane Database of Systematic Reviews 2005, Issue 2. [DOI: 10.1002/14651858.CD005296]

* Indicates the major publication for the study

\section{CHARACTERISTICS OF STUDIES}

Characteristics of included studies [ordered by study ID]

Akbar 2013

Study design: randomised parallel group clinical trial.
Conducted in Pakistan.
Number of centres: 1.
Recruitment period: not reported.
Funding source: not reported.

Participants

Inclusion criteria: one asymptomatic molar tooth with periapical radiolucency.

Exclusion criteria: not reported.

Diagnostic criteria for pulpal or periapical disease: periapical Rx of the involved tooth and patient's history. 
100 participants randomised: 51 males, 49 females, aged between 12 and 40 years.

Group 1: 50 randomised (1 participant 1 tooth), 50 analysed.

Group 2: 50 randomised (1 participant 1 tooth), 50 analysed.

Group 1: single visit.
Group 2: multiple visits (2 visits, not reported how many days after the first the second visit was per-
formed, root canal medication with calcium hydroxide).
Number of operators not reported. Rubber dam isolation. Use of magnification loupes not reported.
Canal shaping: step-back technique by K files and gates Glidden-drills. Canal irrigation: $2 \mathrm{ml}$ of $2.5 \%$
sodium hypochlorite. Working length determined by Rx. Obturation with gutta-percha cones and a zinc
oxide eugenol sealer in lateral condensation technique.

\begin{tabular}{ll}
\hline Outcomes & Flare-up \\
& Measured after obturation and daily for 7 days and defined as moderate to severe pain, or moderate to \\
& severe swelling that begins 12 to 48 hours after treatment and lasts at least 48 hours.
\end{tabular}

\section{Notes}

\section{Risk of bias}

\begin{tabular}{|c|c|c|}
\hline Bias & Authors' judgement & Support for judgement \\
\hline $\begin{array}{l}\text { Random sequence genera- } \\
\text { tion (selection bias) }\end{array}$ & Low risk & Quote: "the patients were randomly assigned into two groups". \\
\hline $\begin{array}{l}\text { Allocation concealment } \\
\text { (selection bias) }\end{array}$ & Unclear risk & Comment: insufficient information to permit judgment. \\
\hline $\begin{array}{l}\text { Blinding of outcome as- } \\
\text { sessment (detection bias) } \\
\text { All outcomes }\end{array}$ & Low risk & Comment: not applicable, radiographic assessment was not among outcomes. \\
\hline $\begin{array}{l}\text { Incomplete outcome data } \\
\text { (attrition bias) } \\
\text { All outcomes }\end{array}$ & Low risk & $100 / 100$ of participants enrolled (100\%) were analysed. \\
\hline $\begin{array}{l}\text { Selective reporting (re- } \\
\text { porting bias) }\end{array}$ & Low risk & Comment: important outcomes and adverse effects reported as planned. \\
\hline Other bias & Low risk & Comment: no other source of bias identified. \\
\hline
\end{tabular}

\section{Al-Negrish 2006}

\begin{tabular}{ll} 
Methods & Study design: quasi-randomised parallel group clinical trial. \\
Conducted in Jordan. & Number of centres: 1. \\
& Recruitment period: not reported. \\
& Funding source: not reported. \\
\hline Participants & Inclusion criteria: one asymptomatic necrotic central incisor. \\
\hline
\end{tabular}


Al-Negrish 2006 (Continued)

Exclusion criteria: any evidence of periapical radiolucent lesion, teeth tender to touch, with intracanal calcification or incompletely formed apices, retreatments, teeth with pulpal sensitivity and vitality.

Diagnostic criteria for pulpal or periapical disease: Rx signs, pulp testing, presence or absence of haemorrhage upon access opening.

120 participants randomised: 66 female and 54 males, aged between 15 to 45 years.

Group 1: 60 quasi-randomised; 54 analysed.

Group 2: 60 quasi randomised; 58 analysed.

Group 2: multiple visits ( 2 visits, second appointment 7 days later the first, root canal medication with calcium hydroxide paste with a dry sterile cotton pledget and temporary filling restoration for 7 days).

Single operator. Rubber dam isolation. Use of magnification loupes not reported. Canal shaping: stepback technique with conventional $\mathrm{K}$ files and gates. Irrigation: $2.5 \%$ sodium hypochlorite. Working length determined by Rx. Obturation with gutta-percha and a zinc oxide eugenol sealer (Tubliseal, Kerr) in lateral condensation.

- Pain
Pain after 2-day postobturation period and after 7 -day postobturation period was reported with a 4 -
grade scale: $1=$ no pain, $2=$ slight pain, $3=$ moderate pain, $4=$ severe pain. In the present review, the
scale was dichotomised: no pain versus pain (slight, moderate or severe).
- Flare-up
Proportion of participants experiencing moderate to severe pain evaluated after 2 and 7 days (see Ta-
ble 2).

Notes

\section{Risk of bias}

\begin{tabular}{|c|c|c|}
\hline Bias & Authors' judgement & Support for judgement \\
\hline $\begin{array}{l}\text { Random sequence genera- } \\
\text { tion (selection bias) }\end{array}$ & High risk & Comment: quasi-random method. \\
\hline $\begin{array}{l}\text { Allocation concealment } \\
\text { (selection bias) }\end{array}$ & High risk & $\begin{array}{l}\text { Comment: no allocation concealment was possible as patients were alterna- } \\
\text { tively assigned to treatments. }\end{array}$ \\
\hline $\begin{array}{l}\text { Blinding of outcome as- } \\
\text { sessment (detection bias) } \\
\text { All outcomes }\end{array}$ & Low risk & Comment: not applicable, radiographic assessment was not among outcomes. \\
\hline $\begin{array}{l}\text { Incomplete outcome data } \\
\text { (attrition bias) } \\
\text { All outcomes }\end{array}$ & Low risk & $\begin{array}{l}112 / 120 \text { patients ( } 93.3 \% \text { ) of patients who entered the study were included in } \\
\text { the final analysis. Eight patients ( } 6 \text { females and } 2 \text { males, } 6 \text { from Group } 1 \text { and } 2 \\
\text { from Group } 2 \text { ) were excluded from the analysis of the results as they failed to } \\
\text { attend postoperative visits. }\end{array}$ \\
\hline $\begin{array}{l}\text { Selective reporting (re- } \\
\text { porting bias) }\end{array}$ & Low risk & Comment: important outcomes and adverse effects reported as planned. \\
\hline Other bias & Low risk & Comment: no other source of bias identified. \\
\hline
\end{tabular}


Albashaireh 1998

Methods
Study design: quasi-randomised parallel group, clinical trial.
Conducted in Jordan.
Number of centres: 1.
Recruitment period: not reported.
Funding source: not reported.
Inclusion criteria: one tooth for each participant.
Exclusion criteria: teeth tender to touch, with extensive intracanal calcification and incompletely
formed apices
Diagnostic criteria for pulpal or periapical disease: pulpal vitality and sensitivity (pulp testing and
direct presence or absence of haemorrhage), presence of periapical radiolucency in periapical radi-
ographs.
300 participants randomised (sex not reported, aged between 15 to 65 years).
Group 1: 150 quasi-randomised; 142 analysed.
Group 2: 150 quasi randomised; 149 analysed.

Interventions
Group 1: single visit.
Group 2: multiple visits (2 visits, no intra-appointment medicament was placed, but a dry sterile cotton
pledget sealed in pulp-chamber with a temporary filling restoration).
One operator. Rubber dam isolation. Use of magnification loupes and working length not report-
ed. Canal shaping with step-back technique, obturation with gutta-percha and a calcium hydrox-
ide-based root canal sealer (Sealapex) with lateral condensation technique. Irrigation with 2.6\% sodi-
um hypochlorite solution.

- Pain
Incidence and degree of pain at the 1 st and 30th postobturation day was reported on a 4-grade scale:
$1=$ no pain, 2 = slight pain, $3=$ moderate pain, $4=$ severe pain. In the present review, the scale was di-
chotomised: no pain versus pain (slight, moderate, or severe).

Notes

\section{Risk of bias}

\begin{tabular}{|c|c|c|}
\hline Bias & Authors' judgement & Support for judgement \\
\hline $\begin{array}{l}\text { Random sequence genera- } \\
\text { tion (selection bias) }\end{array}$ & High risk & Comment: quasi-random method. \\
\hline $\begin{array}{l}\text { Allocation concealment } \\
\text { (selection bias) }\end{array}$ & High risk & $\begin{array}{l}\text { Comment: no allocation concealment was possible as participants were alter- } \\
\text { natively assigned to treatments. }\end{array}$ \\
\hline $\begin{array}{l}\text { Blinding of outcome as- } \\
\text { sessment (detection bias) } \\
\text { All outcomes }\end{array}$ & Low risk & Comment: not applicable, radiographic assessment was not among outcomes. \\
\hline $\begin{array}{l}\text { Incomplete outcome data } \\
\text { (attrition bias) } \\
\text { All outcomes }\end{array}$ & Low risk & $\begin{array}{l}291 / 300(97 \%) \text { of participants who entered the study were included in the final } \\
\text { analysis. }\end{array}$ \\
\hline
\end{tabular}


9 participants (8 from Group 1 and 1 from Group 2) were excluded from the analysis of the results as 5 failed to attend postoperative visits, 3 required surgery 2 weeks after obturation and 1 had the involved tooth extracted elsewhere.

Selective reporting (re- Low risk Comment: important outcomes and adverse effects reported as planned.
porting bias)

Other bias Low risk Comment: no other source of bias identified.

DiRenzo 2002

Study design: randomised two arm parallel group clinical trial.
Conducted in USA.
Number of Centres: 1.
Recruitment period: not reported.
Funding source: not reported.

Participants Inclusion criteria: mature vital and non-vital permanent maxillary and mandibular molars requiring root canal therapy.

Exclusion criteria: pregnancy, use of antibiotics or corticosteroids at the time of treatment, immunocompromised states, subjects under 18 years old.

Diagnostic criteria for pulpal or periapical disease: not reported.

80 participants randomised (sex, age and ethnic group not specified, over 18 years of age).

Group 1: randomised 46; analysed 39.

Group 2: randomised 34; analysed 33.

Interventions

Group 1: Single visit.

Group 2: Multiple visits (2 visits, in the interappointment period the teeth were closed with a sterile dry cotton pellet and Cavit temporary restorative cement).

Two operators (postgraduate students). Rubber dam isolation. Use of magnification loupes not reported. Canal shaping with hand files and nickel titanium rotary files. Irrigation with $2.5 \%$ sodium hypochlorite. Working length determined by an electronic apex locator and 2 or more angled radiographs. Obturation with gutta-percha and Roth 811 sealer in lateral condensation.

\section{Outcomes}

- Pain

A modified VAS was used to measure pain at 6, 12, 24, 48 hours after the first appointment.

- Flare-up

Defined as swelling that needs antibiotics and narcotic analgesics (see Additional Table 2).

\section{Notes}

Data on pain were not available and it was not possible to extract them from the tables, for such reason data on pain were not available for meta-analysis.

\section{Risk of bias}


DiRenzo 2002 (Continued)

Random sequence genera- Low risk $\quad$ Quote: "random assignment by coin toss".
tion (selection bias)

$\begin{array}{ll}\begin{array}{l}\text { Allocation concealment } \\ \text { (selection bias) }\end{array} & \text { Unclear risk } \\ \end{array}$

Blinding of outcome as-
sessment (detection bias) $\quad$ Low risk Comment: not applicable, radiographic assessment was not among outcomes.

All outcomes

\begin{tabular}{|c|c|c|}
\hline $\begin{array}{l}\text { Incomplete outcome data } \\
\text { (attrition bias) } \\
\text { All outcomes }\end{array}$ & Low risk & $\begin{array}{l}90 \% \text { of patients }(72 / 80) \text { who entered the study were included in the final analy- } \\
\text { sis. } \\
5 \text { patients (Group } 1 \text { ) dropped out because of their inability to complete the } \\
\text { treatment in } 1 \text { appointment, } 3 \text { patients ( } 2 \text { group } 1,1 \text { group } 2 \text { ) did not return } \\
\text { the VAS form. }\end{array}$ \\
\hline $\begin{array}{l}\text { Selective reporting (re- } \\
\text { porting bias) }\end{array}$ & Low risk & VAS pain measurements reported. \\
\hline Other bias & Low risk & Comment: no other source of bias identified. \\
\hline
\end{tabular}

\section{Dorasani 2013}

Study design: randomised two arm parallel group clinical trial.
Conducted in: India.
Number of centres: 1.
Recruitment period: not reported.
Funding source: not reported.

- patients aged between 18 and 62 years, only single rooted teeth with Vertucci's type I configuration, teeth with radiographic evidence of periapical pathology (PAI $\geq 3$ ) and pulpal necrosis.

Exclusion criteria:

- any systemic disease, pregnancy, use of antibiotics, corticosteroids or anti-inflammatory drugs prior to time of treatment, necessity of antibiotic premedication for dental treatment, previously accessed tooth, grossly decayed tooth (difficulty in rubber dam isolation), teeth with calcified canals and weeping canals.

Diagnostic criteria for pulpal or periapical disease:

- not reported.

64 teeth from 57 patients ( 30 males, 27 females, mean age 40 years, range 18-62 years) were randomised. 6 patients contributed with more than 1 tooth: 5 patients with 2 teeth and 1 patient with 3 teeth.

Group 1: 34 teeth randomised, 23 analysed.

Group 2: 30 teeth randomised, 21 analysed. 
Group 2: Multiple visits (2 visits, the second one 7 days after the first; in the interappointment period a paste carrier was used to carry calcium hydroxide medicament in the root canal and temporarily restored with Cavit).

Single operator. Rubber dam isolation. Use of magnification loupes not reported. Canal shaping: hand instrumentation with flexo-files using balanced force technique and crow-down technique. Irrigation: $3 \%$ sodium hypochlorite and saline. Working length checked with apex locator and confirmed by Rx. RC-help was used as a lubricant during filling. Obturation with gutta-percha cones and pulp canal sealer (Kerr) with lateral condensation.

Clinical assessment:
- presence of clinical signs and symptoms at 12 months (spontaneous pain, presence of sinus tract,
swelling, mobility, periodontal probing depths greater than baseline measurements, or sensitivity to
percussion or palpation).
Radiographic assessment:
- change in apical bone density at 12 months using PAl. Evaluation at 3 and 6 months was also per-
formed.

Notes The patients who had taken medication for any systemic illness during the follow-up period were excluded from the study.

\section{Risk of bias}

\begin{tabular}{|c|c|c|}
\hline Bias & Authors' judgement & Support for judgement \\
\hline $\begin{array}{l}\text { Random sequence genera- } \\
\text { tion (selection bias) }\end{array}$ & High risk & Comment: insufficient information to permit judgment. \\
\hline $\begin{array}{l}\text { Allocation concealment } \\
\text { (selection bias) }\end{array}$ & Unclear risk & Comment: insufficient information to permit judgment. \\
\hline $\begin{array}{l}\text { Blinding of outcome as- } \\
\text { sessment (detection bias) } \\
\text { All outcomes }\end{array}$ & Unclear risk & Comment: insufficient information to permit judgment. \\
\hline $\begin{array}{l}\text { Incomplete outcome data } \\
\text { (attrition bias) } \\
\text { All outcomes }\end{array}$ & High risk & $\begin{array}{l}44 / 64(70 \%) \text { of teeth included in the study were reported in the study. Two } \\
\text { treatment failures before the } 12 \text {-month examination ( } 1 \text { in } \mathrm{G} 1 \text { and } 1 \text { in G2) } 18 \\
\text { teeth lost at follow-up. }\end{array}$ \\
\hline $\begin{array}{l}\text { Selective reporting (re- } \\
\text { porting bias) }\end{array}$ & Low risk & Comment: important outcomes and adverse effects reported as planned. \\
\hline Other bias & High risk & $\begin{array}{l}\text { The number of teeth exceeds the number of patients and it is not specified } \\
\text { whether patients were randomised a number of time equal to the number of } \\
\text { teeth undergoing treatment. }\end{array}$ \\
\hline
\end{tabular}

Gesi 2006

Study design: Randomised parallel group, clinical trial.
Conducted in Italy.
Number of Centres: 2 , Private dental practices in Pisa and Pistoia, Italy.
Recruitment period: 24 months.


Gesi 2006 (Continued)

Funding source: not reported.

256 participants (141 females, 115 males, age and ethnic group not reported).
Inclusion criteria: patients with teeth with painful and non-painful vital pulp, with bleeding upon ac-
cess of the pulpal chamber.

Exclusion criteria: patients with physical or mental disability, patients that took pain medications or in treatment with antibiotics for systemic or local infection.

Diagnostic criteria for pulpal or periapical disease: vitality testing and thermal and mechanical stimulation.

Group 1: randomised 130; included 130.

Group 2: randomised 126; included 126.

\begin{abstract}
Interventions
Group 1: Single visit.

Group 2: Multiple visits (2 visits, in the interappointment period calcium hydroxide was employed as intracanal medication and Coltosol as temporary cement).

Single operator. Rubber dam. Use of magnification loupes not specified. Canal shaping: hand instrumentation with flexo-files using balanced force technique and crow-down technique. Irrigation: 3\% sodium hypochlorite. Working length established by Rx. Obturation with gutta-percha and pulp canal sealer (Kerr) with lateral condensation.
\end{abstract}

Outcomes Pain

Evaluated at 1 week after canal obturation by clinical examination and by a verbal rating scale to assess pain experience. Participants with multivisit treatments were asked to evaluate their pain after 1 week for each visit. We considered pain-related data only after canal obturation. A verbal rating scale graded 0 to 3 was used. Participants were asked to indicate 0 for no, 1 for mild, 2 for moderate and 3 for severe pain. Teeth were also tapped for percussion sensitivity. We considered only 2 categories: pain (mild, moderate, severe) and no pain.

- Healing

(Follow-up until 3 years): 2 endodontists, experienced in radiographic assessment of endodontic treatments, neither of whom was the operator and both masked to the assigned treatment group, carried out the analysis of the radiographs. Parameters were presence or absence of periapical radiolucency (radiographic lesion) (see Table 1). In 2-or multi-rooted teeth, the tooth was classified according to the diagnosis of the worst root.

Notes

\title{
Risk of bias
}

\begin{tabular}{lll}
\hline Bias & Authors' judgement & Support for judgement \\
\hline $\begin{array}{l}\text { Random sequence genera- } \\
\text { tion (selection bias) }\end{array}$ & Low risk & $\begin{array}{l}\text { Quote: "by a simple randomisation procedure (toss of a coin) patients were al- } \\
\text { located in group 1 or 2". }\end{array}$ \\
\hline $\begin{array}{l}\text { Allocation concealment } \\
\text { (selection bias) }\end{array}$ & Unclear risk & $\begin{array}{l}\text { Unclear by whom and when the coin toss was performed and how the result } \\
\text { was communicate to the operators. }\end{array}$ \\
\hline $\begin{array}{l}\text { Blinding of outcome as- } \\
\text { sessment (detection bias) } \\
\text { All outcomes }\end{array}$ & Low risk & $\begin{array}{l}\text { Healing: Quote:" two endodontists, well experienced in radiographic assess- } \\
\text { ment of endodontic treatments, neither of whom was the operator and both } \\
\text { masked to the assigned treatment group, carried out the analysis of the radi- } \\
\text { ographs". }\end{array}$ \\
\hline
\end{tabular}


Gesi 2006 (Continued)

Incomplete outcome data Low risk 100\% of patients who entered the study were included in the final analysis of (attrition bias) the outcome 'pain.'

All outcomes

$71.8 \%(244 / 256)$ of patients who entered the study were included in the final analysis of the outcome 'healing at 3 years follow-up'.
Selective reporting (re-
Low risk
Planned outcomes reported.

porting bias)

Other bias Low risk Comment: no other source of bias identified.

Study design: three-arm randomised parallel group, clinical trial.
Conducted in Iran.
Number of Centres: 1. Endodontics Department of Mashad Dental School, Iran.
Recruitment period: not reported.
Funding source: a grant from the vice chancellor of research of Mashad University of Medical Sciences,
Iran.

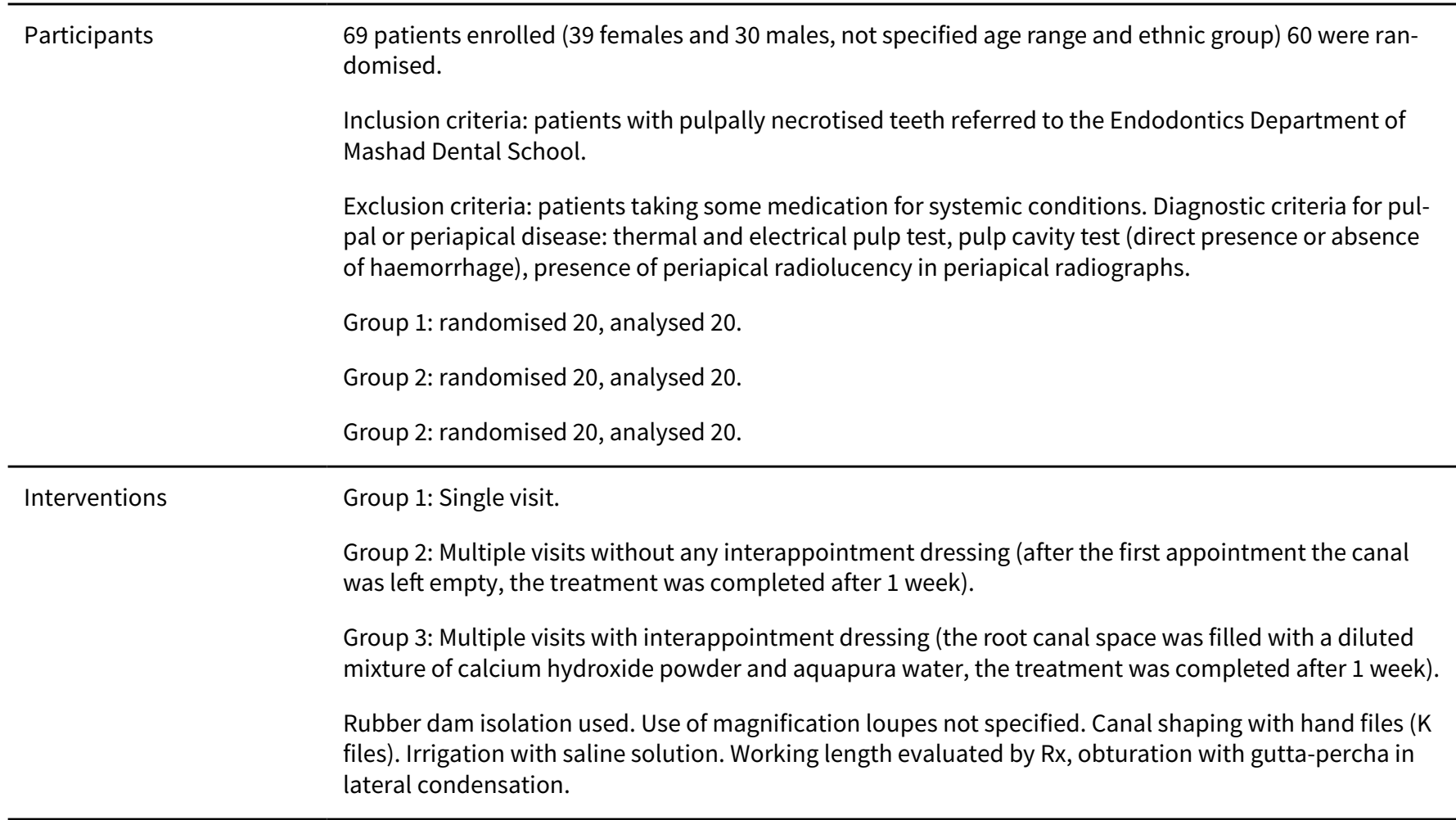

Outcomes

- Pain

Incidence and degree of pain in the immediate canal postobturation until 72 hours was reported as: $1=$ no pain, 2 = mild pain, 3 = moderate pain, 4 = severe pain. We considered only 2 categories: no pain, and pain (mild, moderate and severe pain).

- Flare-up (swelling) 
Ghoddusi 2006 (Continued)

Notes

\section{Risk of bias}

\begin{tabular}{|c|c|c|}
\hline Bias & Authors' judgement & Support for judgement \\
\hline $\begin{array}{l}\text { Random sequence genera- } \\
\text { tion (selection bias) }\end{array}$ & Low risk & Quote "The patients were randomly assigned to the three groups". \\
\hline $\begin{array}{l}\text { Allocation concealment } \\
\text { (selection bias) }\end{array}$ & Unclear risk & Not specified. \\
\hline $\begin{array}{l}\text { Blinding of outcome as- } \\
\text { sessment (detection bias) } \\
\text { All outcomes }\end{array}$ & Low risk & Comment: not applicable, radiographic assessment was not among outcomes. \\
\hline $\begin{array}{l}\text { Incomplete outcome data } \\
\text { (attrition bias) } \\
\text { All outcomes }\end{array}$ & Low risk & $100 \%$ of patients who entered the study were included in the final analysis. \\
\hline $\begin{array}{l}\text { Selective reporting (re- } \\
\text { porting bias) }\end{array}$ & Low risk & Planned outcomes reported. \\
\hline Other bias & Low risk & Comment: no other source of bias identified. \\
\hline
\end{tabular}

\section{Ince 2009}

Study design: randomised parallel group, clinical trial.
Conducted in Turkey.
Number of Centres: more than one. Quote: "...patients who attended participating dental clinics..."
Recruitment period: not reported.
Funding source: not reported.

Participants 306 participants (200 males, 106 females, 18 to 60 (?) years old - average 45 years), 153 vital teeth and
153 non-vital teeth.

Inclusion criteria: patients with one tooth only that required RoCT, between 18 to 60 years of age, in good health.

Exclusion criteria: patients who had previously taken analgesics or antibiotics.

Diagnostic criteria for pulp vitality: electric test with pulp testing device.

Group 1: randomised 153; included 153.

Group 2: randomised 153; included 153.
Interventions
G1: single visit.
G2 : multiple visits (2 visits, second appointment 7 days after the first, no interappointment medication, a sterile cotton pellet was placed in the pulp-chamber and the access cavity was sealed with quick-set- ting zinc oxide eugenol cement).
Two experienced clinicians performed the treatments. 
Ince 2009 (Continued)

Rubber dam isolation - use of magnification loupes not specified.

Canal shaping: step-back technique, hand files and Gates-Glidden drills. Irrigation: $2 \mathrm{ml}$ of 5\% sodium hypochlorite; working length determined radiographically; root canals were filled with gutta-percha points sealed with $\mathrm{AH}-26$ root canal sealer using lateral condensation technique.

\begin{tabular}{|c|c|}
\hline Outcomes & $\begin{array}{l}\text { Pain: preoperative (absence or presence of pain), postoperative at } 3 \text { days after initial appointment (ab- } \\
\text { sence or presence of pain; degree of pain: none, slight, moderate, severe). }\end{array}$ \\
\hline Notes & $\begin{array}{l}\text { No data are reported in text regarding: } 1 \text {. how many centres have been involved in the study; } 2 \text {. the ex- } \\
\text { act age of the participants included in the study (Table } 1 \text { reports a different range of age from that de- } \\
\text { clared in the material and method section); } 3 \text {. data about secondary outcomes (radiographic and clini- } \\
\text { cal data at follow-up) that are not reported in the text. An e-mail was sent to the corresponding author } \\
\text { but no answer was obtained. }\end{array}$ \\
\hline
\end{tabular}

\section{Risk of bias}

\begin{tabular}{lll}
\hline Bias & Authors' judgement & Support for judgement \\
\hline $\begin{array}{l}\text { Random sequence genera- } \\
\text { tion (selection bias) }\end{array}$ & Unclear risk & Not reported. \\
\hline $\begin{array}{l}\text { Allocation concealment } \\
\text { (selection bias) }\end{array}$ & Unclear risk & Quote:" The case and the operator distribution were blinded..." \\
\hline $\begin{array}{l}\text { Blinding of outcome as- } \\
\text { sessment (detection bias) } \\
\text { All outcomes }\end{array}$ & Low risk & Comment: not applicable, radiographic assessment was not among outcomes. \\
\hline $\begin{array}{l}\text { Incomplete outcome data } \\
\text { (attrition bias) } \\
\text { All outcomes }\end{array}$ & Low risk & 100\% of patients were analysed. \\
\hline $\begin{array}{l}\text { Selective reporting (re- } \\
\text { porting bias) }\end{array}$ & Low risk & Outcome reported. \\
\hline \begin{tabular}{l} 
Other bias \\
\hline
\end{tabular} & Low risk & Comment: no other source of bias identified. \\
\hline
\end{tabular}

Molander 2007

\begin{tabular}{ll} 
Methods & Study design: randomised parallel-group, clinical trial. \\
Conducted in Sweden. \\
Number of Centres: 1 . Clinic of Endodontics, Public Dental Health Service, Gothenburg, Sweden. \\
Recruitment period: not reported. \\
Founding Sourse: not reported. \\
\hline Participants \\
Inclusion criteria: asymptomatic teeth with necrotic pulps and apical periodontitis. \\
Exclusion criteria: not specified. \\
Diagnostic criteria for periapical disease: radiography. \\
G1: 53 teeth randomised, analysed 49.
\end{tabular}


Molander 2007 (Continued)

G2: 48 teeth randomised, analysed 40 .

G1: single visit.
G2: multiple visits (2 visits, second appointment 7 days after the first, calcium hydroxide was used as
interappointment medication using a lentulo spiral and access cavity sealed with Coltosol).
Four endodontic specialists performed the treatments.
Rubber dam isolation, use of magnification loupes and working length not specified.
Canal shaping: nickel titanium instruments for rotary and/or hand use, Irrigation: $0.5 \%$ sodium
hypochlorite; root canals were filled with gutta-percha cones using cold lateral condensation tech-
nique including rosin chloroform as sealer.

Outcomes Healing (radiographic and clinical) at 2 years. Two examiners independently evaluated all the RX (previously coded blind and organised in a random order). Observer used a strict definition of periapical disease and reported a positive finding only when absolute certain. In case of disagreement joint re-evaluation was performed. The size of periapical radiolucency was assessed by measuring with a ruler its largest horizontal and vertical width.

Teeth with symptoms of persisting periapical inflammation: not healed.

Cases with unchanged/increased size of periapical radiolucency: not healed.

Teeth with reduced size of periapical rarefaction (sum of horizontal and vertical reduction $>$ or $=2 \mathrm{~mm}$ ): uncertain.

Teeth with complete restitution of periodontal contours: healed.

Teeth with more than 1 root, the least favourable outcome was register.

Notes CONSORT Clinical trial.

3 out of 12 participants lost to follow-up died.

\section{Risk of bias}

\begin{tabular}{lll}
\hline Bias & Authors' judgement & Support for judgement \\
\hline $\begin{array}{l}\text { Random sequence genera- } \\
\text { tion (selection bias) }\end{array}$ & Low risk & $\begin{array}{l}\text { Quote: "Randomistation was performed before the clinical examination using } \\
\text { the minimisation method. Two randomisation factors were considered: tooth } \\
\text { group and size of periapical lesion". }\end{array}$ \\
\hline $\begin{array}{l}\text { Allocation concealment } \\
\text { (selection bias) }\end{array}$ & Low risk & Quote: "Patients were randomly assigned to one or two-visit treatment". \\
\hline $\begin{array}{l}\text { Blinding of outcome as- } \\
\text { sessment (detection bias) } \\
\text { All outcomes }\end{array}$ & Low risk & $\begin{array}{l}\text { Quote: "Two examiners independently evaluated all the Rx exams, previously } \\
\text { coded blind and organised in a random order". }\end{array}$ \\
\hline $\begin{array}{l}\text { Incomplete outcome data } \\
\text { (attrition bias) } \\
\text { All outcomes }\end{array}$ & Low risk & $\begin{array}{l}\text { 89/101 teeth analysed (12 teeth lost, 12\%). Quote "The loss did not alter the re- } \\
\text { sults". }\end{array}$ \\
\hline $\begin{array}{l}\text { Selective reporting (re- } \\
\text { porting bias) }\end{array}$ & Low risk & Outcome reported. \\
\hline \begin{tabular}{l} 
Other bias \\
\hline
\end{tabular} & Low risk & Comment: no other source of bias identified. \\
\hline
\end{tabular}


Mulhern 1982

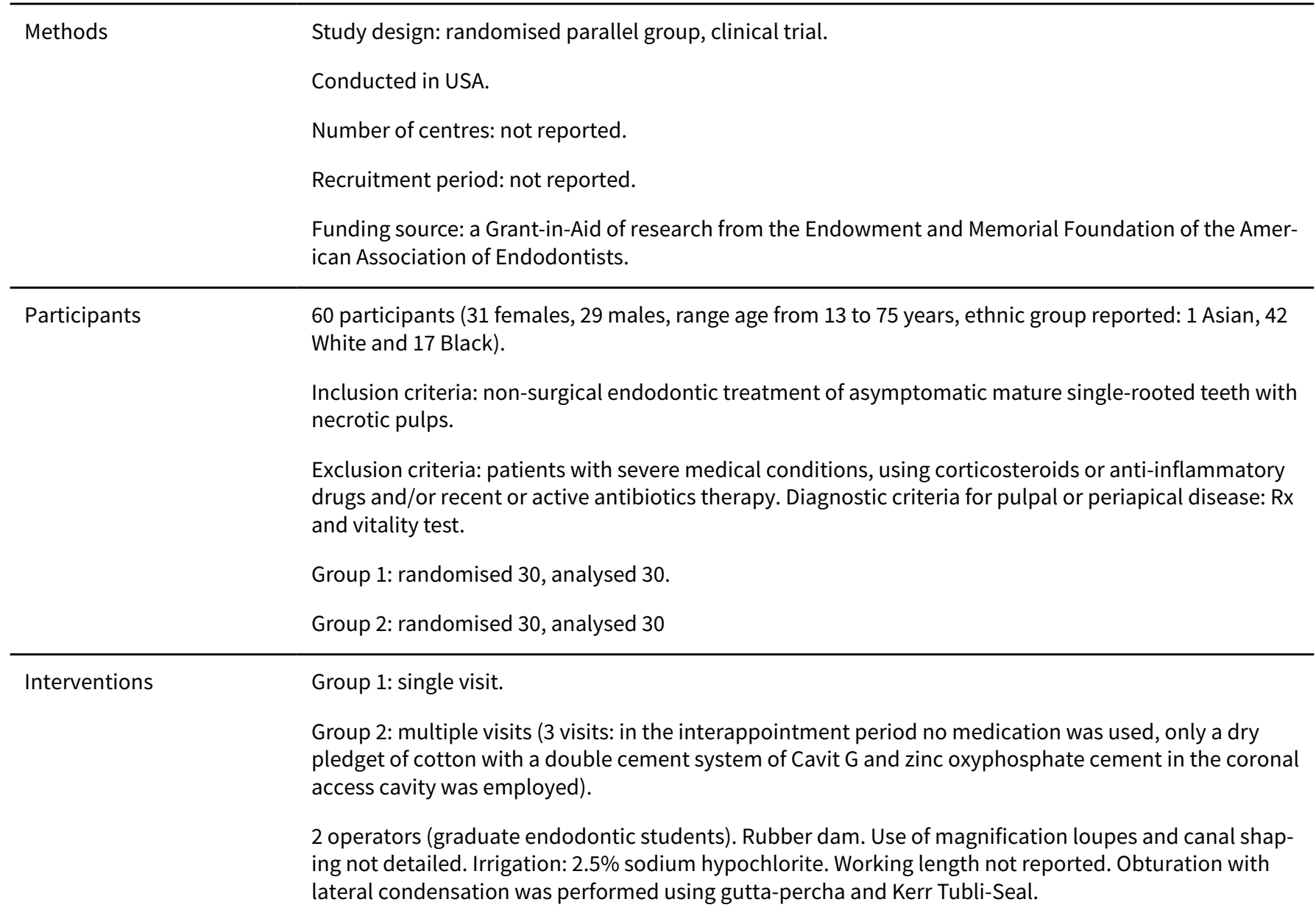

Outcomes

- Pain

Evaluated at 48 hours after treatment (by a questionnaire) and at 1 week (clinical examination). Participants with multivisit treatment were asked to complete a questionnaire for each visit.

- Painkiller use

- Flare-up (swelling) (see Table 2). charged the usual clinic fee for treatment.

\section{Risk of bias}

\begin{tabular}{lll}
\hline Bias & Authors' judgement & Support for judgement \\
\hline $\begin{array}{l}\text { Random sequence genera- } \\
\text { tion (selection bias) }\end{array}$ & Unclear risk & $\begin{array}{l}\text { Quote " The teeth were randomly assigned to group 1 (single visit) or 2 (multi- } \\
\text { ple visits)". }\end{array}$ \\
\hline $\begin{array}{l}\text { Allocation concealment } \\
\text { (selection bias) }\end{array}$ & Unclear risk & Not specified. \\
\hline $\begin{array}{l}\text { Blinding of outcome as- } \\
\text { sessment (detection bias) } \\
\text { All outcomes }\end{array}$ & Low risk & Comment: not applicable, radiographic assessment was not among outcomes. \\
\hline
\end{tabular}


Mulhern 1982 (Continued)

Incomplete outcome data Low risk $\quad 100 \%$ of patients who entered the study were included in the final analysis. (attrition bias)

All outcomes

Selective reporting (re- Low risk Planned outcomes reported.

porting bias)

Other bias Low risk Comment: no other source of bias identified.

Oginni 2004

Study design: randomised parallel group, clinical trial.
Conducted in Nigeria.
Number of Centres: 1 . Restorative Dentistry Department, Obafemi Awolowo University Teaching Hospi-
tals Complex, Ile-Ife, Nigeria.
Recruitment period: 12 months.
Funding source: not reported.
Participants 255 patients (sex, range or mean age not reported) were enrolled in the study for a total of 283 teeth (1.11 teeth per patient); 227 teeth were included in the final analysis about pain and flare-up. For pa- tients with more than 1 tooth requiring treatment, the treatment of each tooth was separated by a peri- od of at least 4 weeks.
Inclusion criteria: all patients referred to the Department of Restorative Dentistry for root canal thera- py.
Exclusion criteria: patients that did not turn up after the first appointment (incomplete treatment).
Diagnostic criteria for pulpal or periapical disease: the pulp vitality was determined by an electric pulp tester in combination with the presence of pulpal haemorrhage.
Group 1: randomised 129107 teeth evaluated (1st postobturation day); 104 (7th postobturation day); 102 (30th postobturation day).
Group 2: randomised 154, 136 teeth evaluated (1st postobturation day); 123 (7th postobturation day); 120 (30th postobturation day).

Interventions Group 1: single visit.

Group 2: multiple visits (medication and number of visits in the multiple-visit treatment not reported).

Rubber dam isolation, use of magnification loupes, canal shaping, irrigation, working length not reported. The root canals were obturated with multiple gutta-percha cones and a zinc oxide-eugenol based sealer, using the lateral condensation technique.

Outcomes

- Pain

Incidence and degree of pain at the 1st, 7 th and 30th days postobturation. Pain was recorded as none, slight or moderate/severe. We considered only 2 categories: pain (slight and moderate/severe), and no pain.

- Flare-up

Defined as either patient reporting pain not controlled with over-the-counter medication or increasing swelling or both (see Table 2). 
Oginni 2004 (Continued)

Notes

\section{Risk of bias}

\begin{tabular}{lll}
\hline Bias & Authors' judgement & Support for judgement \\
\hline $\begin{array}{l}\text { Random sequence genera- } \\
\text { tion (selection bias) }\end{array}$ & Unclear risk & Comment: insufficient information to permit judgement. \\
\hline
\end{tabular}

Allocation concealment Unclear risk Comment: insufficient information to permit judgement.

(selection bias)

Blinding of outcome as- Low risk Comment: not applicable, radiographic assessment was not among outcomes. sessment (detection bias)

All outcomes

Incomplete outcome data Unclear risk (attrition bias)

All outcomes
56 teeth ( 25 from single-visit group, 31 from multiple-visit group) were excluded from the study due to non availability of participants at postobturation recall visits.

$85.86 \%$ of patients who entered the study were included in the final analysis about pain and flare-up in the 1st day;

$80.21 \%$ of patients who entered the study were included in the final analysis of pain and flare-up on the 7 th day;

$78.4 \%$ of patients who entered the study were included in the final analysis at 30th day.

Selective reporting (re- Low risk $\quad$ Planned outcomes reported.
porting bias)

\begin{tabular}{|c|c|c|}
\hline Other bias & High risk & $\begin{array}{l}\text { It is not explicitly stated that participants with more that one tooth needing } \\
\text { treatment were randomised the same number of times. }\end{array}$ \\
\hline
\end{tabular}


Paredes-Vieyra 2012 (Continued)

Exclusion criteria: patients who did not meet inclusion requirements, patients who did not provide authorisation for participation, patients younger than 16 years of age, patients who were pregnant, history of antibiotic use within the past month, patients who were diabetic, patients whose tooth had been previously accessed or endodontically treated.

Diagnostic criteria for pulpal or periapical disease: radiographic evidence of apical periodontitis (minimum size $\geq 2.0 \mathrm{~mm} \times 2.0 \mathrm{~mm}$ ) and a diagnosis of pulpal necrosis confirmed by negative response to hot and cold tests.

Group 1: randomised 155 teeth, analysed after a 2-year follow-up 146 teeth.

Group 2: randomised 145 teeth, analysed after a 2-year follow-up 136 teeth.

Interventions
All treatment sessions were approximately 50 minutes in length to allow for acceptable time for the completion of treatment for 1 or 2 visits.

All treatment was performed by the author.

Rubber dam isolation. The tooth was disinfected with 5.25\% sodium hypochlorite. All caries were removed and endodontic access cavities made with sterile high-speed carbide \#331 and Zekrya Endo burs. The working length was established with the Root ZX Electronic Apex Locator and confirmed radiographically.

The canals were negotiated and enlarged with hand instruments until reaching an ISO \#20 at the working length. The coronal portions of the canals were flared with sizes 2 to 3 Gates Glidden burs.

Canals were then irrigated with $2.0 \mathrm{ml} 5.25 \%$ sodium hypochlorite. LightSpeedLSX rotary instruments were used to complete the canal preparation to a size \#60 for the anteriors and premolars and to a size \#45 to \#55 for molars. RC prep was used as a lubricant. After completion of canal instrumentation, all canals were irrigated with $2.5 \mathrm{ml}$ 17\% EDTA for 30 seconds followed by a final irrigation with $5.0 \mathrm{ml}$ $5.25 \%$ sodium hypochlorite using the EndoVac irrigation system.

Group 1: Single visit: the canals were dried with sterile paper points and obturated at the same appointment by using lateral condensation of gutta-percha and Sealapex sealer. Access cavities of anterior teeth were etched and restored with Fuji IX. For posterior teeth, a build-up restoration was placed by using the same etching technique and Fuji IX.

Group 2: multiple visits ( 2 visits: the second appointment was scheduled at least 1 week after the initial appointment). The canals were dried and calcium hydroxide powder was placed with an amalgam carrier and condensed with a size 9 posterior Schilder plugger. The access cavities were sealed with Cavit, and the quality of the calcium hydroxide powder filling was checked radiographically with post-treatment radiographs. At the second appointment, the calcium hydroxide was removed with hand instruments, and copious irrigation with $5.25 \%$ sodium hypochlorite followed by $2.5 \mathrm{ml} 17 \%$ EDTA and a final rinse of $5.0 \mathrm{ml} \mathrm{5.25 \%}$ sodium hypochlorite using the EndoVac irrigation system was performed. For complete removal of the calcium hydroxide, the canals were dried with sterile paper points, and obturation was performed with the same technique described for the 1-visit group and post-treatment.

Outcomes

The primary outcome measure for this study was classified by using a modification of the Strindberg study used for radiographic healing assessment. Teeth with symptoms of persisting periapical inflammation were scored as not healed as were the cases with periapical radiolucencies that remained unchanged or increased in size.

Secondary outcome measures:

- Presence of clinical symptoms or abnormal findings (i.e. spontaneous pain, presence of sinus tract, swelling, mobility, periodontal probing depths greater than baseline measurements, or sensitivity to percussion or palpation).

Outcomes were evaluated at 2 year follow-up. 
Paredes-Vieyra 2012 (Continued)

Financial incentive to return for follow-up for clinical and radiograph examination.

Discrepancy between data on participants treated for more then one tooth and total number of teeth: authors stated that "Twenty-one patients contributed more than 1 tooth", but since the number of patients enrolled is 287 and the number of teeth enrolled is 300 , it seems that no more than 13 patients could have contributed more than 1 tooth.

\section{Risk of bias}

\begin{tabular}{lll}
\hline Bias & Authors' judgement & Support for judgement \\
\hline $\begin{array}{l}\text { Random sequence genera- } \\
\text { tion (selection bias) }\end{array}$ & Low risk & $\begin{array}{l}\text { The participant was randomly assigned to either the 1-visit or 2-visit group by } \\
\text { using a sequence of random numbers generated by one of the investigators by } \\
\text { a computer programme. }\end{array}$
\end{tabular}

\begin{tabular}{lll}
\hline $\begin{array}{l}\text { Allocation concealment } \\
\text { (selection bias) }\end{array}$ & Unclear risk & Comment: insufficient information to permit judgment. \\
\hline $\begin{array}{l}\text { Blinding of outcome as- } \\
\text { sessment (detection bias) } \\
\text { All outcomes }\end{array}$ & Low risk & $\begin{array}{l}\text { Quote: radiographic images were coded and stored and evaluated blindly and } \\
\text { independently by 2 experienced endodontists. }\end{array}$ \\
\hline
\end{tabular}

\begin{tabular}{lll}
\hline $\begin{array}{l}\text { Incomplete outcome data } \\
\text { (attrition bias) } \\
\text { All outcomes }\end{array}$ & Low risk & Only 18 (9 in each group) out of 300 (6\%) teeth lost at follow-up. \\
\hline $\begin{array}{l}\text { Selective reporting (re- } \\
\text { porting bias) }\end{array}$ & Low risk & Oucomes reported. \\
\hline Other bias & High risk & $\begin{array}{l}\text { It is not explicitly stated that patients with more that one tooth needing treat- } \\
\text { ment were randomised the same number of times. }\end{array}$
\end{tabular}

Patil 2016

Methods Study design: randomised parallel group, open-label clinical trial.

Conducted in India.

Number of centres: 1. Department of Conservative Dentistry and Endodontics, KLE University.

Study period: not reported.

Funding source: not reported.
Participants 66 participants (gender of patients and age range not specified) and 66 teeth were enrolled.
Inclusion criteria: acceptance of the aims and requirements of the study, vital and non-vital maxillary central incisors that needed endodontic treatment and teeth in which initial master file (K-type) binds at the apex was of ISO size \#45 or less.

Exclusion criteria: patients with any systemic diseases, pregnant patients, patients younger than 15 years of age and older than 50 years, patients who had been taking antibiotics, non steroidal ant-inflammatory drugs or corticosteroids at the time of treatment, patients with acute apical periodontitis, acute apical abscess and weeping canals, necrotic painful teeth with absence of sinus tract for drainage, retreatment cases, teeth with calcified canals, teeth with periapical radiolucencies of diameter greater than $0.5 \mathrm{~cm}(5 \mathrm{~mm})$.

Group 1: randomised 33 patients, analysed 32. 
Patil 2016 (Continued)

Group 2: randomised 33 patients, analysed 33.

Interventions All treatment was performed by a single operator.

Rubber dam isolation. All caries were removed and endodontic access cavity prepared and canal patency was checked with a size $15 \mathrm{~K}$ file. Then orifice openers taper 0.12 and 0.10 were used for enlarging the coronal and middle third of the canal, at speed of $350 \mathrm{rpm}$. RC-prep was used as a lubricant and $2.5 \% \mathrm{NaOCl}$ saline as irrigants. The working length was established with $\mathrm{K}$-file using apex locator and confirmed radiographically.

Instrumentation was carried out using 0.06 taper K3 nickel titanium rotary files in crown-down manner along with copious irrigation using $2.5 \%$ sodium hypochlorite and saline.

Group 1: single visit: the canals were dried with sterile paper points and obturated at the same appointment by using lateral condensation of gutta-percha and AH plus sealer. Temporary restoration was done.

Group 2: multiple visits (2 visits: the second appointment was scheduled at 1 week after the initial appointment). The canals were dried and double sealed with cavit and phosphate cement. Final obturation was made with a similar method and materials as used in Group 1.

- Postoperative pain
Using a modified Heft-Parker VAS (0-170) at $6,12,24$, and 48 hours. After one week from obturation, fi-
nal clinical evaluation for pain was done with the vertical percussion method.

Notes

\section{Risk of bias}

\begin{tabular}{|c|c|c|}
\hline Bias & Authors' judgement & Support for judgement \\
\hline $\begin{array}{l}\text { Random sequence genera- } \\
\text { tion (selection bias) }\end{array}$ & Low risk & Quote: "Biased coin randomization". \\
\hline $\begin{array}{l}\text { Allocation concealment } \\
\text { (selection bias) }\end{array}$ & Low risk & $\begin{array}{l}\text { Quote: "Tossing coin, allocation and sequence was operated by a post-gradu- } \\
\text { ate student". }\end{array}$ \\
\hline $\begin{array}{l}\text { Blinding of outcome as- } \\
\text { sessment (detection bias) } \\
\text { All outcomes }\end{array}$ & High risk & Quote: "unblinded/open label". \\
\hline $\begin{array}{l}\text { Incomplete outcome data } \\
\text { (attrition bias) } \\
\text { All outcomes }\end{array}$ & Low risk & $65 / 66$ participants who entered the study were included in the final analysis. \\
\hline $\begin{array}{l}\text { Selective reporting (re- } \\
\text { porting bias) }\end{array}$ & High risk & $\begin{array}{l}\text { One of the outcomes mentioned in the M\&M section (pain by vertical percus- } \\
\text { sion method at one week) was not reported among the results. }\end{array}$ \\
\hline Other bias & Low risk & Comment: no other source of bias identified. \\
\hline
\end{tabular}

\section{Penenis 2008}

Study design: randomised parallel group, clinical trial.
Conducted in USA.
Number of centres: 1. Postgraduate Endodontics Clinic, University of Illinois, USA.


Penenis 2008 (Continued)

Recruitment period: 3 years (August 2003 to May 2006).

Funding source: research grant from the American Association of Endodontist Foundation.

Participants
$\begin{array}{ll} & 97 \text { participants enrolled, analysed } 63 \text { (29 males, } 34 \text { females, mean age } 54 \text { years, range 18-91) } \\ & =2.0 \mathrm{~mm} \times 2.0 \mathrm{~mm} \text { ). }\end{array}$

Exclusion criteria: patients younger than 18 year, pregnant, positive history of antibiotic use in the previous month, needed antibiotic for dental treatments, diabetic or with tooth previously treated.

Diagnostic criteria for pulpal or periapical disease: radiography and vital testing performed with cold and electric pulp test.

Group 1: 49 randomised, analysed 33 for PAl at 12 months; analysed 35 for sinus tract formation.

Group 2: 48 randomised, analysed 30 for PAl at 12 months, analysed 31 for sinus tract formation.

Interventions
G2: multiple visits (the second at least two weeks but no more than 4 weeks after the first, in the inter-
appointment period a paste made by mixing calcium hydroxide powder with $2 \%$ of chlorhexidine liquid
was filled in the canals using a lentulo spiral).
Multiple operators. Rubber dam and dental operating microscope use reported. Canal shaping: 0.06
taper K3 nickel titanium crown-down technique with RC prep as lubricant. Irrigation: $5.25 \%$ sodium
hypochloride. Working length established using Root ZX electronic apex locator. Obturation with gut-
ta-percha using warm vertical condensation technique.

- Healing
Change in apical bone density at 1 year, the PAI was used to evaluate radiographic healing.
Secondary outcomes measures:
- Presence of clinical symptoms or abnormal findings at 12 months (i.e. spontaneous pain, presence
of sinus tract, swelling, mobility, periodontal probing depths grater than baseline measurements, or
sensitivity to percussion or palpation) and proportion of teeth in each group that could be considered
improved (decreased PAI score) or healed (PAI < or $=2$ ).

Notes CONSORT Clinical Trial; financial incentive to join the study.

\section{Risk of bias}

\begin{tabular}{lll}
\hline Bias & Authors' judgement & Support for judgement \\
\hline $\begin{array}{l}\text { Random sequence genera- } \\
\text { tion (selection bias) }\end{array}$ & Low risk & $\begin{array}{l}\text { Quote: "Patients were randomly assigned to the one-visit or two-visit group by } \\
\text { using a block of random numbers generated by one of the investigators". }\end{array}$ \\
\hline $\begin{array}{l}\text { Allocation concealment } \\
\text { (selection bias) }\end{array}$ & Low risk & $\begin{array}{l}\text { Quote: "Neither the postgraduate clinician nor the patient was aware of the } \\
\text { group assignment before agreeing to participate in the study". }\end{array}$ \\
\hline $\begin{array}{l}\text { Blinding of outcome as- } \\
\text { sessment (detection bias) } \\
\text { All outcomes }\end{array}$ & Low risk & $\begin{array}{l}\text { Quote: "The clinical and radiographic examination was performed by an en- } \\
\text { dodontic resident unaware of the patient's group assignment or baseline pre- } \\
\text { sentation". }\end{array}$ \\
\hline
\end{tabular}

\begin{tabular}{|c|c|c|}
\hline $\begin{array}{l}\text { Incomplete outcome data } \\
\text { (attrition bias) }\end{array}$ & High risk & $63 / 97(65 \%)$ participants ( $33 \mathrm{G} 1,30 \mathrm{G} 2$ ) were analysed at 1 year follow-up. \\
\hline All outcomes & & $\begin{array}{l}16 \text { participants lost in group } 1: 2 \text { elected not participate in follow-up visits, } 12 \\
\text { unable to contact, } 2 \text { treatment failures. }\end{array}$ \\
\hline
\end{tabular}


Penenis 2008 (Continued)

18 participants lost in group 2: 1 elected not participate in follow-up visits, 16 unable to contact, 1 treatment failure.

\begin{tabular}{lll}
\hline $\begin{array}{l}\text { Selective reporting (re- } \\
\text { porting bias) }\end{array}$ & Low risk & Outcomes reported. \\
\hline Other bias & Low risk & Comment: no other source of bias identified. \\
\hline
\end{tabular}

\section{Peters 2002}

Study design: quasi-randomised, parallel-group, clinical trial.
Conducted in The Netherlands.
Number of Centres: 1 . Academic Centre for Dentistry, Amsterdam, The Netherlands.
Recruitment period: not reported.
Funding source: not reported.

\section{Participants}

39 participants (19 females and 20 males, mean age 40 years, range 19 to 86 years; ethnic groups not specified).

Inclusion criteria: root with 1 canal, teeth asymptomatic that did not respond to sensitivity testing and never had endodontic treatment, root that showed radiographic evidence of periapical bone loss.

Exclusion criteria: maxillary molars, patients $<19$ and $>86$ years old.

Diagnostic criteria for pulpal or periapical disease: Rx evaluated with PAI score, sensitivity testing.

Group 1: randomised 21, analysed 21.

Group 2: randomised 18, analysed 17.

Interventions Group 1: single visit.

Group 2: multiple visits (2, the second appointment 4 weeks later. In this group in the interappointment period the canals were dressed with a thick mix of calcium hydroxide in sterile saline and the cavity access filled with 2 layers of Cavit and a glass ionomer restoration).

1 operator (endodontist). Use of rubber dam isolation and magnification loupes reported. Canal shaping: hand instrumentation by double flare technique. Irrigation: $2 \%$ sodium hypochlorite. Working length evaluated by Rx and electronic apex locator. Obturation: gutta-percha and AH 26 sealer in lateral condensation.

Outcomes Healing

Follow-up 4.5 years. Routine evaluation during follow-up: 3, 12, 24 months to 4.5 years. The authors evaluated the treatment outcome as: score A (success: the width and contour of the periodontal ligament is normal, or there is a slight radiolucent zone around excess filling material); score B (uncertain: the radiolucency is clearly decreased but additional follow-up is not available); score C (failure: there is an unchanged, increased or new periradicular radiolucency). We considered only 2 categories: success (score A) and failure (score B and C) (see Table 1).

Notes

\section{Risk of bias}


Peters 2002 (Continued)

Random sequence genera- High risk Quote: "The teeth were randomly divided into two treatment groups, every tion (selection bias) second patient was assigned to group 2". Quasi-random method.

\begin{tabular}{lll}
\hline $\begin{array}{l}\text { Allocation concealment } \\
\text { (selection bias) }\end{array}$ & High risk & Alternative assignment (randomly and consecutively, quasi-random method). \\
\hline $\begin{array}{l}\text { Blinding of outcome as- } \\
\text { sessment (detection bias) } \\
\begin{array}{l}\text { All outcomes } \\
\text { L }\end{array}\end{array}$ & Low risk & $\begin{array}{l}\text { Quote "Three experienced endodontists who had not been involved in the } \\
\text { treatment or follow-up appointments were asked to analysed the radi- } \\
\text { ographs". }\end{array}$
\end{tabular}

$\begin{array}{ll}\begin{array}{l}\text { Incomplete outcome data } \\ \text { (attrition bias) }\end{array} & \text { Low risk } \\ \text { All outcomes } & \begin{array}{l}97.44 \% \text { of participants who entered the study were included in the final analy- } \\ \text { sis. } 1 \text { participant lost because his series of radiographs for imperfections of ra- } \\ \text { diographic technique was excluded. }\end{array}\end{array}$

\begin{tabular}{lll}
\hline $\begin{array}{l}\text { Selective reporting (re- } \\
\text { porting bias) }\end{array}$ & Low risk & Planned outcomes reported. \\
\hline Other bias & Low risk & Comment: no other source of bias identified. \\
\hline
\end{tabular}

\section{Rao 2014}

Study design: quasi-randomised parallel-group, clinical trial.
Conducted in India.
Number of centres: not reported.
Recruitment period: not reported.
Funding source: not reported.

Participants

148 participants (range 18 to 50 years; males-female not specified, ethnic groups not specified).

Inclusion criteria: root with single uncomplicated canal with full formed apex (anterior teeth), non vital teeth: negative test of pulpal sensitivity by thermal stimuli prior to anaesthesia and no bleeding response on access to the pulp.

Exclusion criteria: patients with multiple teeth that required treatment, non-restorable teeth, teeth affected by periodontal diseases, patients $<18$, affected by systemic diseases, affected by severe pain or acute periapical abscesses, using antibiotics or corticosteriods.

Diagnostic criteria for pulpal or periapical disease: Rx evaluated with PAI score, sensitivity testing.

Group 1: randomised 74, analysed 74 .

Group 2: randomised 74, analysed 74 .

\section{Interventions Group 1: single visit.}

Group 2: multiple visits (2, the second appointment 1 week later the first. In this group in the interappointment period the canal was sealed with a sterile dry cotton pellet and a temporary filling material).

Use of rubber dam isolation, use of magnification loupe not specified. Canal shaping: combination of hand files ( $\mathrm{K}$ files) and ProTaper, engine-driven rotary nickel titanium files using hybrid technique. Irrigation: $2.5 \%$ sodium hypochlorite. Working length evaluated by electronic apex locator and 2 or more angled radiographs. Obturation: gutta-percha cones and resin sealer using lateral condensation technique.

\section{Outcomes}

- Pain 
(Postobturation) using a VAS ( 0 to 4: $0=$ no pain, $1=$ slight pain/discomfort, $2=$ moderate pain relieved by analgesics, $3=$ moderate to severe pain not completely relieved by analgesics, $4=$ severe pain/ swelling not relieved by analgesics and required unscheduled visit) form filled by participants at 6,24 , 48 hours and 7 days after treatment.

- Painkiller use

- Clinical examination after 1 week

\section{Notes}

\section{Risk of bias}

\begin{tabular}{lll}
\hline Bias & Authors' judgement & Support for judgement \\
\hline $\begin{array}{l}\text { Random sequence genera- } \\
\text { tion (selection bias) }\end{array}$ & High risk & $\begin{array}{l}\text { Quote:"the patients were randomly assigned to either the one-visit or two-visit } \\
\text { by using a set of random numbers generated buy one of the investigators. }\end{array}$ \\
\hline $\begin{array}{l}\text { Allocation concealment } \\
\text { (selection bias) }\end{array}$ & Unclear risk & Alternative assignment (randomly and consecutively, quasi-random method). \\
\hline
\end{tabular}

Blinding of outcome as- Low risk Comment: not applicable, radiographic assessment was not among outcomes. sessment (detection bias) All outcomes

$\begin{array}{ll}\begin{array}{l}\text { Incomplete outcome data } \\ \text { (attrition bias) }\end{array} & \begin{array}{l}100 \% \text { of participants }(148 / 148) \text { who entered the study were included in the fi- } \\ \text { nal analysis. }\end{array} \\ \text { All outcomes } & \end{array}$

Selective reporting (re- Unclear risk $\quad$ Not specified.
porting bias)

Other bias Low risk Comment: no other source of bias identified.

Conducted in Brazil.

Number of centres: 1 . Endodontics Clinic of the School of Dentistry of Federal University of Rio de Janeiro, Brazil.

Recruitment period: not reported.

Funding source: Brazilian Grant from CAPES and FAPER. 18 years, mean age 13.6 years).

Inclusion criteria: healthy, no analgesics, antibiotics or anti-inflammatory during the 10 days prior to the beginning of the treatment, age between 11-18 years, lower first or second permanent molar presenting complete root formation and necrotic pulp with or without symptoms, absence of periodontal disease, pulp calcification or acute dento-alveolar abscesses.

Exclusion criteria: age $<11$ or $>18$ years, teeth with haemorrhage in the canal during medication.

Diagnostic criteria for pulp necrosis were determined with pulp testing (Cold test), percussion-palpation, examination and direct observation of the presence or absence of haemorrhage in the canal. 
Risso 2008 (Continued)

Group 1: randomised not specified, analysed 57.

Group 2: randomised not specified, analysed 61.

Interventions

G1: single visit.

G2: multiple visit (2 visits, the second appointment 10-12 days after the first, in the interappointment period the canals were medicated with calcium hydroxide paste and sterile distilled water with lentulo spiral and the complete filling of the canal was verified through periapical radiography. A dry-sterile cotton pad was sealed in the pulp chamber with a minimum of $3 \mathrm{~mm}$ thickness temporary filling restoration (cavit).

Single operator (first author, RPA). Rubber dam isolation, magnification loupes not reported.

Canal shaping: middle coronal preflaring with hand instruments: (initial passive instrumentation and Gates-Glidden burs). Ideal working length determined by an electronic apex locator and periapical radiography. Irrigation: $5.25 \%$ sodium hypochlorite solution, then $10 \%$ citric acid and $5.25 \%$ sodium hypochlorite solution and then $5 \%$ sodium thiosulfate. Obturation with gutta-percha cones using a lateral compaction filling technique as well as zinc oxide. Eugenol-based root canal sealer. Teeth filled with light cured resin.

Outcomes Pain

Preoperative and postoperative measured with VAS ( 0 to 5 : no $=0$, yes $=1-5)$ in a 10 -day period (6-12-24 hours during the first day and then every 24 hours during the 9 following days). VAS equal to 4 or 5 were considered flare-up.

Notes

\section{Risk of bias}

\begin{tabular}{lll}
\hline Bias & Authors' judgement & Support for judgement \\
\hline $\begin{array}{l}\text { Random sequence genera- } \\
\text { tion (selection bias) }\end{array}$ & Low risk & $\begin{array}{l}\text { Quote:" Randomisation was performed using a random numbers listed in a ta- } \\
\text { ble". }\end{array}$ \\
\hline $\begin{array}{l}\text { Allocation concealment } \\
\text { (selection bias) }\end{array}$ & Unclear risk & Not reported. \\
\hline $\begin{array}{l}\text { Blinding of outcome as- } \\
\text { sessment (detection bias) } \\
\begin{array}{l}\text { All outcomes } \\
\text { L }\end{array}\end{array}$ & Low risk & Comment: not applicable, radiographic assessment was not among outcomes. \\
\end{tabular}

\begin{tabular}{|c|c|c|}
\hline $\begin{array}{l}\text { Incomplete outcome data } \\
\text { (attrition bias) }\end{array}$ & Low risk & $\begin{array}{l}121 \text { participants enrolled, } 118 / 121 \text { ( } 97.5 \%) \text { evaluated in the final analysis ( } 3 \\
\text { participants were excluded because they missed the obturation visit). }\end{array}$ \\
\hline
\end{tabular}

All outcomes

Selective reporting (re- High risk Painkiller use not reported in the results.
porting bias)

Other bias Low risk Comment: no other source of bias identified.


Singh 2012 (Continued)

Number of centres: 1. Department of Conservative Dentistry and endodontics, Darshan dental College, Udaipur, Rajasthan, India.

Recruitment period: not reported.

Founding source: not reported.

\section{Participants}

200 participants, 188 included in the final analysis (105 males, 83 females, aged between 20 and 60 years).

Inclusion criteria: participants over 18 years of age, healthy. Only one tooth with a single root of each patient was included.

Exclusion criteria: pregnant patients, patients taking antibiotics or corticosteroids at the time of treatment, affected by complicating systemic diseases or immunocompromised, below 18 years of age. Any tooth with periodontal disease or periapical radiolucency of more than $0.5 \mathrm{~cm}$ was excluded.

Diagnostic criteria for pulp vitality were based on the results of electric pulp tester and by direct clinical observation of haemorrhage in the canal, without considering the clinical diagnosis as being normal pulp, reversible pulpitis or irreversible pulpitis. All teeth had completely formed foramina and no calcified canals, which were preliminary evaluated by preoperative periapical radiographs.

Group 1: 100 participants, analysed 94.

Group 2: 100 participants, analysed 94.

G2: multiple visit (2 visits, the second appointment 7 days after the first, no intracanalar medication in the interappointment period but a dry-sterile cotton pellet was placed in the pulp chamber and the access was sealed with a temporary filling restoration, Cavit-G).

Rubber dam isolation or use of magnification loupes not reported. Working length determined by electronic apex locator.

Canal shaping: combination of hand files and ProTaper engine-driven rotary nickel titanium files. RC prep used as lubricant. Irrigation: $2.5 \%$ sodium hypochlorite. Obturation: ProTaper universal gutta-percha and $\mathrm{AH}$ plus sealer using lateral compaction technique and restored with temporary restorative material, Cavit-G.

$\begin{array}{ll}\text { Outcomes } & \text { Pain } \\ \text { Preoperative and postobturation at 6, 12, } 24 \text { and } 48 \text { hours after obturation) measured with Heft Parker } \\ \text { VAS. }\end{array}$

VAS.

Notes

\section{Risk of bias}

\section{Bias \\ Authors' judgement Support for judgement}

Random sequence genera- Low risk tion (selection bias)
Quote "Patients were randomly assigned to either one-or two-visit treatment by biased coin randomisation, a dynamic randomisation method, which was specially designed to get the same number in both groups and the sequence..."

$\begin{array}{ll}\begin{array}{l}\text { Allocation concealment } \\ \text { (selection bias) }\end{array} & \text { Low risk } \\ & \text { who was blind to the nature of the study". }\end{array}$


Singh 2012 (Continued)

Incomplete outcome data Low risk 12/200 participants (6\%, 6 from each group) were excluded from the study be(attrition bias) cause they did not attend the recall visits.

All outcomes

Selective reporting (re- $\quad$ Low risk $\quad$ Outcome reported.
porting bias)

Other bias Low risk Comment: no other source of bias identified.

Soltanoff 1978

Study design: randomised, parallel group clinical trial.
Conducted in USA.
Number of centres: 1 . Department of Endodontics, New Jersey Dental School, USA.
Recruitment period: 20 years.
Funding source: not reported.

Participants 330 participants (sex, range or mean age, ethnic group not reported).

Inclusion and exclusion criteria not reported.

Diagnostic criteria for pulpally or periapical disease not specified.

Group 1: 135 randomised; analysed 88 (pain) and 80 (radiographical healing).

Group 2: 195 randomised; analysed 193 (pain) and 186 (radiographical healing).

Interventions Group 1: single visit.

Group 2: multiple visits (the medication and the total number of visits were not specified).

Rubber dam, use of magnification loupes and working length not reported. Canal shaping using root canal files.

In both groups, sterile saline solution was used as irrigation, the canals were filled with gutta-percha cones and Ostby's Kloroperka as the cementing medium for lateral condensation.

- Pain
Incidence, severity and duration: less than 1 day, 1 to 3 days, 4 to 7 days, more than 1 week. Pain was
categorised as no pain, mild pain, moderate pain, severe pain. We considered only 2 categories: no pain
and pain (mild, moderate, severe pain).
- Painkiller use
- Healing
Observed radiographically in periods ranging from 6 months to 2 years postoperatively. The criteria for
success or failure were: healed (success) and non-healed (failure).

Notes

\section{Risk of bias}


Soltanoff 1978 (Continued)

Random sequence genera- Low risk Quote:" Cases selected at random are the basis of this report". tion (selection bias)

\begin{tabular}{lll}
\hline $\begin{array}{l}\text { Allocation concealment } \\
\text { (selection bias) }\end{array}$ & Unclear risk & Not reported. \\
\hline $\begin{array}{l}\text { Blinding of outcome as- } \\
\text { sessment (detection bias) } \\
\text { All outcomes }\end{array}$ & Unclear risk & Not reported. \\
\hline
\end{tabular}

Incomplete outcome data Low risk

$85.1 \%$ of participants who entered the study were included in the final analysis

(attrition bias) about pain and use of painkillers, $80.6 \%$ of participants who entered the study

All outcomes were included in the final analysis about healing.

Selective reporting (re- Low risk Planned outcomes reported.

porting bias)

Other bias Low risk Comment: no other source of bias identified.

Trope 1999

Study design: randomised, parallel group clinical trial.
Conducted in USA.
Number of Centres: 1 . School of Dentistry, University of North Carolina, USA.
Recruitment period: not reported.
Funding source: not reported.

Participants 81 participants (54 females and 27 males had a mean age of 44.6 years, with a range of 19 to 79 ) with 102 teeth (61 participants had a single teeth to treat, 18 had 2, 2 had 3).

Inclusion criteria: presence of radiographically demonstrable apical periodontitis on a single-rooted tooth or on 1 root with a single canal in a multi-rooted tooth.

Exclusion criteria: patients with diagnosis of diabetes, HIV infection or other immunocompromising disease, patients $<16$ or $>80$ years old and teeth with $2 / 3$ of the root canal treated before enrolment.

Group 1: 45 single visits.

Group 2: 57 multiple visits.

Interventions

Group 1: single visit.

Group 2: multiple visits without any dressing (the instrumentation was completed at the first appointment, the canal was left empty, the treatment was completed after 1 week). 1 operator, 9 observers ( 4 graduate oral and maxillofacial radiology residents, 2 graduate endodontic residents, 1 oral epidemiologist, 1 general dentist, 1 experienced endodontist) to evaluated radiographs using the PAl scoring system.

Rubber dam isolation used. Use of magnification loupes and canal shaping not specified in a satisfactory way. Irrigation with $2.5 \%$ sodium hypochlorite. Working length evaluated by Rx, obturation with gutta-percha and Roth 801 sealer in lateral condensation.

Outcomes Healing


Trope 1999 (Continued)

Follow-up 52 weeks. The criteria for success or failure were the following: success (PAI 1 or 2), failure

(PAl 3, 4, 5) (see Table 1).

Notes

\section{Risk of bias}

\begin{tabular}{|c|c|c|}
\hline Bias & Authors' judgement & Support for judgement \\
\hline $\begin{array}{l}\text { Random sequence genera- } \\
\text { tion (selection bias) }\end{array}$ & Low risk & $\begin{array}{l}\text { Quote: "The patients were assigned to a treatment group by the throwing of a } \\
\text { die". }\end{array}$ \\
\hline $\begin{array}{l}\text { Allocation concealment } \\
\text { (selection bias) }\end{array}$ & Low risk & Unclear who performed the throw of a dice. \\
\hline $\begin{array}{l}\text { Blinding of outcome as- } \\
\text { sessment (detection bias) } \\
\text { All outcomes }\end{array}$ & Low risk & $\begin{array}{l}\text { Quote "The } 9 \text { observers that participated in the study (...) were all blinded to } \\
\text { the treatment groups and aims of the study". }\end{array}$ \\
\hline $\begin{array}{l}\text { Incomplete outcome data } \\
\text { (attrition bias) } \\
\text { All outcomes }\end{array}$ & Low risk & $100 \%$ of patients who entered the study were included in the final analysis. \\
\hline $\begin{array}{l}\text { Selective reporting (re- } \\
\text { porting bias) }\end{array}$ & Low risk & Planned outcomes reported. \\
\hline Other bias & High risk & $\begin{array}{l}\text { It is not explicitly stated that participants with more that one tooth needing } \\
\text { treatment, were randomised the same number of times. }\end{array}$ \\
\hline
\end{tabular}

Wang 2010

Methods

Study design: Randomised parallel-group, clinical study.

Conducted in: China.

Number of Centres: 1. Endodontic Centre, West China Dental Hospital Sichuan University, China.

Recruitment period: 3 years.

Founding source: not reported.

\section{Participants}

100 patients ( 56 women, 44 men, aged 20 to 60 years).

Inclusion criteria: Patients over 18 years of age with vital single-rooted teeth with preoperative vital pulps. One tooth only for each participant.

Exclusion criteria: Pregnant patients, patients taking antibiotics or corticosteroids at the time of treatment, with immuno-compromised, complicating systemic disease or under 18 years of age. Any tooth with periodontal disease or periapical pathosis was also excluded.

Diagnostic criteria for pulpal vitality based on electric pulp tester and thermal test. Vitality of pulps was confirmed by direct clinical observation of haemorrhage in the canal. All teeth had completely formed foramina and no calcified canals, evaluated with preoperative radiography.

Group 1: 50 participants randomised, analysed 43.

Group 2: 50 participants randomised, analysed 46.

Interventions Group 1: One visit.


Wang 2010 (Continued)

Group 2: Multiple visit (2 appointments, the second 1 week later the first, intermedication with calcium hydroxide paste, a sterile dry cotton pellet and $3.0 \mathrm{~mm}$ of Caviton).

Two experienced operators. Rubber dam isolation or use of magnification loupes not reported.

Canal shaping: combination of hand files and ProTaper engine-driven rotary nickel titanium files. Irrigation: $2.5 \%$ sodium hypochlorite. Working length verified using Root ZX II apex locator. Obturation: ProTaper universal gutta-percha and $\mathrm{AH}$ plus sealer, using a lateral compaction technique.

- Pain
(Verbal descriptor scale-VDS: preoperative and postoperative at 6-24-48 $\mathrm{h}$ and $1 \mathrm{week}$ after the treat-
ment). Pain categorised as no pain, slight pain, moderate pain, strong pain, severe pain, maximum
pain.
- Flare-up and swelling

Notes

\section{Risk of bias}

\begin{tabular}{|c|c|c|}
\hline Bias & Authors' judgement & Support for judgement \\
\hline $\begin{array}{l}\text { Random sequence genera- } \\
\text { tion (selection bias) }\end{array}$ & Low risk & $\begin{array}{l}\text { Quote "Patients were randomly assigned to either one-or two-visit treatment } \\
\text { by biased coin randomisation, a dynamic randomisation method, which was } \\
\text { specially design to get the same number in both groups and the sequence... " }\end{array}$ \\
\hline $\begin{array}{l}\text { Allocation concealment } \\
\text { (selection bias) }\end{array}$ & Low risk & $\begin{array}{l}\text { Quote:"...tossing coin and allocation were operated by someone who was a } \\
\text { graduate student and was not aware of the nature of the study". }\end{array}$ \\
\hline $\begin{array}{l}\text { Blinding of outcome as- } \\
\text { sessment (detection bias) } \\
\text { All outcomes }\end{array}$ & Low risk & Comment: not applicable, radiographic assessment was not among outcomes. \\
\hline $\begin{array}{l}\text { Incomplete outcome data } \\
\text { (attrition bias) } \\
\text { All outcomes }\end{array}$ & Low risk & $\begin{array}{l}11 / 100(11 \%) \text { were excluded from the study. } \\
11 \text { patients ( } 7 \text { from Group } 1 \text { and } 4 \text { from Group } 2 \text { ) were excluded from the analy- } \\
\text { sis: } 7 \text { ( } 5 \text { from } G 1 \text { and } 2 \text { from } G 2 \text { ) did not attend the recall visits, } 2 \text { ( } 1 \text { from } G 1 \text { and } \\
1 \text { from } G 2 \text { ) failed to return the forms used to monitor postobturation pain, and } \\
2 \text { ( } 1 \text { from } G 1 \text { and } 1 \text { from } G 2 \text { ) had more than one root canal. }\end{array}$ \\
\hline
\end{tabular}

Selective reporting (re- Low risk Outcome reported.
porting bias)
Other bias
Low risk
Comment: no other source of bias identified.

Weiger 2000

Methods

Study design: Randomised, parallel group clinical trial.

Conducted in: Germany.

Number of Centres: 1. Department of Conservative Dentistry, University of Tubingen, Germany.

Recruitment period: Duration of the study: 5 years.

Funding source: not reported. 
Weiger 2000 (Continued)

Participants
73 participants recruited, 67 entered final analysis ( 37 females and 30 males, mean age 38 years range: 11 to 84$)$.

Inclusion criteria: teeth with periapical lesion radiographically demonstrated and where the vitality test was negative; in each patients only 1 tooth was selected.

Exclusion criteria: teeth having pockets communicated with the lesion, teeth treated previously, patients that had taken antibiotics 4 weeks prior to the treatment.

Diagnostic criteria for pulpally or periapical disease: Rx and vitality test.

Group 1: randomised not specified, analysed 36.

Group 2: randomised not specified, analysed 31.
Interventions
Group 1: Single visit.

Group 2: Multiple visits (2 visits, the interappointment medication used was calcium hydroxide mixed with sterile physiological saline, that was left in the canals for 7-47 days. The cavity access was filled by a temporary cement).

2 operators (experienced endodontists). Use of rubber dam isolation. Use of magnification loupes not reported. Canal shaping: K- files and Gates Glidden used in step-back technique. Irrigation: $1 \%$ sodium hypochlorite. Working length determined by Rx. Obturation: gutta-percha with Sealapex in lateral condensation.
Follow-up 5 years. The criteria for success or failure were the following in the paper: complete healing, incomplete healing, no healing. The radiographs were judged by both dentists involved in the study by using a magnifying glass and a light box. The operators did not know whether the tooth belonged to the 1-visit or the 2-visit group. In case of disagreement a joint decision was made. We considered only 2 categories: success (complete healing) and failure (incomplete healing and no healing).

\section{Notes}

\section{Risk of bias}

\begin{tabular}{lll}
\hline Bias & Authors' judgement & Support for judgement \\
\hline $\begin{array}{l}\text { Random sequence genera- } \\
\text { tion (selection bias) }\end{array}$ & Low risk & $\begin{array}{l}\text { Quote: " The allocation of the tooth modality followed the method of mini- } \\
\text { mization to balance the two groups of teeth with regard to the criterion tooth } \\
\text { type". }\end{array}$ \\
\hline $\begin{array}{l}\text { Allocation concealment } \\
\text { (selection bias) }\end{array}$ & Unclear risk & Not reported. \\
\hline $\begin{array}{l}\text { Blinding of outcome as- } \\
\text { sessment (detection bias) } \\
\text { All outcomes }\end{array}$ & Low risk & $\begin{array}{l}\text { Quote: "The radiographs were judged by both dentists involved in the study, } \\
\text { the operators did not know whether the tooth belonged to the one-visit or the } \\
\text { two-visits group". }\end{array}$ \\
\hline $\begin{array}{l}\text { Incomplete outcome data } \\
\text { (attrition bias) } \\
\text { All outcomes }\end{array}$ & Low risk & $\begin{array}{l}\text { 91.7\% of participants who entered the study were included in the final analy- } \\
\text { sis. } \\
6 \text { patients lost at follow-up (5 did not return at recall appointments, } 1 \text { de- } \\
\text { ceased prior to the first scheduled recall rate). }\end{array}$ \\
\hline $\begin{array}{l}\text { Selective reporting (re- } \\
\text { porting bias) }\end{array}$ & Low risk & \begin{tabular}{l} 
Outcome reported. \\
\hline
\end{tabular}
\end{tabular}


Weiger 2000 (Continued)
Other bias
Low risk
Comment: no other source of bias identified.

Wong 2015

Study design: Randomised, parallel group clinical trial.
Conducted in: China.
Number of Centres: 1 . Health Service Dental Clinic of the University of Hong Kong.
Recruitment period: 30 months.
Funding source: not reported.

Participants

256 teeth from 228 participants: 115 in group 1 and 113 in group 2. A total of 194 participants with 220 teeth entered final analysis ( 85 males, 135 females, aged from $46.38 \pm 14.06$ ).

Inclusion criteria: participants without history of periodontitis, tooth that required primary endodontic treatment was periodontally healthy and at least half of the coronal structure had to be remaining.

Exclusion criteria: teeth with pulpotomy, participants who had severe acute pulpitis with facial swelling or systemic infection, severe systemic disease, increased stress on the temporomandibular joint musculature or increased psychological stress.

Group 1: randomised 128 teeth from 115 participants, analysed 117 teeth from 105 participants.

Group 2: randomised 128 teeth from 113 participants, analysed 103 teeth from 89 participants.

Interventions

Two general dentists carried out the endodontic treatments. Rubber dam isolation. One of the operator was trained to use a magnifying loupe (2.5x). The two dentists received a calibration workshop prior to this clinical trial to standardise the instrumentation and obturation technique.

The root canals were cleaned and shaped using Ni-Ti rotary files. A $5.25 \%$ sodium hypochlorite was used for irrigation.Temporary restoration was made using a resin-modified zinc oxide and eugenol cement until obturation. All teeth were obturated using a core-carrier technique. The total chairside time was recorded by the dental assistant. The treated teeth were restored with silver amalgam or composite resin. All patients were reviewed 1 week after obturation, and were advised to have indirect extracoronal restoration (partial or full veneer) to avoid failure due to extra-coronal leakage or tooth fracture.

Group 1: One visit.

Group 2: Multiple visits (2 or 3 appointments, depending on the complexity of the treatment, the second one scheduled one week after the first). A non-setting $5 \%$ calcium hydroxide paste was used as interappointment medication.

Outcomes Success or failure of endodontic treatment

(Success was graded as no clinical signs/symptoms and no radiographic radiolucency found in the periapical radiograph).

- Pain at 1 week after obturation: 10-point Likert scale (0 to 10)

- Radiological assessment according to Chu 2005, based on absence-presence of periapical radiolucency (see Table 1). Multiple-rooted teeth with different periapical statuses at different roots were classified according to the most severe periapical condition. 
Wong 2015 (Continued)

Risk of bias

\begin{tabular}{|c|c|c|}
\hline Bias & Authors' judgement & Support for judgement \\
\hline $\begin{array}{l}\text { Random sequence genera- } \\
\text { tion (selection bias) }\end{array}$ & Low risk & $\begin{array}{l}\text { Quote: "The treated teeth were randomly assigned to either single-visit or mul- } \\
\text { tiple-visit treatments using the random-number generating function of a cal- } \\
\text { culator". }\end{array}$ \\
\hline $\begin{array}{l}\text { Allocation concealment } \\
\text { (selection bias) }\end{array}$ & Low risk & $\begin{array}{l}\text { Quote: "patients were randomly assigned by the receptionist for endodontic } \\
\text { treatment". }\end{array}$ \\
\hline $\begin{array}{l}\text { Blinding of outcome as- } \\
\text { sessment (detection bias) } \\
\text { All outcomes }\end{array}$ & Low risk & $\begin{array}{l}\text { Quote: "A number unknown to the operators and the independent assessor } \\
\text { was given to each treated tooth for clinical and radiographic assessment, data } \\
\text { entry and analysis". }\end{array}$ \\
\hline $\begin{array}{l}\text { Incomplete outcome data } \\
\text { (attrition bias) } \\
\text { All outcomes }\end{array}$ & High risk & 36 teeth (14.6) from 34 patients (14.1\%) were lost at follow at follow-up. \\
\hline $\begin{array}{l}\text { Selective reporting (re- } \\
\text { porting bias) }\end{array}$ & Low risk & Outcomes reported. \\
\hline Other bias & Low risk & Comment: no other source of bias identified. \\
\hline
\end{tabular}

Xiao 2010

Methods Study design: Randomised, parallel group clinical trial.

Conducted in: China.

Number of Centres: 1. Shijitan Hospital of Beijing, Beijing, China.

Recruitment period: February 2005 to February 2006.

Funding source: not reported.

Participants

138 teeth from 86 participants: 76 in group 1 and 62 in group 2.

Not clear the exact number of males and females who were enrolled in the study.

Inclusion criteria: tooth with pulp necrosis, acute or chronic periapical periodontitis and had only one root canal.

Exclusion criteria: tooth with out-of-control intra-root canal exudation, periapical periodontitis with space infection, retreatment, resorption of the alveolar bone which exceeded $1 / 2$ of the root, patients with systemic disease and that could not keep follow-up.

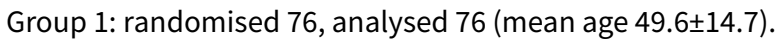

Group 2: randomised 62, analysed 62 (mean age 45.7 \pm 13.7 ).

Interventions Group 1: One visit.

Group 2: Multiple visit (2 appointments, the second 1 week later the first, interappointment medication with calcium hydroxide paste).

Use of rubber dam and magnification loupes not specified. 
Xiao 2010 (Continued)

Root canal was prepared with ProTaper, work length was detected by Root-ZX, irrigated with $2 \%$ sodium hypochlorite. The restorative materials were Cortisomol and gutta-percha.

\begin{tabular}{|c|c|}
\hline Outcomes & $\begin{array}{l}\text { - Pain } \\
\text { Evaluated before treatment, immediately after treatment and } 7 \text { days after treatment. } \\
\text { - Cured } \\
\text { No symptom, well-functioned, no clinical sign, PAl level was } 1 \text { to } 2 \text {. } \\
\text { - Relieved } \\
\text { No symptom, well-functioned, no clinical sign, PAl level stayed the same or decreased. } \\
\text { - Failed } \\
\text { Symptoms, with red or swelling of the periapical area, sinus formation, tenderness and periapical indis- } \\
\text { posed after percussion. PAl level increased. }\end{array}$ \\
\hline Notes & $\begin{array}{l}\text { Healing: authors evaluated the treatment outcome as: cured (no symptom, well-functioned, no clini- } \\
\text { cal sign, PAI level was 1-2), relieved (no symptom, well-functioned, no clinical sign, PAI level stayed the } \\
\text { same or decreased), failed (with symptom, with red or swelling of the periapical area, sinus formation, } \\
\text { tenderness and periapical indisposed after percussion. PAl level increased). } \\
\text { Pain postobturation as reported by participant, measured by VAS and than dichotomised, and after } \\
\text { percussion test immediately after treatment and } 7 \text { days after the treatment. }\end{array}$ \\
\hline
\end{tabular}

\section{Risk of bias}

\begin{tabular}{|c|c|c|}
\hline Bias & Authors' judgement & Support for judgement \\
\hline $\begin{array}{l}\text { Random sequence genera- } \\
\text { tion (selection bias) }\end{array}$ & Low risk & Quote: all the participants were allocated by tossing coins. \\
\hline $\begin{array}{l}\text { Allocation concealment } \\
\text { (selection bias) }\end{array}$ & Low risk & Quote: all the participants were allocated by tossing coins. \\
\hline $\begin{array}{l}\text { Blinding of outcome as- } \\
\text { sessment (detection bias) } \\
\text { All outcomes }\end{array}$ & Low risk & $\begin{array}{l}\text { Quote: the x-rays of pretreatment, } 6 \text { months, } 1 \text { year and } 2 \text { years were num- } \\
\text { bered and were assessed by } 2 \text { radiologists and a clinician blindly. Thus, on- } \\
\text { ly one component (x-ray evaluation) of the composite outcome (healing) was } \\
\text { blinded to the assessors. }\end{array}$ \\
\hline $\begin{array}{l}\text { Incomplete outcome data } \\
\text { (attrition bias) } \\
\text { All outcomes }\end{array}$ & Low risk & $100 \%$ of participants who entered the study were included in the final analysis. \\
\hline $\begin{array}{l}\text { Selective reporting (re- } \\
\text { porting bias) }\end{array}$ & Low risk & Outcomes reported. \\
\hline Other bias & High risk & $\begin{array}{l}\text { Participants with more that one tooth needing RoCT were treated alternatively } \\
\text { with the two methods. }\end{array}$ \\
\hline
\end{tabular}

Yoldas 2004

Methods $\quad$ Study design: Randomised, parallel group clinical trial.
Conducted in: Turkey.


Yoldas 2004 (Continued)

Number of Centres: 1. Department of Conservative Dentistry and Endodontics, Faculty of Dentistry, University of Cukurova, Turkey.

Recruitment period: 2 years.

Funding source: not reported.

\section{Participants}

227 participants (sex and ethnic group not reported; age over 18 years).

Inclusion criteria: teeth with inadequate root canal filling.

Exclusion criteria: patients with complicating systemic disease, severe pain or acute apical abscess or both, under 18 years of age, use of antibiotics or corticosteroids, multiple teeth requiring retreatment, root canals that could not be treated well with initial RoCT.

Diagnostic criteria for pulpal or periapical disease: evaluation of periapical status with Rx evaluated by 1 author according to PAI.

Group 1: randomised 115, analysed 106.

Group 2: randomised 112, analysed 112

9 patients ( 7 from Group 1 and 2 from Group 2) were excluded from the study because did not participate to recall visits.

Interventions Group 1: Single visit.

Group 2: Multiple visits (2 visits, the second appointment 7 days after the first). The canals in the interappointment period were medicated with calcium hydroxide chlorhexidine paste and closed with a sterile dry cotton pellet and a temporary restorative material (Cavit) for 7 days).

3 operators. Use of rubber dam and magnification loupes not specified. Canal shaping with Gates Glidden, hand files nickel titanium rotary instruments with step-back technique. Irrigation: $2.5 \%$ sodium hypochlorite. Working length: determined by apexes locator and periapical radiograph. Obturation: gutta-percha and AH 26 sealer with lateral condensation.

- Pain
(1 week after initial appointment the patients were recalled and asked about the occurrence
operative pain): the level of discomfort was rated as follows: no pain, mild pain, moderate pain
pain. We considered only 2 categories: no pain, pain (mild, moderate, severe).
- Flare-up
Participants with severe postoperative pain or occurrence of swelling or both (see Table 2).
- Painkiller use

Notes

\section{Risk of bias}

\begin{tabular}{lll}
\hline Bias & Authors' judgement & Support for judgement \\
\hline $\begin{array}{l}\text { Random sequence genera- } \\
\text { tion (selection bias) }\end{array}$ & High risk & $\begin{array}{l}\text { Quote: "randomisation of assignment into the treatment groups was made by } \\
1 \text { author according to the PAl, the tooth type and patient symptoms". }\end{array}$ \\
\hline $\begin{array}{l}\text { Allocation concealment } \\
\text { (selection bias) }\end{array}$ & High risk & Assigment by 1 of the authors. \\
\hline
\end{tabular}

Blinding of outcome as- Low risk Comment: not applicable, radiographic assessment was not among outcomes. sessment (detection bias) 
Yoldas 2004 (Continued)

All outcomes

\begin{tabular}{lll}
\hline $\begin{array}{l}\text { Incomplete outcome data } \\
\text { (attrition bias) } \\
\text { All outcomes }\end{array}$ & Low risk & $\begin{array}{l}\text { 218/227 (96\%) of participants who entered the study were included in the final } \\
\text { analysis. }\end{array}$ \\
\hline $\begin{array}{l}\text { Selective reporting (re- } \\
\text { porting bias) }\end{array}$ & Low risk & Outcomes reported. \\
\hline Other bias & Low risk & Comment: no other source of bias identified. \\
\hline
\end{tabular}

AH-26 and AH-plus: root canal filling and sealer materials

EDTA: ethylene-diamine-tetraacetic acid

ISO: International Organization for Standardization

M\&M: material and methods

PAl: periapical index

RC-prep: chemo-mechanical preparation for root canals

RC-help: lubricating paste for root canals

Rx: radiological evaluation

VAS: visual analogue scale

Root-ZX: apex locator

Characteristics of excluded studies [ordered by study ID]

\begin{tabular}{|c|c|}
\hline Study & Reason for exclusion \\
\hline ElMubarak 2010 & This study is not randomised or quasi-randomised. \\
\hline Fava 1989 & This study is not randomised or quasi-randomised. \\
\hline Fava 1994 & $\begin{array}{l}\text { This study design was unclear. We sent an e-mail to authors asking for more details about their } \\
\text { randomisation method but we did not consider the answer satisfactory to consider the paper ran- } \\
\text { domised or quasi-randomised. }\end{array}$ \\
\hline Friedman 1995 & This study is not randomised or quasi-randomised. \\
\hline Gurgel-Filho 2007 & This study evaluates only the microbiological aspects of RoCT. \\
\hline Holland 2003 & This study evaluates single versus multiple-visit RoCT in dogs. \\
\hline Jabeen 2014 & This study is not randomised or quasi-randomised. \\
\hline Kabaktchieva 2013 & The study included children and primary teeth. \\
\hline Kvist 2004 & This study evaluates only the microbiological aspects of RoCT. \\
\hline Ng 2004 & This study is not randomised or quasi-randomised. \\
\hline Orhan 2010 & The study included children and primary teeth. \\
\hline Papworth B 1998 & This study is not randomised or quasi-randomised. \\
\hline Prashanth 2011 & The study is not randomised or quasi-randomised. \\
\hline Roane 1983 & This study is not randomised or quasi-randomised. \\
\hline
\end{tabular}




\begin{tabular}{ll}
\hline Study & Reason for exclusion \\
\hline Silveira 2007 & This study evaluates single versus multiple-visit RoCT in dogs. \\
\hline Trusewicz 2005 & This study considers only the microbiological aspects of RoCT. \\
\hline Vera 2012 & This study evaluates only the microbiological aspects of RoCT. \\
\hline Waltimo 2005 & The study does not include any of the outcomes considered in the review. \\
\hline Walton 1992 & This study is not randomised or quasi-randomised. \\
\hline Xavier 2013 & This study evaluates only the microbiological aspects of RoCT. \\
\hline
\end{tabular}

RoCT: root canal treatment

DATA AND ANALYSES

Comparison 1. Single versus multiple visits for endodontic treatment of permanent teeth - primary outcomes

\begin{tabular}{lllll}
\hline Outcome or subgroup title & No. of studies & $\begin{array}{l}\text { No. of partici- } \\
\text { pants }\end{array}$ & Statistical method & Effect size \\
\hline $\begin{array}{l}1 \text { Extraction due to endodontic } \\
\text { problems }\end{array}$ & 1 & & $\begin{array}{l}\text { Risk Ratio (M-H, Random, 95\% } \\
\text { Cl) }\end{array}$ & Totals not selected \\
\hline $\begin{array}{llll}\text { 2 Radiological failure } \\
\text { 2.1 Radiological failure }\end{array}$ & 11 & $\begin{array}{l}\text { Risk Ratio (M-H, Random, 95\% } \\
\text { Cl) }\end{array}$ & Subtotals only \\
\hline $\begin{array}{l}\text { 2.2 Radiological failure in necrot- } \\
\text { ic teeth }\end{array}$ & 8 & 1493 & $\begin{array}{l}\text { Risk Ratio (M-H, Random, 95\% } \\
\text { Cl) }\end{array}$ & $0.91[0.68,1.21]$ \\
\hline
\end{tabular}

Analysis 1.1. Comparison 1 Single versus multiple visits for endodontic treatment of permanent teeth - primary outcomes, Outcome 1 Extraction due to endodontic problems.

\begin{tabular}{|c|c|c|c|c|c|c|c|}
\hline Study or subgroup & $\begin{array}{l}\text { Single visit } \\
\mathrm{n} / \mathrm{N}\end{array}$ & $\begin{array}{c}\text { Multiple visits } \\
\mathrm{n} / \mathrm{N}\end{array}$ & & M-H, & $\begin{array}{l}\text { Ratio } \\
\text { dom, } 95 \% \mathrm{Cl}\end{array}$ & & $\begin{array}{c}\text { Risk Ratio } \\
\text { M-H, Random, } 95 \% \mathrm{CI}\end{array}$ \\
\hline Wong 2015 & $1 / 117$ & $2 / 103$ & & 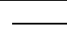 & 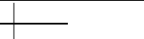 & & $0.44[0.04,4.78]$ \\
\hline
\end{tabular}


Analysis 1.2. Comparison 1 Single versus multiple visits for endodontic treatment of permanent teeth - primary outcomes, Outcome 2 Radiological failure.

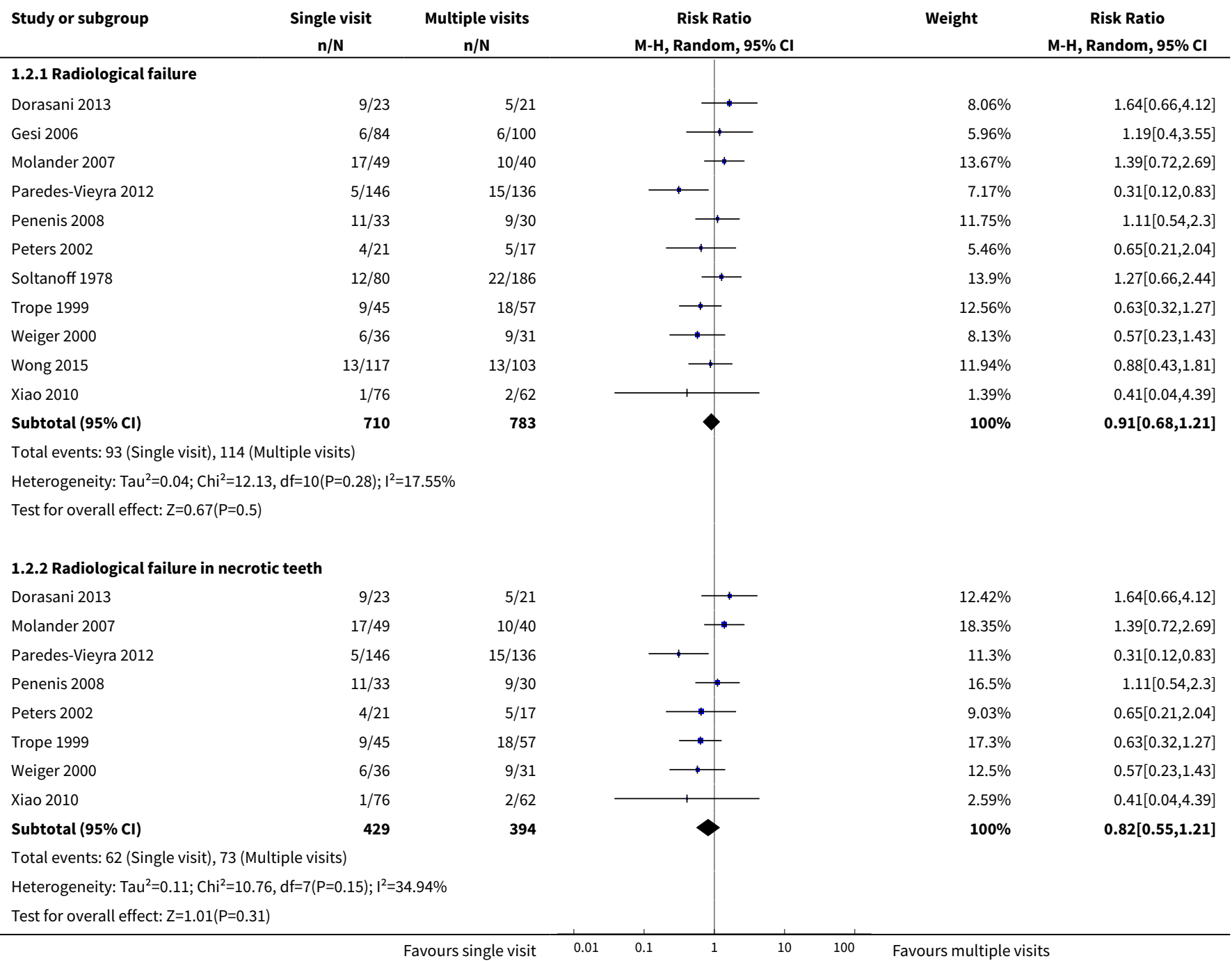

\section{Comparison 2. Single versus multiple visits for endodontic treatment of permanent teeth - secondary outcomes}

\begin{tabular}{lllll}
\hline Outcome or subgroup title & No. of studies & $\begin{array}{l}\text { No. of partici- } \\
\text { pants }\end{array}$ & Statistical method & Effect size \\
\hline 1 Pain (dichotomous) & 12 & & $\begin{array}{l}\text { Risk Ratio (M-H, Random, } \\
95 \% \mathrm{Cl} \text { ) }\end{array}$ & Subtotals only \\
\hline $\begin{array}{l}1.1 \text { Pain in the immediate postopera- } \\
\text { tive period (until 72 hours postobtu- } \\
\text { ration) }\end{array}$ & 9 & 1560 & $\begin{array}{l}\text { Risk Ratio (M-H, Random, } \\
95 \% \mathrm{Cl})\end{array}$ & $0.99[0.84,1.17]$ \\
\hline $\begin{array}{l}1.2 \text { Pain in the immediate postopera- } \\
\text { tive period in necrotic teeth (until } 72 \\
\text { hours postobturation) }\end{array}$ & 6 & 718 & $\begin{array}{l}\text { Risk Ratio (M-H, Random, } \\
95 \% \mathrm{Cl})\end{array}$ & $0.84[0.62,1.16]$ \\
\hline
\end{tabular}




\begin{tabular}{|c|c|c|c|c|}
\hline Outcome or subgroup title & No. of studies & $\begin{array}{l}\text { No. of partici- } \\
\text { pants }\end{array}$ & Statistical method & Effect size \\
\hline $\begin{array}{l}1.3 \text { Pain in the immediate postoper- } \\
\text { ative period in vital teeth (until } 72 \\
\text { hours postobturation) }\end{array}$ & 3 & 318 & $\begin{array}{l}\text { Risk Ratio (M-H, Random, } \\
95 \% \mathrm{Cl})\end{array}$ & $1.04[0.86,1.27]$ \\
\hline 1.4 Pain at 1 week & 8 & 1383 & $\begin{array}{l}\text { Risk Ratio (M-H, Random, } \\
95 \% \mathrm{Cl} \text { ) }\end{array}$ & $1.50[0.99,2.28]$ \\
\hline 1.5 Pain at 1 week in necrotic teeth & 2 & 172 & $\begin{array}{l}\text { Risk Ratio (M-H, Random, } \\
95 \% \mathrm{Cl})\end{array}$ & $0.70[0.17,2.85]$ \\
\hline 1.6 Pain at 1 week in vital teeth & 1 & 89 & $\begin{array}{l}\text { Risk Ratio (M-H, Random, } \\
95 \% \mathrm{Cl} \text { ) }\end{array}$ & $1.40[0.78,2.52]$ \\
\hline 1.7 Pain at 1 month & 2 & 513 & $\begin{array}{l}\text { Risk Ratio (M-H, Random, } \\
95 \% \mathrm{Cl} \text { ) }\end{array}$ & $0.0[0.0,0.0]$ \\
\hline 1.8 Pain at 18 months & 1 & 220 & $\begin{array}{l}\text { Risk Ratio (M-H, Random, } \\
95 \% \mathrm{Cl} \text { ) }\end{array}$ & $0.88[0.06,13.90]$ \\
\hline 2 Pain (continuous) & 4 & & $\begin{array}{l}\text { Mean Difference (IV, Random, } \\
95 \% \mathrm{CI} \text { ) }\end{array}$ & Subtotals only \\
\hline $\begin{array}{l}2.1 \text { Pain in the immediate postopera- } \\
\text { tive period (until } 72 \text { hours postobtu- } \\
\text { ration) }\end{array}$ & 4 & 414 & $\begin{array}{l}\text { Mean Difference (IV, Random, } \\
95 \% \mathrm{CI} \text { ) }\end{array}$ & $0.12[-0.59,0.82]$ \\
\hline $\begin{array}{l}\text { 2.2 Pain in the immediate postopera- } \\
\text { tive period in necrotic teeth (until } 72 \\
\text { hours postobturation) }\end{array}$ & 3 & 158 & $\begin{array}{l}\text { Mean Difference (IV, Random, } \\
95 \% \mathrm{CI} \text { ) }\end{array}$ & $-0.21[-0.44,0.03]$ \\
\hline $\begin{array}{l}2.3 \text { Pain in the immediate postoper- } \\
\text { ative period in vital teeth (until } 72 \\
\text { hours postobturation) }\end{array}$ & 1 & 30 & $\begin{array}{l}\text { Mean Difference (IV, Random, } \\
95 \% \mathrm{CI} \text { ) }\end{array}$ & $0.60[-1.03,2.23]$ \\
\hline 3 Swelling or flare-up & 4 & & $\begin{array}{l}\text { Risk Ratio (M-H, Random, } \\
95 \% \mathrm{Cl} \text { ) }\end{array}$ & Subtotals only \\
\hline 3.1 Swelling or flare-up & 4 & 281 & $\begin{array}{l}\text { Risk Ratio (M-H, Random, } \\
95 \% \mathrm{Cl})\end{array}$ & $1.36[0.66,2.81]$ \\
\hline $\begin{array}{l}3.2 \text { Swelling or flare-up in necrotic } \\
\text { teeth }\end{array}$ & 2 & 120 & $\begin{array}{l}\text { Risk Ratio (M-H, Random, } \\
95 \% \mathrm{Cl} \text { ) }\end{array}$ & $1.52[0.70,3.31]$ \\
\hline 3.3 Swelling or flare-up in vital teeth & 1 & 89 & $\begin{array}{l}\text { Risk Ratio (M-H, Random, } \\
95 \% \mathrm{Cl} \text { ) }\end{array}$ & $1.07[0.07,16.57]$ \\
\hline 4 Painkiller use & 4 & 648 & $\begin{array}{l}\text { Risk Ratio (M-H, Random, } \\
95 \% \mathrm{Cl} \text { ) }\end{array}$ & $2.35[1.60,3.45]$ \\
\hline 5 Persistent sinus track or fistula & 2 & 345 & $\begin{array}{l}\text { Risk Ratio (M-H, Random, } \\
95 \% \mathrm{Cl} \text { ) }\end{array}$ & $0.98[0.15,6.48]$ \\
\hline 6 Any complication & 10 & & $\begin{array}{l}\text { Risk Ratio (M-H, Random, } \\
95 \% \mathrm{Cl} \text { ) }\end{array}$ & Subtotals only \\
\hline
\end{tabular}




\begin{tabular}{lllll}
\hline Outcome or subgroup title & No. of studies & $\begin{array}{l}\text { No. of partici- } \\
\text { pants }\end{array}$ & Statistical method & Effect size \\
\hline 6.1 Any complication & 10 & 1686 & $\begin{array}{l}\text { Risk Ratio (M-H, Random, } \\
95 \% \mathrm{Cl})\end{array}$ & $0.92[0.77,1.11]$ \\
\hline 6.2 Any complication in necrotic teeth & 9 & 1201 & $\begin{array}{l}\text { Risk Ratio (M-H, Random, } \\
95 \% \mathrm{Cl})\end{array}$ & $0.88[0.68,1.13]$ \\
\hline 6.3 Any complication in vital teeth & 3 & 485 & $\begin{array}{l}\text { Risk Ratio (M-H, Random, } \\
95 \% \mathrm{Cl})\end{array}$ & $1.02[0.83,1.25]$ \\
\hline
\end{tabular}

\section{Analysis 2.1. Comparison 2 Single versus multiple visits for endodontic treatment} of permanent teeth - secondary outcomes, Outcome 1 Pain (dichotomous).

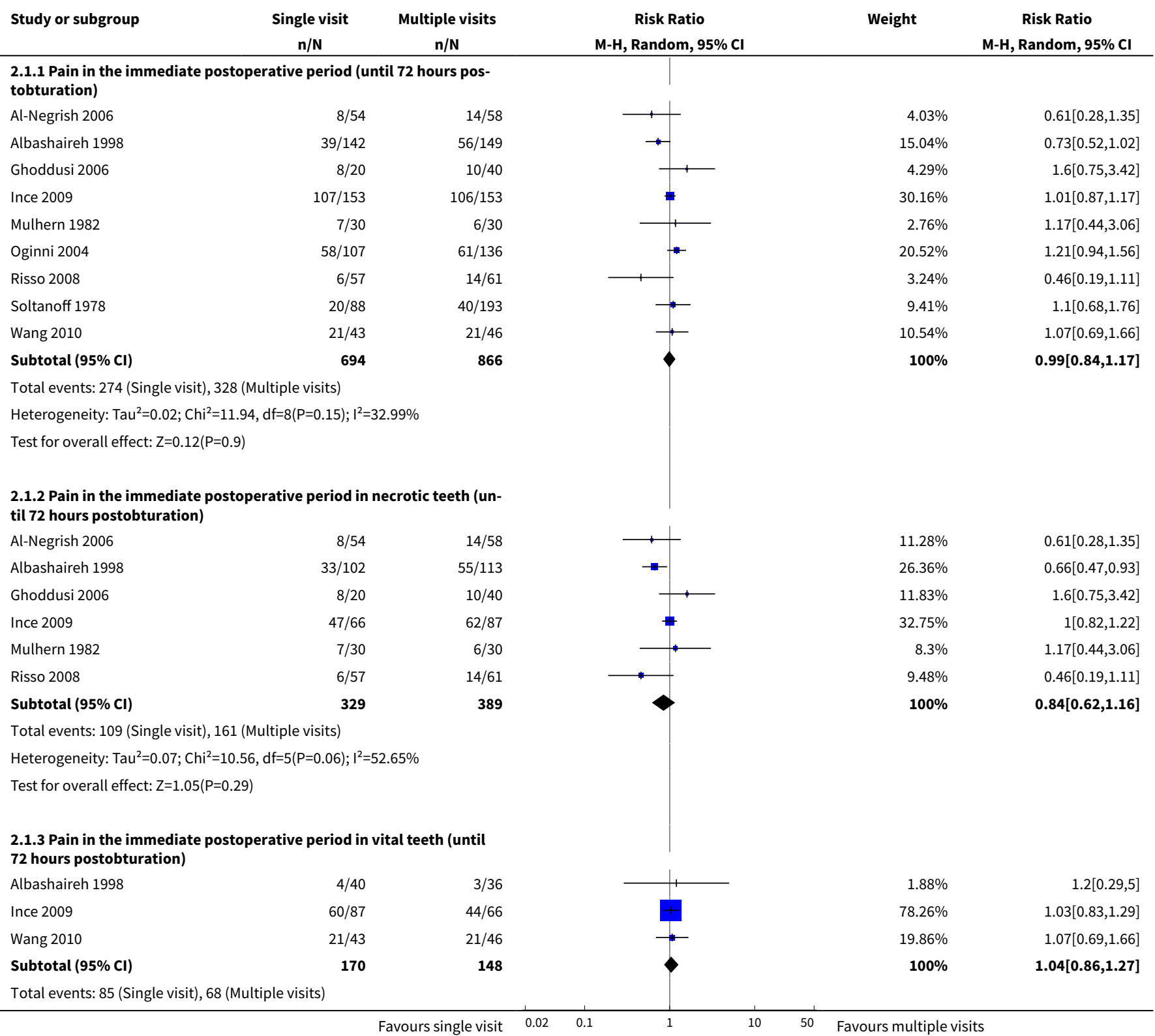




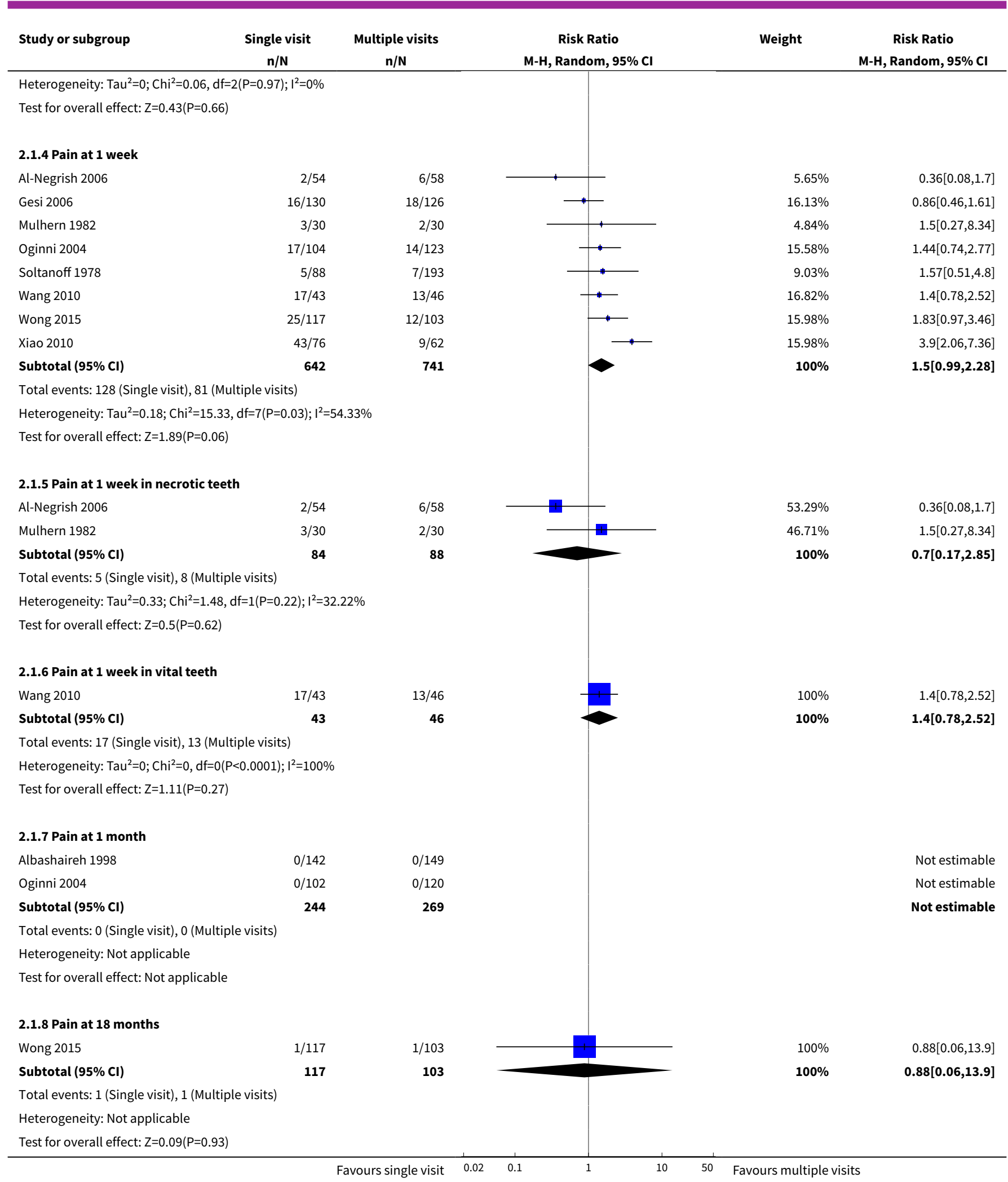


Analysis 2.2. Comparison 2 Single versus multiple visits for endodontic treatment of permanent teeth - secondary outcomes, Outcome 2 Pain (continuous).

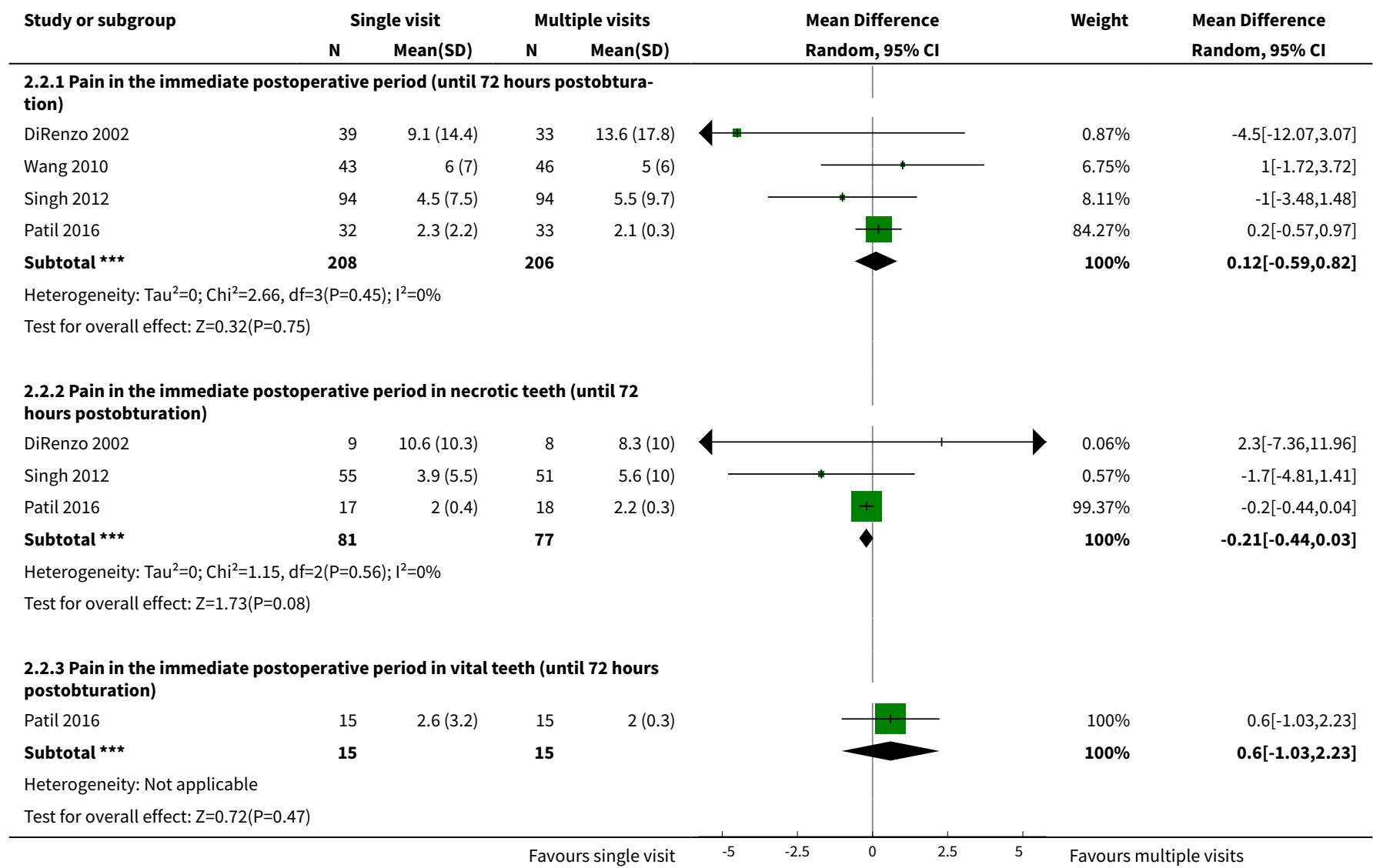

\section{Analysis 2.3. Comparison 2 Single versus multiple visits for endodontic treatment of permanent teeth - secondary outcomes, Outcome 3 Swelling or flare-up.}

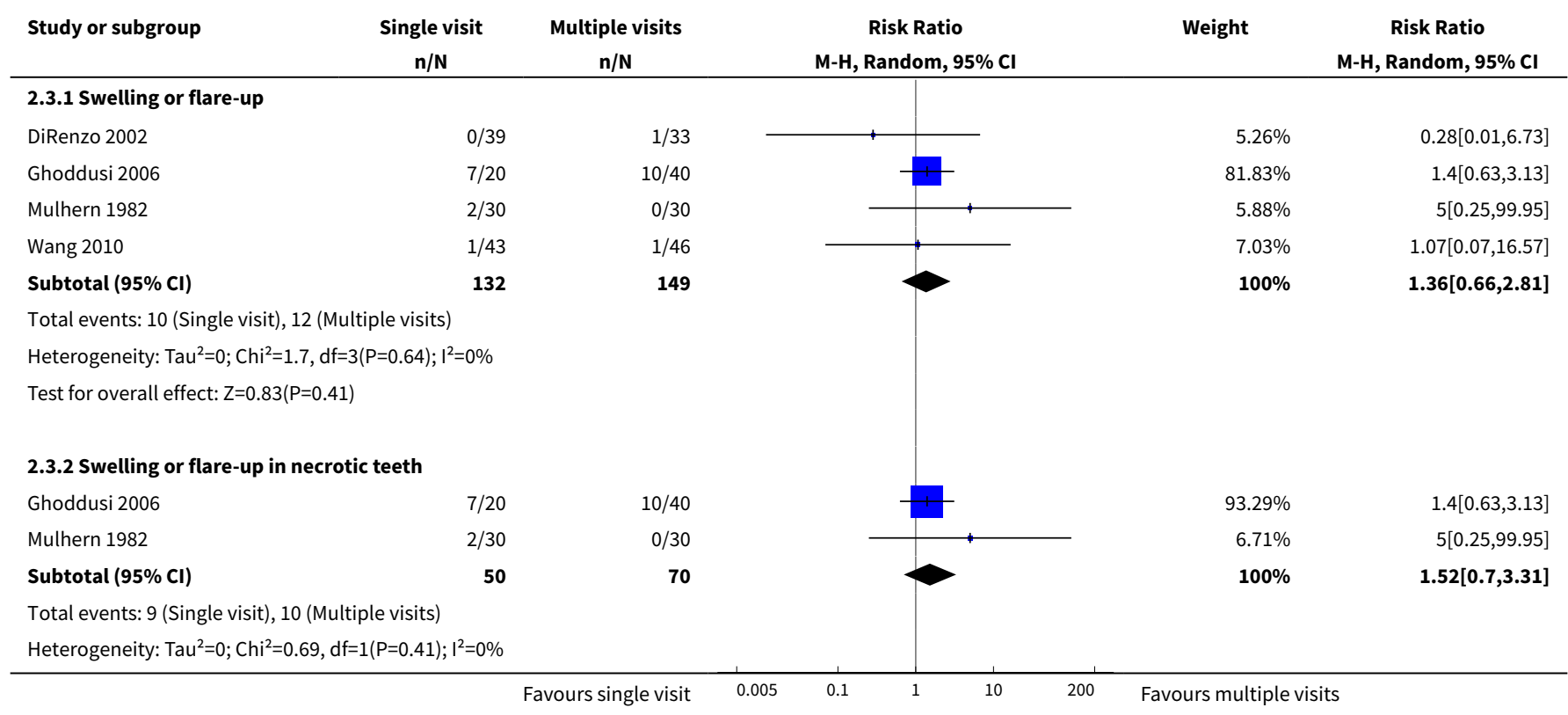




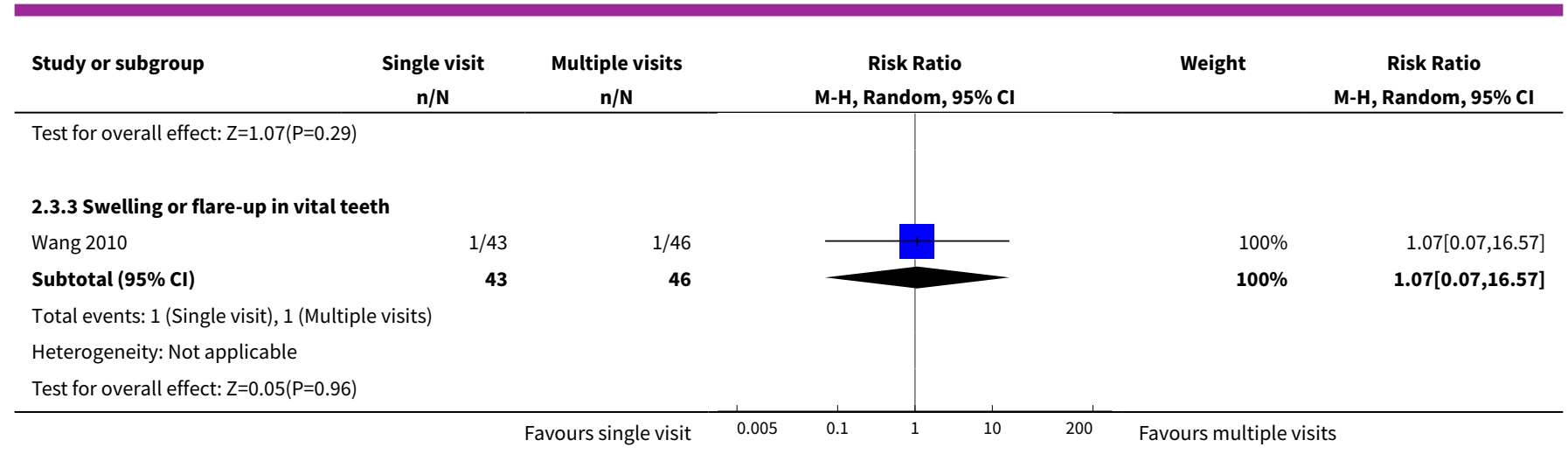

Analysis 2.4. Comparison 2 Single versus multiple visits for endodontic treatment of permanent teeth - secondary outcomes, Outcome 4 Painkiller use.

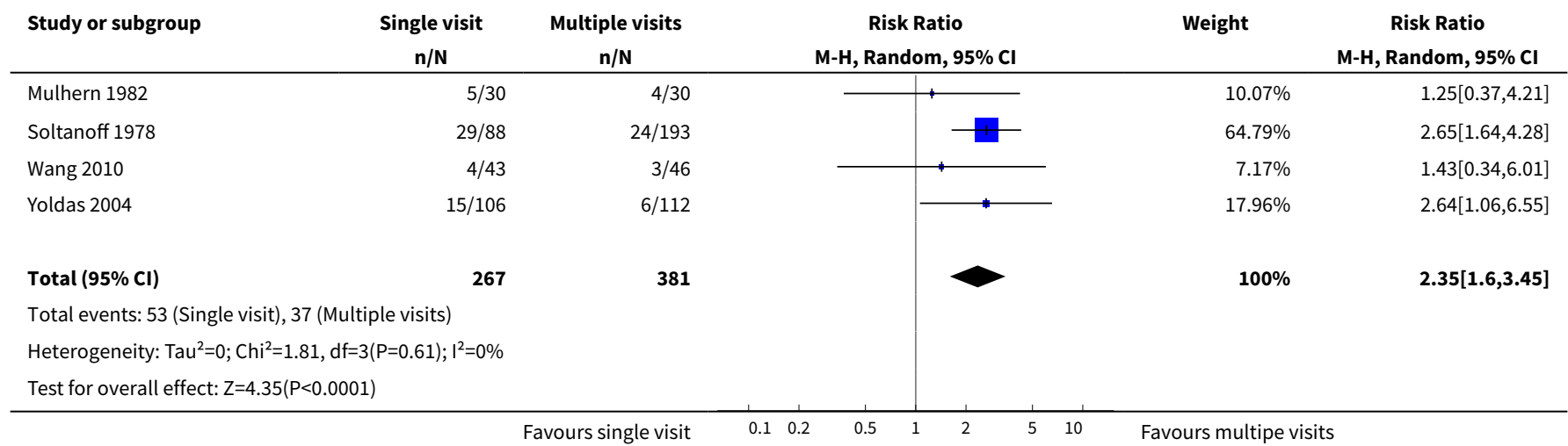

Analysis 2.5. Comparison 2 Single versus multiple visits for endodontic treatment of permanent teeth - secondary outcomes, Outcome 5 Persistent sinus track or fistula.

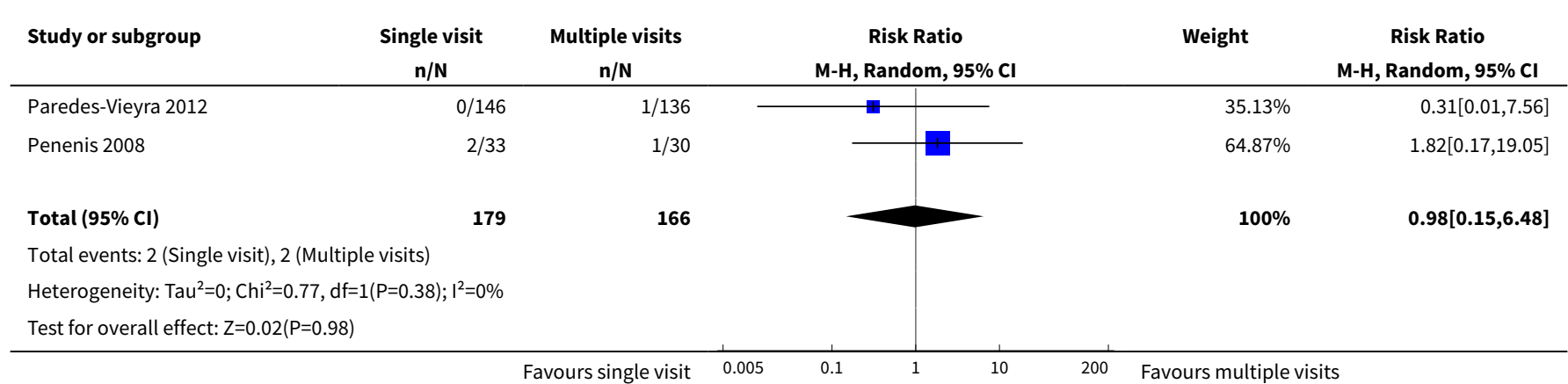


Analysis 2.6. Comparison 2 Single versus multiple visits for endodontic treatment of permanent teeth - secondary outcomes, Outcome 6 Any complication.

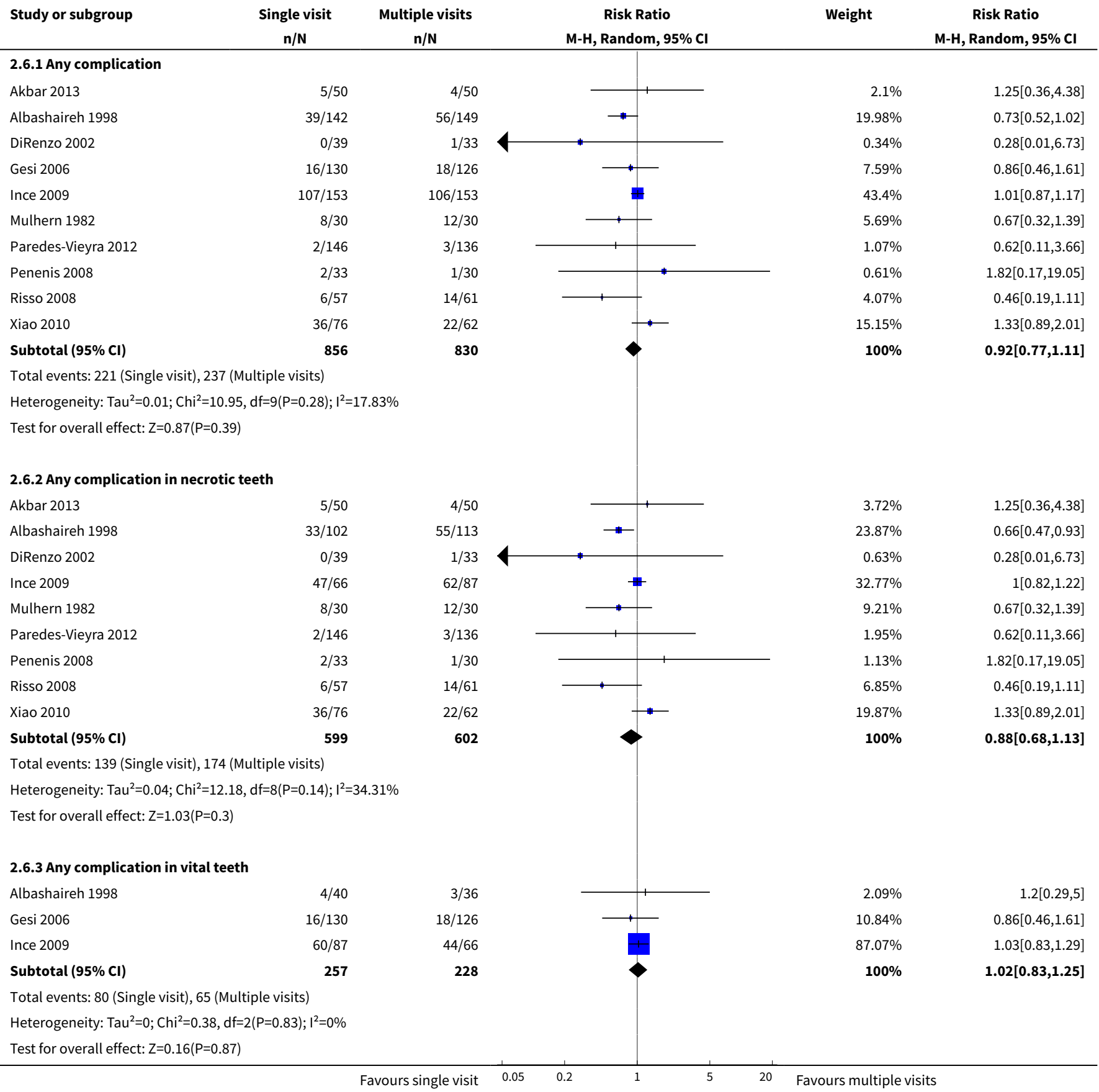

\section{ADDITIONAL TABLES}

Table 1. Endodontic radiological success and failure: from scales to binary outcome

Classification Success (binary) Failure (binary)




\section{Table 1. Endodontic radiological success and failure: from scales to binary outcome (Continued)}

\section{Trope 1999; Orstavik PAl score 1 (normal periapical), PAI 1991; Orstavik 1998}

PAl score 3 (structural changes with mineral loss), PAI score 4 (radiolucency), PAI score 5 (radiolucency with features of exacerbation)

$\begin{array}{lll}\text { Strinberg } 1956 & \begin{array}{l}\text { Success (normal to slightly thick- } \\ \text { ened periodontal ligament space }< \\ 1 \mathrm{~mm} \text {, elimination of previous rar- } \\ \text { efaction, normal lamina dura in } \\ \text { relation to adjacent teeth, no evi- } \\ \text { dence of resorption) }\end{array} & \begin{array}{l}\text { Questionable (increased periodontal ligament space }>1 \mathrm{~mm} \text { and } \\ \text { lamina dura in relation to adjacent teeth, evidence of resorption); } \\ \text { failure (increased width of periodontal ligament space }>2 \mathrm{~mm},\end{array} \\ & \begin{array}{l}\text { lack of osseous repair within rarefaction or increased rarefaction, } \\ \text { lack of new lamina dura, presence of osseous rarefactions in peri- } \\ \text { radicular areas where previously none existed) }\end{array}\end{array}$

\begin{tabular}{|c|c|c|}
\hline Katebzadeh 2000 & $\begin{array}{l}\text { Healed (normal pattern of trabecu- } \\
\text { lar bone and normal width of peri- } \\
\text { odontal ligament space) }\end{array}$ & $\begin{array}{l}\text { Improved (reduction in lesion size); failed (increased or no change } \\
\text { in the lesion size) }\end{array}$ \\
\hline Halse 1986 & $\begin{array}{l}\text { Healed (normal pattern of trabecu- } \\
\text { lar bone and normal width of peri- } \\
\text { odontal ligament space) }\end{array}$ & Increased width of the periodontal space, pathological findings \\
\hline Peters 2002; Kvist 2004 & $\begin{array}{l}\text { Success }(A) \text { the width and contour } \\
\text { of the periodontal ligament is nor- } \\
\text { mal, or there is a slight radiolucent } \\
\text { zone around apical }\end{array}$ & $\begin{array}{l}\text { Uncertain (B) the radiolucency is clearly decreased but addition- } \\
\text { al follow-up is not available; failure }(C) \text { there is an unchanged, in- } \\
\text { creased, or new periradicular radiolucency }\end{array}$ \\
\hline Weiger 2000 & $\begin{array}{l}\text { Complete healing: no clinical signs } \\
\text { and symptoms, radiographically a } \\
\text { periodontal ligament space of nor- } \\
\text { mal width }\end{array}$ & $\begin{array}{l}\text { Incomplete healing: no clinical signs and symptoms, radiographi- } \\
\text { cally a reduction of the lesion in size or an unchanged lesion with- } \\
\text { in an observation time of } 4 \text { years. No healing: clinical signs and } \\
\text { symptoms indicating an acute phase of apical periodontitis and } \\
\text { lor radiographically a persisting lesion after a follow-up time of } \\
4 \text { to } 5 \text { years and } \text { lor a new lesion formed at an initially uninvolved } \\
\text { root of a multi-rooted tooth }\end{array}$ \\
\hline Soltanoff 1978 & $\begin{array}{l}\text { Healed (by Rx but the criteria not } \\
\text { specified in a satisfactory way) }\end{array}$ & $\begin{array}{l}\text { Not healed (by Rx but the criteria not specified in a satisfactory } \\
\text { way) }\end{array}$ \\
\hline Gesi 2006 & $\begin{array}{l}\text { Normal periapical condition or un- } \\
\text { clear apical condition (widened api- } \\
\text { cal periodontal space or diffused } \\
\text { lamina dura) }\end{array}$ & $\begin{array}{l}\text { Presence of periapical radiolucency when there was a distinct ra- } \\
\text { diolucent area associated with the apical portion of the root }\end{array}$ \\
\hline $\begin{array}{l}\text { Petersson 1991; Chu } \\
2005\end{array}$ & $\begin{array}{l}\text { Normal - normal appearance of the } \\
\text { surrounding } \\
\text { osseous structure }\end{array}$ & $\begin{array}{l}\text { Apical periodontitis - periapical radiolucency observed } \\
\text { Periapical status not classified - the quality of the radiograph was } \\
\text { insufficient for examination of the periapical structure }\end{array}$ \\
\hline
\end{tabular}

PAl: periapical index

$\mathrm{Rx}$ : radiological evaluation

Table 2. Definition of flare-up in the included studies

Study Definition of flare-up

\begin{tabular}{ll}
\hline Akbar 2013 & $\begin{array}{l}\text { Moderate to severe postoperative pain or moderate to severe swelling that begins } 12 \text { to } 48 \text { hours } \\
\text { after treatment and lasts at least } 48 \text { hours }\end{array}$ \\
\hline Al-Negrish 2006 & Percentage of participants experiencing moderate to severe pain evaluated after 2 and 7 days \\
\hline \hline
\end{tabular}


Table 2. Definition of flare-up in the included studies (Continued)

\begin{tabular}{ll} 
DiRenzo 2002 & Swelling that needs antibiotics and narcotic analgesics \\
\hline Ghoddusi 2006 & Swelling \\
\hline Mulhern 1982 & Swelling \\
\hline Oginni 2004 & $\begin{array}{l}\text { Participant report of pain not controlled with over-the-counter medication or increasing swelling } \\
\text { or both }\end{array}$ \\
\hline Risso 2008 & Intensive pain (visual analogue scale $>4$ ) \\
\hline Wang 2010 & Swelling \\
\hline Yoldas 2004 & Severe postoperative pain or occurrence of swelling or both \\
\hline
\end{tabular}

\section{AP PE N D I C E S}

\section{Appendix 1. Cochrane Oral Health's Trials Register search strategy}

Updated searches of Cochrane Oral Health's Trials Register were undertaken using the Cochrane Register of Studies and the search strategy below:

\#1 ((endodontic* OR "root canal" OR pulp* OR "root fill*"):ti,ab) AND (INREGISTER)

\#2 (("single visit*" OR single-visit* OR "single appoint*" OR single-appoint* OR "single session*" OR single-session* OR "multiple visit*" OR multiple-visit* OR "multiple appoint*" OR multiple-appoint* OR "multiple session*" OR multiple-session* OR "first visit*" OR firstvisit* OR "1st visit*" OR 1st-visit* OR "one visit" OR one-visit OR "first appointment" OR "one appointment" OR one-appointment OR "first session*" OR "one session" OR one-session OR "second visit*" OR "2nd visit*" OR "two visit*" OR two-visit* OR "two appointment*" OR twoappointment ${ }^{\star}$ OR "two session*" OR "two-session*" OR "third visit*" OR third-visit OR "three visit*" OR three-visit* OR "third apointment*" OR third-appointment ${ }^{\star}$ OR "three appointment ${ }^{\star}$ " OR three-appointment* OR "three session*" OR three-session* OR "single and multiple visit*" OR "one and two visit*"):ti,ab) AND (INREGISTER)

\#3 (\#1 and \#2) AND (INREGISTER)

Previous searches of Cochrane Oral Health's Trials Register were undertaken using the Procite software and the search strategy below:

((endodontic* OR "root canal" OR pulp* OR "root fill*") AND ("single visit*" OR single-visit* OR "single appoint*" OR single-appoint* OR "single session*" OR single-session* OR "multiple visit*" OR multiple-visit* OR "multiple appoint*" OR multiple-appoint* OR "multiple session*" OR multiple-session* OR "first visit*" OR first-visit* OR "1st visit*" OR 1st-visit* OR "one visit" OR one-visit OR "first appointment" OR "one appointment" OR one-appointment OR "first session*" OR "one session" OR one-session OR "second visit" OR "2nd visit" OR "two visit*" OR two-visit* OR "two appointment " OR two-appointment* OR "two session*" OR "two-session" visit OR "three visit*" OR three-visit* OR "third apointment*" OR third-appointment* OR "three appointment*" OR three-appointment* OR "three session*" OR three-session* OR "single and multiple visit*" OR "one and two visit" $)$ )

\section{Appendix 2. Cochrane Central Register of Controlled Trials (CENTRAL) search strategy}

\#1 MeSH descriptor Endodontics explode all trees

\#2 (endodontic* in All Text or pulpectom* in All Text or pulpotom* in All Text)

\#3 "root canal" in All Text

\#4 ( (pulp in All Text near/4 cap* in All Text) or (pulp in All Text near/4 devital* in All Text) )

\#5 (\#1 or \#2 or \#3 or \#4)

\#6 (single next visit* in All Text or single next appointment* in All Text or single next session* in All Text)

\#7 (multi ${ }^{\star}$ next visit* in All Text or multi* next appointment ${ }^{\star}$ in All Text or multi* next session ${ }^{\star}$ in All Text)

\#8 (first next visit* in All Text or first next appointment* in All Text or first next session* in All Text or second next visit* in All Text or second next appointment ${ }^{*}$ in All Text or second next session* in All Text or third next visit* in All Text or third next appointment* in All Text or third next session* in All Text)

\#9 (1st next visit* in All Text or 1st next appointment* in All Text or 1st next session* in All Text or 2nd next visit* in All Text or 2nd next appointment ${ }^{\star}$ in All Text or 2nd next session* in All Text or 3rd next visit* in All Text or 3rd next appointment ${ }^{\star}$ in All Text or 3rd next session* in All Text) 
\#10 (one next visit* in All Text or one next appointment* in All Text or one next session* in All Text or two next visit* in All Text or two next appointment* in All Text or two next session* in All Text or three next visit* in All Text or three next appointment* in All Text or three next session* in All Text)

$\# 11$ (\#6 or \#7 or \#8 or \#9 or \#10)

$\# 12$ (\#5 and \#11)

\section{Appendix 3. MEDLINE Ovid search strategy}

\section{ENDODONTICS/}

2. exp ROOT CANAL THERAPY/

3. dental pulp capping/ or pulpectomy/ or pulpotomy/

4. (endodontic\$ or pulpectom\$ or pulpotom\$)

5. (root canal adj (therapy or treat\$))

6. ((pulp adj3 cap\$) or (pulp\$ adj3 devitali\$))

7. or/1-6

8. (single adj (visit\$ or appointment\$ or session\$))

9. (multi\$ adj (visit\$ or appointment\$ or session\$))

10. ((first or second or third) adj (visit\$ or appointment $\$$ or session\$))

11. ((1st or 2nd or 3rd) adj (visit\$ or appointment\$ or session\$))

12. ((one or two or three) adj (appointment\$ or visit\$ or session\$))

13 or/8-12

14. 7 and 13

\section{Appendix 4. Embase Ovid search strategy}

\section{ENDODONTICS/}

2. exp ROOT CANAL THERAPY/

3. dental pulp capping/ or pulpectomy/ or pulpotomy/

4. (endodontic\$ or pulpectom\$ or pulpotom\$)

5. (root canal adj (therapy or treat\$))

6. ((pulp adj3 cap\$) or (pulp\$ adj3 devitali\$))

7. or/1-6

8. (single adj (visit\$ or appointment\$ or session\$))

9. (multi\$ adj (visit\$ or appointment\$ or session\$))

10. ((first or second or third) adj (visit\$ or appointment $\$$ or session\$))

11. ((1st or 2nd or 3rd) adj (visit\$ or appointment\$ or session\$))

12. ((one or two or three) adj (appointment\$ or visit\$ or session\$)

13 or/8-12

14. 7 and 13

\section{Appendix 5. US National Institutes of Health Ongoing Trials Register (ClinicalTrials.gov) and the WHO International Clinical Trials Registry Platform search strategy}

endodontic and visit

endodontic and appointment

endodontic and session

\section{WHAT'S NEW}

\begin{tabular}{lll}
\hline Date & Event & Description \\
\hline 9 November 2016 & $\begin{array}{l}\text { New citation required but conclusions } \\
\text { have not changed }\end{array}$ & $\begin{array}{l}\text { Our substantive conclusions have not changed. On the basis of } \\
\text { the available evidence, it seems likely that the benefit of a sin- } \\
\text { gle-visit treatment, in terms of time and convenience, for both } \\
\text { patient and dentist, has the cost of a higher frequency of late } \\
\text { postoperative pain (and as a consequence, painkiller use). }\end{array}$ \\
& $\begin{array}{l}\text { One of the newly included studies reported data on tooth loss, } \\
\text { which was no different between the two approaches (single visit } \\
\text { and multiple visits). }\end{array}$ \\
\hline
\end{tabular}




\begin{tabular}{lll}
\hline Date & Description \\
\hline & $\begin{array}{l}\text { Thirteen new studies added to the previous version of the re- } \\
\text { view, making a total of } 25 .\end{array}$ \\
\hline
\end{tabular}

\section{HISTORY}

Protocol first published: Issue 2, 2005

Review first published: Issue 4, 2007

\begin{tabular}{lll}
\hline Date & Event & Description \\
\hline 31 July 2008 & Amended & Converted to new review format. \\
\hline
\end{tabular}

\section{CONTRIBUTIONS OF AUTHORS}

- Maddalena Manfredi: main review author, participation in all phases of the review's preparation.

- Lara Figini: participation in all phases of the review's preparation.

- Massimo Gagliani: manuscript preparation, interpretation of results.

- Giovanni Lodi: group co-ordinator, contributor in all phases of the review's preparation, article retrieval, data collection, interpretation of results.

\section{DECLARATIONS OF INTEREST}

- Maddalena Manfredi: none known.

- Lara Figini: none known.

- Massimo Gagliani: none known.

- Giovanni Lodi: none known.

\section{SOURCES OF SUPPORT}

\section{Internal sources}

- School of Dentistry, The University of Manchester, UK.

\section{External sources}

- National Institute for Health Research (NIHR), UK.

This project was supported by the NIHR, via Cochrane Infrastructure funding to Cochrane Oral Health. The views and opinions expressed therein are those of the authors and do not necessarily reflect those of the Systematic Reviews Programme, NIHR, National Health Service (NHS) or the Department of Health

- Cochrane Oral Health Group Global Alliance, Other.

The production of Cochrane Oral Health reviews has been supported financially by our Global Alliance since 2011 (ohg.cochrane.org/ partnerships-alliances). Contributors over the past year have been the British Association for the Study of Community Dentistry, UK; the British Society of Paediatric Dentistry, UK; the Canadian Dental Hygienists Association, Canada; the Centre for Dental Education and Research at All India Institute of Medical Sciences, India; the National Center for Dental Hygiene Research \& Practice, USA; New York University College of Dentistry, USA; and NHS Education for Scotland, UK

\section{DIFFERENCES BETWEEN PROTOCOLANDREVIEW}

The outcomes were modified from the protocol in the last version of the review. We added 'any complication' as a secondary outcome in this version. 


\section{N D EX TERMS}

\section{Medical Subject Headings (MeSH)}

${ }^{\star}$ Dentition, Permanent; Analgesics [*therapeutic use]; Anti-Bacterial Agents [therapeutic use]; Appointments and Schedules; Dental Pulp Necrosis [diagnostic imaging] [*therapy]; Office Visits [ ${ }^{\star}$ statistics \& numerical data]; Pain, Postoperative [etiology]; Pulpitis [diagnostic imaging] [ ${ }^{\star}$ therapy]; Radiography; Randomized Controlled Trials as Topic; Root Canal Therapy [adverse effects] [*methods]; Tooth Extraction; Treatment Outcome

\section{MeSH check words}

Humans 